\title{
World Summit on the Information Society
}

The Plenipotentiary Conference of the International Telecommunication Union (Minneapolis, 1998),

\section{considering}

a. the provisions of the Constitution and the Convention of the International Telecommunication Union concerning the role of the Union with regard to policies and strategies;

b. the resolutions adopted by this conference concerning strategic issues in the telecommunication sector,

\section{Noting}

that the Union is required to fulfil its tasks in an environment where telecommunications are playing an increasingly decisive and driving role at the political, economic, social and cultural levels,

\section{recognizing}

a. that ITU is the organization best able to seek appropriate ways to provide for development of the telecommunication sector geared to economic, social and cultural development;

b. the complementarity between the work of the Union and the activities of other international and regional organizations;

c. the interpenetration between issues of telecommunication development and those of economic, social and cultural development, as well as the impact of such interpenetration on social structures in all Member States,

\section{conscious}

a. of the fact that the globalization of telecommunications must take account of a harmonious evolution in policies, regulations, networks and services in all Member States;

b. of the emergence of the concept of the information society in which telecommunications play a central role,

\section{taking into account}

a. the results of the World Telecommunication Standardization Conference (Geneva, 1996), the World Radiocommunication Conference (Geneva, 1997) and the World Telecommunication Development Conference (Valletta, 1998);

b. the role and results of the world telecommunication policy forums held,

\section{resolves to instruct the Secretary-General}

1. to place the question of holding a world summit on the information society on the agenda of the United Nations Administrative Committee on Coordination, with a view to meeting the necessary conditions for holding such a summit before the next plenipotentiary conference;

2. to report to the Council on the results of this consultation and to evaluate the financial burden that might result from the Union's contribution to holding a world summit on the information society, 


\section{instructs the Council}

in the light of the results of this consultation:

1. to consider and decide on the Union's contribution to the holding of a world summit on the information society, with a view to:

- establishing an overall framework identifying, with the contribution of all partners, a joint and harmonized understanding of the information society;

- drawing up a strategic plan of action for concerted development of the information society by defining an agenda covering the objectives to be achieved and the resources to be mobilized;

- identifying the roles of the various partners to ensure smooth coordination of the establishment in practice of the information society in all Member States;

2. to ask the Secretary-General to coordinate with other international organizations and with the various partners concerned (Member States, Sector Members, etc.), with a view to holding a world summit on the information society;

3. to report on the results of the world summit on the information society to the next plenipotentiary conference. 
Fifty-sixth session

Agenda item 95 (c)

\section{Resolution adopted by the General Assembly}

[on the report of the Second Committee (A/56/558/Add.3)]

\section{6/183. World Summit on the Information Society}

\section{The General Assembly,}

Recognizing the urgent need to harness the potential of knowledge and technology for promoting the goals of the United Nations Millennium Declaration ${ }^{1}$ and to find effective and innovative ways to put this potential at the service of development for all,

Recognizing also the pivotal role of the United Nations system in promoting development, in particular with respect to access to and transfer of technology, especially information and communication technologies and services, inter alia, through partnerships with all relevant stakeholders,

Convinced of the need, at the highest political level, to marshal the global consensus and commitment required to promote the urgently needed access of all countries to information, knowledge and communication technologies for development so as to reap the full benefits of the information and communication technologies revolution, and to address the whole range of relevant issues related to the information society, through the development of a common vision and understanding of the information society and the adoption of a declaration and plan of action for implementation by Governments, international institutions and all sectors of civil society,

Recalling the contributions to international consensus in this field achieved by the Millennium Declaration and the agreements reached at other international conferences and summits in recent years,

Taking note of the action plan presented by the Secretary-General of the International Telecommunication Union to the Administrative Committee on Coordination $^{2}$ for the holding of the World Summit on the Information Society and the creation, by the Administrative Committee on Coordination, of a high-level Summit organizing committee, chaired by the Secretary-General of the International Telecommunication Union and consisting of the heads of United Nations bodies and

\footnotetext{
${ }^{1}$ See resolution 55/2.

${ }^{2}$ The Administrative Committee on Coordination was renamed the United Nations System Chief Executives Board for Coordination pursuant to Economic and Social Council decision 2001/321 of 24 October 2001.
} 
other international organizations interested in participating in the process leading to the Summit,

Considering that the Summit is to be convened under the patronage of the Secretary-General of the United Nations, with the International Telecommunication Union taking the lead role in its preparation, in cooperation with interested United Nations bodies and other international organizations as well as the host countries,

Recalling the ministerial declaration concerning information and communication technologies, adopted by the Economic and Social Council at the high-level segment of its substantive session of $2000,{ }^{3}$ and the subsequent work done in this regard, including the creation of the Information and Communication Technologies Task Force, as well as the welcoming of the forthcoming Summit by the Council in its agreed conclusions 2001/1,

Recognizing the need to harness synergies and to create cooperation among the various information and communication technologies initiatives, at the regional and global levels, currently being undertaken or planned to promote and foster the potential of information and communication technologies for development by other international organizations and civil society,

1. Welcomes the resolution adopted by the Council of the International Telecommunication Union at its 2001 session, in which the Council endorsed the proposal of the Secretary-General of the International Telecommunication Union to hold the World Summit on the Information Society at the highest possible level in two phases, the first in Geneva from 10 to 12 December 2003 and the second in Tunis in 2005, pursuant to resolution 73 adopted by the Plenipotentiary Conference of the International Telecommunication Union at its 1998 session, held in Minneapolis, United States of America;

2. Recommends that the preparations for the Summit take place through an open-ended intergovernmental preparatory committee, which would define the agenda of the Summit, finalize both the draft declaration and the draft plan of action, and decide on the modalities of the participation of other stakeholders in the Summit;

3. Invites the International Telecommunication Union to assume the leading managerial role in the executive secretariat of the Summit and its preparatory process;

4. Invites Governments to participate actively in the preparatory process of the Summit and to be represented in the Summit at the highest possible level;

5. Encourages effective contributions from and the active participation of all relevant United Nations bodies, in particular the Information and Communication Technologies Task Force, and encourages other intergovernmental organizations, including international and regional institutions, non-governmental organizations, civil society and the private sector to contribute to, and actively participate in, the intergovernmental preparatory process of the Summit and the Summit itself;

\footnotetext{
${ }^{3}$ See Official Records of the General Assembly, Fifty-fifth Session, Supplement No. 3 (A/55/3/Rev.1), chap. III, para. 17.

${ }^{4}$ A/56/3, chap. V, agreed conclusions 2001/1, para 7. For the final text see Official Records of the General Assembly, Fifty-sixth session, Supplement No. 3.
} 
6. Invites the international community to make voluntary contributions to the special trust fund established by the International Telecommunication Union to support the preparations for and the holding of the Summit, as well as to facilitate the effective participation of representatives of developing countries, in particular the least developed countries, in the regional meetings to be held in the second half of 2002, in the preparatory meetings to be held in the first half of 2002 and in 2003, and in the Summit itself;

7. Invites the Secretary-General of the United Nations to inform all heads of State and Government of the adoption of the present resolution;

8. Invites the Secretary-General of the International Telecommunication Union to submit to the General Assembly, at its fifty-seventh and fifty-eighth sessions, through the Economic and Social Council, for information, a report on the preparations for the Summit.

90th plenary meeting

21 December 2001 
Fifty-fifth session

Agenda item $60(b)$

\title{
Resolution adopted by the General Assembly
}

[without reference to a Main Committee (A/55/L.2)]

\section{5/2. United Nations Millennium Declaration}

\author{
The General Assembly
}

Adopts the following Declaration:

\section{United Nations Millennium Declaration}

\section{Values and principles}

1. We, heads of State and Government, have gathered at United Nations Headquarters in New York from 6 to 8 September 2000, at the dawn of a new millennium, to reaffirm our faith in the Organization and its Charter as indispensable foundations of a more peaceful, prosperous and just world.

2. We recognize that, in addition to our separate responsibilities to our individual societies, we have a collective responsibility to uphold the principles of human dignity, equality and equity at the global level. As leaders we have a duty therefore to all the world's people, especially the most vulnerable and, in particular, the children of the world, to whom the future belongs.

3. We reaffirm our commitment to the purposes and principles of the Charter of the United Nations, which have proved timeless and universal. Indeed, their relevance and capacity to inspire have increased, as nations and peoples have become increasingly interconnected and interdependent.

4. We are determined to establish a just and lasting peace all over the world in accordance with the purposes and principles of the Charter. We rededicate ourselves to support all efforts to uphold the sovereign equality of all States, respect for their territoria] integrity and political independence, resolution of disputes by peaceful means and in conformity with the principles of justice and international law, the right to self-determination of peoples which remain under colonial domination and foreign occupation, non-interference in the internal affairs of States, respect for human rights and fundamental freedoms, respect for the equal rights of all without distinction as to race, sex, language or religion and international cooperation in solving international problems of an economic, social, cultural or humanitarian character. 
5. We believe that the central challenge we face today is to ensure that globalization becomes a positive force for all the world's people. For while globalization offers great opportunities, at present its benefits are very unevenly shared, while its costs are unevenly distributed. We recognize that developing countries and countries with economies in transition face special difficulties in responding to this central challenge. Thus, only through broad and sustained efforts to create a shared future, based upon our common humanity in all its diversity, can globalization be made fully inclusive and equitable. These efforts must include policies and measures, at the global level, which correspond to the needs of developing countries and economies in transition and are formulated and implemented with their effective participation.

6. We consider certain fundamental values to be essential to international relations in the twenty-first century. These include:

- Freedom. Men and women have the right to live their lives and raise their children in dignity, free from bunger and from the fear of violence, oppression or injustice. Democratic and participatory governance based on the will of the people best assures these rights.

-. Equality. No individual and no nation must be denied the opportunity to benefit from development. The equal rights and opportunities of women and men must be assured.

- Solidarity. Global challenges must be managed in a way that distributes the costs and burdens fairly in accordance with basic principles of equity and social justice. Those who suffer or who benefit least deserve help from those who benefit most.

- Tolerance. Human beings must respect one other, in all their diversity of belief, culture and language. Differences within and between societies should be neither feared nor repressed, but cherished as a precious asset of humanity. A culture of peace and dialogue among all civilizations should be actively promoted.

- Respect for nature. Prudence must be shown in the management of all living species and natural resources, in accordance with the precepts of sustainable development. Only in this way can the immeasurable riches provided to us by nature be preserved and passed on to our descendants. The current unsustainable patterns of production and consumption must be changed in the interest of our future welfare and that of our descendants.

- Shared responsibility. Responsibility for managing worldwide economic and social development, as well as threats to international peace and security, must be shared among the nations of the world and should be exercised multilaterally. As the most universal and most representative organization in the world, the United Nations must play the central role.

7. In order to translate these shared values into actions, we have identified key objectives to which we assign special significance.

1I. Peace, security and disarmament

8. We will spare no effort to free our peoples from the scourge of war, whether within or between States, which has claimed more than 5 million lives in the 
past decade. We will also seek to eliminate the dangers posed by weapons of mass destruction.

9. We resolve therefore:

- To strengthen respect for the rule of law in international as in national affairs and, in particular, to ensure compliance by Member States with the decisions of the International Court of Justice, in compliance with the Charter of the United Nations, in cases to which they are parties.

- To make the United Nations more effective in maintaining peace and security by giving it the resources and tools it needs for conflict prevention, peaceful resolution of disputes, peacekeeping, post-conflict peace-building and reconstruction. In this context, we take note of the report of the Panel on United Nations Peace Operations ${ }^{1}$ and request the General Assembly to consider its recommendations expeditiously.

- To strengthen cooperation between the United Nations and regional organizations, in accordance with the provisions of Chapter VIII of the Charter.

- To ensure the implementation, by States Parties, of treaties in areas such as arms control and disarmament and of international humanitarian law and human rights law, and call upon all States to consider signing and ratifying the Rome Statute of the International Criminal Court. ${ }^{2}$

- To take concerted action against international terrorism, and to accede as soon as possible to all the relevant international conventions.

- To redouble our efforts to implement our commitment to counter the world drug problem.

- To intensify our efforts to fight transnational crime in all its dimensions, including trafficking as well as smuggling in human beings and money laundering.

- To minimize the adverse effects of United Nations economic sanctions on innocent populations, to subject such sanctions regimes to regular reviews and to eliminate the adverse effects of sanctions on third parties.

- To strive for the elimination of weapons of mass destruction, particularly nuclear weapons, and to keep all options open for achieving this aim, including the possibility of convening an international conference to identify ways of eliminating nuclear dangers.

- To take concerted action to end illicit traffic in small arms and light weapons, especially by making arms transfers more transparent and supporting regional disarmament measures, taking account of all the recommendations of the forthcoming United Nations Conference on Illicit Trade in Small Arms and Light Weapons.

- To call on all States to consider acceding to the Convention on the Probibition of the Use, Stockpiling, Production and Transfer of Anti-personnel Mines and

'A/55/305-S/2000/809; see Official Records of the Security Council, Fifty-fifth Year, Supplement for Juby. August and September 2000, document S/2000/809.

${ }^{2}$ A/CONF.183/9. 
on Their Destruction, ${ }^{3}$ as well as the amended mines protocol to the Convention on conventional weapons. ${ }^{4}$

10. We urge Member States to observe the Olympic Truce, individually and collectively, now and in the future, and to support the International Olympic Committee in its efforts to promote peace and human understanding through sport and the Olympic Ideal.

\section{Development and poverty eradication}

11. We will spare no effort to free our fellow men, women and children from the abject and dehumanizing conditions of extreme poverty, to which more than a billion of them are currently subjected. We are committed to making the right to development a reality for everyone and to freeing the entire buman race from want.

12. We resolve therefore to create an environment - at the national and global levels alike - which is conducive to development and to the elimination of poverty.

13. Success in meeting these objectives depends, inter alia, on good governance within each country. It also depends on good governance at the international level and on transparency in the financial, monetary and trading systems. We are committed to an open, equitable, rule-based, predictable and nondiscriminatory multilateral trading and financial system.

14. We are concerned about the obstacles developing countries face in mobilizing the resources needed to finance their sustained development. We will therefore make every effort to ensure the success of the High-level International and Intergovernmental Event on Financing for Development, to be held in 2001.

15. We also undertake to address the special needs of the least developed countries. In this context, we welcome the Third United Nations Conference on the Least Developed Countries to be held in May 2001 and will endeavour to ensure its success. We call on the industrialized countries:

- To adopt, preferably by the time of that Conference, a policy of duty- and quota-free access for essentially all exports from the least developed countries;

- To implement the enhanced programme of debt relief for the heavily indebted poor countries without further delay and to agree to cancel all official bilateral debts of those countries in return for their making demonstrable commitments to poverty reduction; and

- To grant more generous development assistance, especially to countries that are genuinely making an effort to apply their resources to poverty reduction.

16. We are also determined to deal comprehensively and effectively with the debt problems of low- and middle-income developing countries, through various national and international measures designed to make their debt sustainable in the long term.

\footnotetext{
${ }^{3}$ See $\mathrm{CD} / 1478$.

4 Amended protocol on prohibitions or restrictions on the use of mines, booby-traps and other devices (CCW/CONF.V/16 (Part I), annex B).
} 
17. We also resolve to address the special needs of small island developing States, by implementing the Barbados Programme of Action ${ }^{5}$ and the outcome of the twenty-second special session of the General Assembly rapidly and in full. We urge the international community to ensure that, in the development of a vulnerability index, the special needs of small island developing States are taken into account.

18. We recognize the special needs and problems of the landlocked developing countries, and urge both bilateral and multilateral donors to increase financial and technical assistance to this group of countries to meet their special development needs and to help them overcome the impediments of geography by improving their transit transport systems.

19. We resolve further:

- To halve, by the year 2015, the proportion of the world's people whose income is less than one dollar a day and the proportion of people who suffer from hunger and, by the same date, to halve the proportion of people who are unable to reach or to afford safe drinking water.

- To ensure that, by the same date, children everywhere, boys and girls alike, will be able to complete a full course of primary schooling and that girls and boys will have equal access to all levels of education.

- By the same date, to have reduced maternal mortality by three quarters, and under-five child mortality by two thirds, of their current rates.

- To have, by then, halted, and begun to reverse, the spread of HIV/AIDS, the scourge of malaria and other major diseases that afflict humanity.

- To provide special assistance to children orphaned by HIV/AIDS.

- By 2020, to have achieved a significant improvement in the lives of at least 100 million slum dwellers as proposed in the "Cities Without Slums" initiative.

20. We also resolve:

- To promote gender equality and the empowerment of women as effective ways to combat poverty, hunger and disease and to stimulate development that is truly sustainable.

- To develop and implement strategies that give young people everywhere a real chance to find decent and productive work.

- To encourage the pharmaceutical industry to make essential drugs more widely available and affordable by all who need them in developing countries.

- To develop strong partnerships with the private sector and with civil society organizations in pursuit of development and poverty eradication.

${ }^{5}$ Programme of Action for the Sustainable Development of Small lsland Developing States (Report of the Global Conference on the Sustainable Development of Small Island Developing States, Bridgetown, Barbados, 25 April-6May 1994 (United Nations publication, Sales No. E.94.1.18 and corrigenda), chap. I, resolution 1 , annex II). 
- To ensure that the benefits of new technologies, especially information and communication technologies, in conformity with recommendations contained. in the ECOSOC 2000 Ministerial Declaration, ${ }^{6}$ are available to all.

\section{Protecting our common environment}

21. We must spare no effort to free all of humanity, and above all our children and grandchildren, from the threat of living on a planet irredeemably spoilt by human activities, and whose resources would no longer be sufficient for their needs.

22. We reaffirm our support for the principles of sustainable development, including those set out in Agenda 21, agreed upon at the United Nations. Conference on Environment and Development.

23. We resolve therefore to adopt in all our environmental actions a new ethic of conservation and stewardship and, as first steps, we resolve:

- To make every effort to ensure the entry into force of the Kyoto Protocol, preferably by the tenth anniversary of the United Nations Conference on Environment and Development in 2002, and to embark on the required reduction in emissions of greenhouse gases.

- To intensify our collective efforts for the management, conservation and sustainable development of all types of forests.

- To press for the full implementation of the Convention on Biological Diversity ${ }^{8}$ and the Convention to Combat Desertification in those Countries Experiencing Serious Drought and/or Desertification, particularly in Africa."

- To stop the unsustainable exploitation of water resources by developing water management strategies at the regional, national and local levels, which promote both equitable access and adequate supplies.

- To intensify cooperation to reduce the number and effects of natural and manmade disasters.

- To ensure free access to information on the human genome sequence.

\section{Human rights, democracy and good governance}

24. We will spare no effort to promote democracy and strengthen the rule of law, as well as respect for all internationally recognized buman rights and fundamental freedoms, including the right to development.

25. We resolve therefore:

\footnotetext{
${ }^{6} \mathrm{E} / 2000 / \mathrm{L} .9$.

${ }^{7}$ Report of the United Nations Conference on Environment and Development, Rio de Janeiro. 3-14 June 1992 (United Nations publication, Sales No. E.93.1.8 and corrigenda), vol. I: Resolutions adopted by the Conference, resolution 1 , annex II.

${ }^{8}$ See United Nations Environment Programme, Convention on Biological Diversitj (Environmental Law and Institution Programme Activity Centre), June 1992.
}

${ }^{9} \mathrm{~A} / 49 / 84 / \mathrm{Add} .2$, annex, appendix II. 
- To respect fully and uphold the Universal Declaration of Human Rights. ${ }^{10}$

- To strive for the full protection and promotion in all our countries of civil, political, economic, social and cultural rights for all.

- To strengthen the capacity of all our countries to implement the principles and practices of democracy and respect for human rights, including minority rights.

- To combat all forms of violence against women and to implement the Convention on the Elimination of All Forms of Discrimination against Women."

- To take measures to ensure respect for and protection of the human rights of migrants, migrant workers and their families, to eliminate the increasing acts of racism and xenophobia in many societies and to promote greater harmony and tolerance in all societies.

- To work collectively for more inclusive political processes, allowing genuine participation by all citizens in all our countries.

- To ensure the freedom of the media to perform their essential role and the right of the public to have access to information.

\section{Protecting the vulnerable}

26. We will spare no effort to ensure that children and all civilian populations that suffer disproportionately the consequences of natural disasters, genocide, armed conflicts and other humanitarian emergencies are given every assistance and protection so that they can resume normal life as soon as possible.

We resolve therefore:

- To expand and strengthen the protection of civilians in complex emergencies, in conformity with international humanitarian law.

- To strengthen international cooperation, including burden sharing in, and the coordination of humanitarian assistance to, countries hosting refugees and to help all refugees and displaced persons to return voluntarily to their homes, in safety and dignity and to be smoothly reintegrated into their societies.

- To encourage the ratification and full implementation of the Convention on the Rights of the Child ${ }^{12}$ and its optional protocols on the involvement of children in armed conflict and on the sale of children, child prostitution and child pornography. ${ }^{13}$

\section{Meeting the special needs of Africa}

27. We will support the consolidation of democracy in Africa and assist Africans in their struggle for lasting peace, poverty eradication and sustainable development, thereby bringing Africa into the mainstream of the world economy.

\footnotetext{
${ }^{10}$ Resolution 217 A (III).

$"$ Resolution 34/1 80, annex.

12 Resolution 44/25, annex.

${ }^{13}$ Resolution 54/263, annexes I and II.
} 
28. We resolve therefore:

- To give full support to the political and institutional structures of emerging democracies in Africa.

- To encourage and sustain regional and subregional mechanisms for preventing conflict and promoting political stability, and to ensure a reliable flow of resources for peacekeeping operations on the continent.

- To take special measures to address the challenges of poverty eradication and sustainable development in Africa, including debt cancellation, improved market access, enhanced Official Development Assistance and increased flows of Foreign Direct Investment, as well as transfers of technology.

- To help Africa build up its capacity to tackle the spread of the HIV/AIDS pandemic and other infectious diseases.

\section{Strengthening the United Nations}

29. We will spare no effort to make the United Nations a more effective instrument for pursuing all of these priorities: the fight for development for all the peoples of the world, the fight against poverty, ignorance and disease; the fight against injustice; the fight against violence, terror and crime; and the fight against the degradation and destruction of our common home.

30. We resolve therefore:

- To reaffirm the central position of the General Assembly as the chief deliberative, policy-making and representative organ of the United Nations, and to enable it to play that role effectively.

- To intensify our efforts to achieve a comprehensive reform of the Security Council in all its aspects.

- To strengthen further the Economic and Social Council, building on its recent achievements, to help it fulfil the role ascribed to it in the Charter.

- To strengthen the International Court of Justice, in order to ensure justice and the rule of law in international affairs.

- To encourage regular consultations and coordination among the principal organs of the United Nations in pursuit of their functions.

- To ensure that the Organization is provided on a timely and predictable basis with the resources it needs to carry out its mandates.

- To urge the Secretariat to make the best use of those resources, in accordance with clear rules and procedures agreed by the General Assembly, in the interests of all Member States, by adopting the best management practices and technologies available and by concentrating on those tasks that reflect the agreed priorities of Member States.

- To promote adherence to the Convention on the Safety of United Nations and Associated Personnel. ${ }^{14}$

\footnotetext{
${ }^{14}$ Resolution 49/59, annex.
} 
- To ensure greater policy coherence and better cooperation between the United Nations, its agencies, the Bretton Woods Institutions and the World Trade Organization, as well as other multilateral bodies, with a view to achieving a fully coordinated approach to the problems of peace and development.

- To strengthen further cooperation between the United Nations and national parliaments through their world organization, the Inter-Parliamentary Union, in various fields, including peace and security, economic and social development, international law and human rights and democracy and gender issues.

- To give-greater opportunities to the private sector, non-governmental organizations and civil society, in general, to contribute to the realization of the Organization's goals and programmes.

31. We request the General Assembly to review on a regular basis the progress made in implementing the provisions of this Declaration, and ask the Secretary-General to issue periodic reports for consideration by the General Assembly and as a basis for further action.

32. We solemnly reaffirm, on this historic occasion, that the United Nations is the indispensable common house of the entire human family, through which we will seek to realize our universal aspirations for peace, cooperation and development. We therefore pledge our unstinting support for these common objectives and our determination to achieve them.

8 th plenary meeting 8 September 2000 


\section{Declaration of Principles}

\section{Building the Information Society: a global challenge in the new Millennium}

\section{A. Our Common Vision of the Information Society}

1. We, the representatives of the peoples of the world, assembled in Geneva from 10-12 December 2003 for the first phase of the World Summit on the Information Society, declare our common desire and commitment to build a people-centred, inclusive and development-oriented Information Society, where everyone can create, access, utilize and share information and knowledge, enabling individuals, communities and peoples to achieve their full potential in promoting their sustainable development and improving their quality of life, premised on the purposes and principles of the Charter of the United Nations and respecting fully and upholding the Universal Declaration of Human Rights.

2. Our challenge is to harness the potential of information and communication technology to promote the development goals of the Millennium Declaration, namely the eradication of extreme poverty and hunger; achievement of universal primary education; promotion of gender equality and empowerment of women; reduction of child mortality; improvement of maternal health; to combat HIV/AIDS, malaria and other diseases; ensuring environmental sustainability; and development of global partnerships for development for the attainment of a more peaceful, just and prosperous world. We also reiterate our commitment to the achievement of sustainable development and agreed development goals, as contained in the Johannesburg Declaration and Plan of Implementation and the Monterrey Consensus, and other outcomes of relevant United Nations Summits.

3. We reaffirm the universality, indivisibility, interdependence and interrelation of all human rights and fundamental freedoms, including the right to development, as enshrined in the Vienna Declaration. We also reaffirm that democracy, sustainable development, and respect for human rights and fundamental freedoms as well as good governance at all levels are interdependent and mutually reinforcing. We further resolve to strengthen respect for the rule of law in international as in national affairs.

4. We reaffirm, as an essential foundation of the Information Society, and as outlined in Article 19 of the Universal Declaration of Human Rights, that everyone has the right to freedom of opinion and expression; that this right includes freedom to hold opinions without interference and to seek, receive and impart information and ideas through any media and regardless of frontiers. Communication is a fundamental social process, a basic human need and the foundation of all social organization. It is central to the Information Society. Everyone, everywhere should have the 
opportunity to participate and no one should be excluded from the benefits the Information Society offers.

5. We further reaffirm our commitment to the provisions of Article 29 of the Universal Declaration of Human Rights, that everyone has duties to the community in which alone the free and full development of their personality is possible, and that, in the exercise of their rights and freedoms, everyone shall be subject only to such limitations as are determined by law solely for the purpose of securing due recognition and respect for the rights and freedoms of others and of meeting the just requirements of morality, public order and the general welfare in a democratic society. These rights and freedoms may in no case be exercised contrary to the purposes and principles of the United Nations. In this way, we shall promote an Information Society where human dignity is respected.

6. In keeping with the spirit of this declaration, we rededicate ourselves to upholding the principle of the sovereign equality of all States.

7. We recognize that science has a central role in the development of the Information Society. Many of the building blocks of the Information Society are the result of scientific and technical advances made possible by the sharing of research results.

8. We recognize that education, knowledge, information and communication are at the core of human progress, endeavour and well-being. Further, Information and Communication Technologies (ICTs) have an immense impact on virtually all aspects of our lives. The rapid progress of these technologies opens completely new opportunities to attain higher levels of development. The capacity of these technologies to reduce many traditional obstacles, especially those of time and distance, for the first time in history makes it possible to use the potential of these technologies for the benefit of millions of people in all corners of the world.

9. We are aware that ICTs should be regarded as tools and not as an end in themselves. Under favourable conditions, these technologies can be a powerful instrument, increasing productivity, generating economic growth, job creation and employability and improving the quality of life of all. They can also promote dialogue among people, nations and civilizations.

10. We are also fully aware that the benefits of the information technology revolution are today unevenly distributed between the developed and developing countries and within societies. We are fully committed to turning this digital divide into a digital opportunity for all, particularly for those who risk being left behind and being further marginalized.

11. We are committed to realizing our common vision of the Information Society for ourselves and for future generations. We recognize that young people are the future workforce and leading creators and earliest adopters of ICTs. They must therefore be empowered as learners, developers, contributors, entrepreneurs and decision-makers. We must focus especially on young people who have not yet been able to benefit fully from the opportunities provided by ICTs. We are also committed to ensuring that the development of ICT applications and operation of services respects the rights of children as well as their protection and well-being.

12. We affirm that development of ICTs provides enormous opportunities for women, who should be an integral part of, and key actors, in the Information Society. We are committed to ensuring that the Information Society enables women's empowerment and their full participation on the basis on equality in all spheres of society and in all decision-making processes. To this end, we should mainstream a gender equality perspective and use ICTs as a tool to that end.

13. In building the Information Society, we shall pay particular attention to the special needs of marginalized and vulnerable groups of society, including migrants, internally displaced persons and 
refugees, unemployed and underprivileged people, minorities and nomadic people. We shall also recognize the special needs of older persons and persons with disabilities.

14. We are resolute to empower the poor, particularly those living in remote, rural and marginalized urban areas, to access information and to use ICTs as a tool to support their efforts to lift themselves out of poverty.

15. In the evolution of the Information Society, particular attention must be given to the special situation of indigenous peoples, as well as to the preservation of their heritage and their cultural legacy.

16. We continue to pay special attention to the particular needs of people of developing countries, countries with economies in transition, Least Developed Countries, Small Island Developing States, Landlocked Developing Countries, Highly Indebted Poor Countries, countries and territories under occupation, countries recovering from conflict and countries and regions with special needs as well as to conditions that pose severe threats to development, such as natural disasters.

17. We recognize that building an inclusive Information Society requires new forms of solidarity, partnership and cooperation among governments and other stakeholders, i.e. the private sector, civil society and international organizations. Realizing that the ambitious goal of this Declaration - bridging the digital divide and ensuring harmonious, fair and equitable development for all-will require strong commitment by all stakeholders, we call for digital solidarity, both at national and international levels.

18. Nothing in this Declaration shall be construed as impairing, contradicting, restricting or derogating from the provisions of the Charter of the United Nations and the Universal Declaration of Human Rights, any other international instrument or national laws adopted in furtherance of these instruments.

\section{B. An Information Society for All: Key Principles}

19. We are resolute in our quest to ensure that everyone can benefit from the opportunities that ICTs can offer. We agree that to meet these challenges, all stakeholders should work together to: improve access to information and communication infrastructure and technologies as well as to information and knowledge; build capacity; increase confidence and security in the use of ICTs; create an enabling environment at all levels; develop and widen ICT applications; foster and respect cultural diversity; recognize the role of the media; address the ethical dimensions of the Information Society; and encourage international and regional cooperation. We agree that these are the key principles for building an inclusive Information Society.

\section{1) The role of governments and all stakeholders in the promotion of ICTs for development}

20. Governments, as well as private sector, civil society and the United Nations and other international organizations have an important role and responsibility in the development of the Information Society and, as appropriate, in decision-making processes. Building a people-centred Information Society is a joint effort which requires cooperation and partnership among all stakeholders.

2) Information and communication infrastructure: an essential foundation for an inclusive information society

21. Connectivity is a central enabling agent in building the Information Society. Universal, ubiquitous, equitable and affordable access to ICT infrastructure and services, constitutes one of the challenges of the Information Society and should be an objective of all stakeholders involved in 
building it. Connectivity also involves access to energy and postal services, which should be assured in conformity with the domestic legislation of each country.

22. A well-developed information and communication network infrastructure and applications, adapted to regional, national and local conditions, easily-accessible and affordable, and making greater use of broadband and other innovative technologies where possible, can accelerate the social and economic progress of countries, and the well-being of all individuals, communities and peoples.

23. Policies that create a favourable climate for stability, predictability and fair competition at all levels should be developed and implemented in a manner that not only attracts more private investment for ICT infrastructure development but also enables universal service obligations to be met in areas where traditional market conditions fail to work. In disadvantaged areas, the establishment of ICT public access points in places such as post offices, schools, libraries and archives, can provide effective means for ensuring universal access to the infrastructure and services of the Information Society.

\section{3) Access to information and knowledge}

24. The ability for all to access and contribute information, ideas and knowledge is essential in an inclusive Information Society.

25. The sharing and strengthening of global knowledge for development can be enhanced by removing barriers to equitable access to information for economic, social, political, health, cultural, educational, and scientific activities and by facilitating access to public domain information, including by universal design and the use of assistive technologies.

26. A rich public domain is an essential element for the growth of the Information Society, creating multiple benefits such as an educated public, new jobs, innovation, business opportunities, and the advancement of sciences. Information in the public domain should be easily accessible to support the Information Society, and protected from misappropriation. Public institutions such as libraries and archives, museums, cultural collections and other community-based access points should be strengthened so as to promote the preservation of documentary records and free and equitable access to information.

27. Access to information and knowledge can be promoted by increasing awareness among all stakeholders of the possibilities offered by different software models, including proprietary, open-source and free software, in order to increase competition, access by users, diversity of choice, and to enable all users to develop solutions which best meet their requirements. Affordable access to software should be considered as an important component of a truly inclusive Information Society.

28. We strive to promote universal access with equal opportunities for all to scientific knowledge and the creation and dissemination of scientific and technical information, including open access initiatives for scientific publishing.

\section{4) Capacity building}

29. Each person should have the opportunity to acquire the necessary skills and knowledge in order to understand, participate actively in, and benefit fully from, the Information Society and the knowledge economy. Literacy and universal primary education are key factors for building a fully inclusive information society, paying particular attention to the special needs of girls and women. Given the wide range of ICT and information specialists required at all levels, building institutional capacity deserves special attention. 
30. The use of ICTs in all stages of education, training and human resource development should be promoted, taking into account the special needs of persons with disabilities and disadvantaged and vulnerable groups.

31. Continuous and adult education, re-training, life-long learning, distance-learning and other special services, such as telemedicine, can make an essential contribution to employability and help people benefit from the new opportunities offered by ICTs for traditional jobs, self-employment and new professions. Awareness and literacy in ICTs are an essential foundation in this regard.

32. Content creators, publishers, and producers, as well as teachers, trainers, archivists, librarians and learners, should play an active role in promoting the Information Society, particularly in the Least Developed Countries.

33. To achieve a sustainable development of the Information Society, national capability in ICT research and development should be enhanced. Furthermore, partnerships, in particular between and among developed and developing countries, including countries with economies in transition, in research and development, technology transfer, manufacturing and utilization of ICT products and services are crucial for promoting capacity building and global participation in the Information Society. The manufacture of ICTs presents a significant opportunity for creation of wealth.

34. The attainment of our shared aspirations, in particular for developing countries and countries with economies in transition, to become fully-fledged members of the Information Society, and their positive integration into the knowledge economy, depends largely on increased capacity building in the areas of education, technology know-how and access to information, which are major factors in determining development and competitiveness.

\section{5) Building confidence and security in the use of ICTs}

35. Strengthening the trust framework, including information security and network security, authentication, privacy and consumer protection, is a prerequisite for the development of the Information Society and for building confidence among users of ICTs. A global culture of cyber-security needs to be promoted, developed and implemented in cooperation with all stakeholders and international expert bodies. These efforts should be supported by increased international cooperation. Within this global culture of cyber-security, it is important to enhance security and to ensure the protection of data and privacy, while enhancing access and trade. In addition, it must take into account the level of social and economic development of each country and respect the development-oriented aspects of the Information Society.

36. While recognizing the principles of universal and non-discriminatory access to ICTs for all nations, we support the activities of the United Nations to prevent the potential use of ICTs for purposes that are inconsistent with the objectives of maintaining international stability and security, and may adversely affect the integrity of the infrastructure within States, to the detriment of their security. It is necessary to prevent the use of information resources and technologies for criminal and terrorist purposes, while respecting human rights.

37. Spam is a significant and growing problem for users, networks and the Internet as a whole. Spam and cyber-security should be dealt with at appropriate national and international levels.

\section{6) Enabling environment}

38. An enabling environment at national and international levels is essential for the Information Society. ICTs should be used as an important tool for good governance.

39. The rule of law, accompanied by a supportive, transparent, pro-competitive, technologically neutral and predictable policy and regulatory framework reflecting national realities, is essential for 
building a people-centred Information Society. Governments should intervene, as appropriate, to correct market failures, to maintain fair competition, to attract investment, to enhance the development of the ICT infrastructure and applications, to maximize economic and social benefits, and to serve national priorities.

40. A dynamic and enabling international environment, supportive of foreign direct investment, transfer of technology, and international cooperation, particularly in the areas of finance, debt and trade, as well as full and effective participation of developing countries in global decision-making, are vital complements to national development efforts related to ICTs. Improving global affordable connectivity would contribute significantly to the effectiveness of these development efforts.

41. ICTs are an important enabler of growth through efficiency gains and increased productivity, in particular by small and medium sized enterprises (SMEs). In this regard, the development of the Information Society is important for broadly-based economic growth in both developed and developing economies. ICT-supported productivity gains and applied innovations across economic sectors should be fostered. Equitable distribution of the benefits contributes to poverty eradication and social development. Policies that foster productive investment and enable firms, notably SMEs, to make the changes needed to seize the benefits from ICTs, are likely to be the most beneficial.

42. Intellectual Property protection is important to encourage innovation and creativity in the Information Society; similarly, the wide dissemination, diffusion, and sharing of knowledge is important to encourage innovation and creativity. Facilitating meaningful participation by all in intellectual property issues and knowledge sharing through full awareness and capacity building is a fundamental part of an inclusive Information Society.

43. Sustainable development can best be advanced in the Information Society when ICT-related efforts and programmes are fully integrated in national and regional development strategies. We welcome the New Partnership for Africa's Development (NEPAD) and encourage the international community to support the ICT-related measures of this initiative as well as those belonging to similar efforts in other regions. Distribution of the benefits of ICT-driven growth contributes to poverty eradication and sustainable development.

44. Standardization is one of the essential building blocks of the Information Society. There should be particular emphasis on the development and adoption of international standards. The development and use of open, interoperable, non-discriminatory and demand-driven standards that take into account needs of users and consumers is a basic element for the development and greater diffusion of ICTs and more affordable access to them, particularly in developing countries. International standards aim to create an environment where consumers can access services worldwide regardless of underlying technology.

45. The radio frequency spectrum should be managed in the public interest and in accordance with principle of legality, with full observance of national laws and regulation as well as relevant international agreements.

46. In building the Information Society, States are strongly urged to take steps with a view to the avoidance of, and refrain from, any unilateral measure not in accordance with international law and the Charter of the United Nations that impedes the full achievement of economic and social development by the population of the affected countries, and that hinders the well-being of their population. 
47. Recognizing that ICTs are progressively changing our working practices, the creation of a secure, safe and healthy working environment, appropriate to the utilisation of ICTs, respecting all relevant international norms, is fundamental.

48. The Internet has evolved into a global facility available to the public and its governance should constitute a core issue of the Information Society agenda. The international management of the Internet should be multilateral, transparent and democratic, with the full involvement of governments, the private sector, civil society and international organizations. It should ensure an equitable distribution of resources, facilitate access for all and ensure a stable and secure functioning of the Internet, taking into account multilingualism.

49. The management of the Internet encompasses both technical and public policy issues and should involve all stakeholders and relevant intergovernmental and international organizations. In this respect it is recognized that:

a) Policy authority for Internet-related public policy issues is the sovereign right of States. They have rights and responsibilities for international Internet-related public policy issues;

b) The private sector has had and should continue to have an important role in the development of the Internet, both in the technical and economic fields;

c) Civil society has also played an important role on Internet matters, especially at community level, and should continue to play such a role;

d) Intergovernmental organizations have had and should continue to have a facilitating role in the coordination of Internet-related public policy issues;

e) International organizations have also had and should continue to have an important role in the development of Internet-related technical standards and relevant policies.

50. International Internet governance issues should be addressed in a coordinated manner. We ask the Secretary-General of the United Nations to set up a working group on Internet governance, in an open and inclusive process that ensures a mechanism for the full and active participation of governments, the private sector and civil society from both developing and developed countries, involving relevant intergovernmental and international organizations and forums, to investigate and make proposals for action, as appropriate, on the governance of Internet by 2005.

\section{7) ICT applications: benefits in all aspects of life}

51. The usage and deployment of ICTs should seek to create benefits in all aspects of our daily life. ICT applications are potentially important in government operations and services, health care and health information, education and training, employment, job creation, business, agriculture, transport, protection of environment and management of natural resources, disaster prevention, and culture, and to promote eradication of poverty and other agreed development goals. ICTs should also contribute to sustainable production and consumption patterns and reduce traditional barriers, providing an opportunity for all to access local and global markets in a more equitable manner. Applications should be user-friendly, accessible to all, affordable, adapted to local needs in languages and cultures, and support sustainable development. To this effect, local authorities should play a major role in the provision of ICT services for the benefit of their populations.

\section{8) Cultural diversity and identity, linguistic diversity and local content}

52. Cultural diversity is the common heritage of humankind. The Information Society should be founded on and stimulate respect for cultural identity, cultural and linguistic diversity, traditions and religions, and foster dialogue among cultures and civilizations. The promotion, affirmation and 
preservation of diverse cultural identities and languages as reflected in relevant agreed United Nations documents including UNESCO's Universal Declaration on Cultural Diversity, will further enrich the Information Society.

53. The creation, dissemination and preservation of content in diverse languages and formats must be accorded high priority in building an inclusive Information Society, paying particular attention to the diversity of supply of creative work and due recognition of the rights of authors and artists. It is essential to promote the production of and accessibility to all content - educational, scientific, cultural or recreational - in diverse languages and formats. The development of local content suited to domestic or regional needs will encourage social and economic development and will stimulate participation of all stakeholders, including people living in rural, remote and marginal areas.

54. The preservation of cultural heritage is a crucial component of identity and self-understanding of individuals that links a community to its past. The Information Society should harness and preserve cultural heritage for the future by all appropriate methods, including digitisation.

\section{9) Media}

55. We reaffirm our commitment to the principles of freedom of the press and freedom of information, as well as those of the independence, pluralism and diversity of media, which are essential to the Information Society. Freedom to seek, receive, impart and use information for the creation, accumulation and dissemination of knowledge are important to the Information Society. We call for the responsible use and treatment of information by the media in accordance with the highest ethical and professional standards. Traditional media in all their forms have an important role in the Information Society and ICTs should play a supportive role in this regard. Diversity of media ownership should be encouraged, in conformity with national law, and taking into account relevant international conventions. We reaffirm the necessity of reducing international imbalances affecting the media, particularly as regards infrastructure, technical resources and the development of human skills.

\section{0) Ethical dimensions of the Information Society}

56. The Information Society should respect peace and uphold the fundamental values of freedom, equality, solidarity, tolerance, shared responsibility, and respect for nature.

57. We acknowledge the importance of ethics for the Information Society, which should foster justice, and the dignity and worth of the human person. The widest possible protection should be accorded to the family and to enable it to play its crucial role in society.

58. The use of ICTs and content creation should respect human rights and fundamental freedoms of others, including personal privacy, and the right to freedom of thought, conscience, and religion in conformity with relevant international instruments.

59. All actors in the Information Society should take appropriate actions and preventive measures, as determined by law, against abusive uses of ICTs, such as illegal and other acts motivated by racism, racial discrimination, xenophobia, and related intolerance, hatred, violence, all forms of child abuse, including paedophilia and child pornography, and trafficking in, and exploitation of, human beings.

\section{1) International and regional cooperation}

60. We aim at making full use of the opportunities offered by ICTs in our efforts to reach the internationally agreed development goals, including those contained in the Millennium Declaration, and to uphold the key principles set forth in this Declaration. The Information Society is intrinsically global in nature and national efforts need to be supported by effective international and 
regional cooperation among governments, the private sector, civil society and other stakeholders, including the international financial institutions.

61. In order to build an inclusive global Information Society, we will seek and effectively implement concrete international approaches and mechanisms, including financial and technical assistance. Therefore, while appreciating ongoing ICT cooperation through various mechanisms, we invite all stakeholders to commit to the "Digital Solidarity Agenda" set forth in the Plan of Action. We are convinced that the worldwide agreed objective is to contribute to bridge the digital divide, promote access to ICTs, create digital opportunities, and benefit from the potential offered by ICTs for development. We recognize the will expressed by some to create an international voluntary "Digital Solidarity Fund", and by others to undertake studies concerning existing mechanisms and the efficiency and feasibility of such a Fund.

62. Regional integration contributes to the development of the global Information Society and makes strong cooperation within and among regions indispensable. Regional dialogue should contribute to national capacity building and to the alignment of national strategies with the goals of this Declaration of Principles in a compatible way, while respecting national and regional particularities. In this context, we welcome and encourage the international community to support the ICT-related measures of such initiatives.

63. We resolve to assist developing countries, LDCs and countries with economies in transition through the mobilization from all sources of financing, the provision of financial and technical assistance and by creating an environment conducive to technology transfer, consistent with the purposes of this Declaration and the Plan of Action.

64. The core competences of the International Telecommunication Union (ITU) in the fields of ICTs - assistance in bridging the digital divide, international and regional cooperation, radio spectrum management, standards development and the dissemination of information-are of crucial importance for building the Information Society.

\section{Towards an Information Society for All Based on Shared Knowledge}

65. We commit ourselves to strengthening cooperation to seek common responses to the challenges and to the implementation of the Plan of Action, which will realize the vision of an inclusive Information Society based on the Key Principles incorporated in this Declaration.

66. We further commit ourselves to evaluate and follow-up progress in bridging the digital divide, taking into account different levels of development, so as to reach internationally agreed development goals, including those contained in the Millennium Declaration, and to assess the effectiveness of investment and international cooperation efforts in building the Information Society.

67. We are firmly convinced that we are collectively entering a new era of enormous potential, that of the Information Society and expanded human communication. In this emerging society, information and knowledge can be produced, exchanged, shared and communicated through all the networks of the world. All individuals can soon, if we take the necessary actions, together build a new Information Society based on shared knowledge and founded on global solidarity and a better mutual understanding between peoples and nations. We trust that these measures will open the way to the future development of a true knowledge society. 


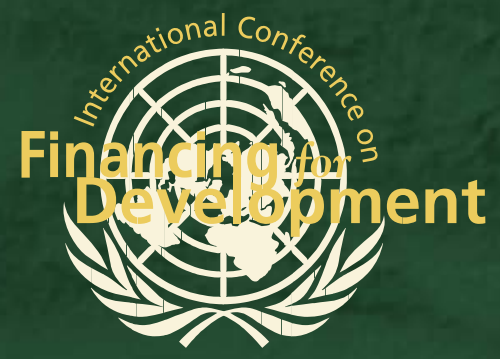

Monterrey, Mexico

18-22 March 2002

\section{Monterrey Consensus Financing for
Development}

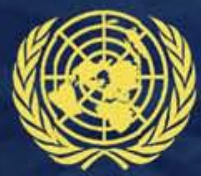

United Nations 


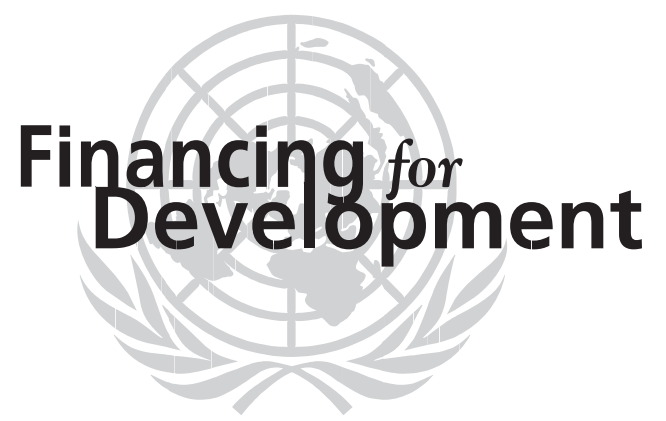

\section{Monterrey Consensus}

\section{OF THE INTERNATIONAL CONFERENCE on FinANCING for DeVElopMent}

The final text of agreements and commitments adopted at the International Conference on Financing for Development Monterrey, Mexico, 18-22 March 2002

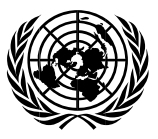




\section{FOR MORE INFORMATION, PLEASE CONTACT:}

United Nations Department of Economic and Social Affairs Financing for Development Office

E-mail: ffdoffice@un.org

Website: www.un.org/esa/ffd 


\section{Monterrey Consensus of the International Conference on Financing for Development*}

\section{Contents}

I. Confronting the challenges of financing for development: a global response

II. Leading actions . . . . . . . . . . . . . . . . . 10-67

A. Mobilizing domestic financial resources for development . . . . . . . . . . . . . . . . . . . . . 10-19

B. Mobilizing international resources for development: foreign direct investment and other private flows . . . . 20-25

C. International trade as an engine for development . . . . . 26-38

D. Increasing international financial and technical cooperation for development ...........39-46 14

E. External debt . . . . . . . . . . . . . . . . . . . . . . . .47-51 16

F. Addressing systemic issues: enhancing the coherence and consistency of the international monetary, financial and trading systems in support of development . . . . . . . . . . . . . . . .52-67

III. Staying engaged $.68-73$ 


\section{Confronting the challenges of financing for development: a global response}

1. We the heads of State and Government, gathered in Monterrey, Mexico, on 21 and 22 March 2002, have resolved to address the challenges of financing for development around the world, particularly in developing countries. Our goal is to eradicate poverty, achieve sustained economic growth and promote sustainable development as we advance to a fully inclusive and equitable global economic system.

2. We note with concern current estimates of dramatic shortfalls in resources required to achieve the internationally agreed development goals, including those contained in the United Nations Millennium Declaration. ${ }^{1}$

3. Mobilizing and increasing the effective use of financial resources and achieving the national and international economic conditions needed to fulfil internationally agreed development goals, including those contained in the Millennium Declaration, to eliminate poverty, improve social conditions and raise living standards, and protect our environment, will be our first step to ensuring that the twenty-first century becomes the century of development for all.

4. Achieving the internationally agreed development goals, including those contained in the Millennium Declaration, demands a new partnership between developed and developing countries. We commit ourselves to sound policies, good governance at all levels and the rule of law. We also commit ourselves to mobilizing domestic resources, attracting international flows, promoting international trade as an engine for development, increasing international financial and technical cooperation for development, sustainable debt financing and external debt relief, and enhancing the coherence and consistency of the international monetary, financial and trading systems.

5. The terrorist attacks on 11 September 2001 exacerbated the global economic slowdown, further reducing growth rates. It has now become all the more urgent to enhance collaboration among all stakeholders to promote sustained economic growth and to address the long-term challenges of financing for development. Our resolve to act together is stronger than ever.

6. Each country has primary responsibility for its own economic and social development, and the role of national policies and development strategies cannot be overemphasized. At the same time, domestic economies

${ }^{1}$ General Assembly resolution 55/2. 
are now interwoven with the global economic system and, inter alia, the effective use of trade and investment opportunities can help countries to fight poverty. National development efforts need to be supported by an enabling international economic environment. We encourage and support development frameworks initiated at the regional level, such as the New Partnership for Africa's Development and similar efforts in other regions.

7. Globalization offers opportunities and challenges. The developing countries and countries with economies in transition face special difficulties in responding to those challenges and opportunities. Globalization should be fully inclusive and equitable, and there is a strong need for policies and measures at the national and international levels, formulated and implemented with the full and effective participation of developing countries and countries with economies in transition to help them respond effectively to those challenges and opportunities.

8. In the increasingly globalizing interdependent world economy, a holistic approach to the interconnected national, international and systemic challenges of financing for development - sustainable, gender-sensitive, people-centred development - in all parts of the globe is essential. Such an approach must open up opportunities for all and help to ensure that resources are created and used effectively and that strong, accountable institutions are established at all levels. To that end, collective and coherent action is needed in each interrelated area of our agenda, involving all stakeholders in active partnership.

9. Recognizing that peace and development are mutually reinforcing, we are determined to pursue our shared vision for a better future, through our individual efforts combined with vigorous multilateral action. Upholding the Charter of the United Nations and building upon the values of the Millennium Declaration, we commit ourselves to promoting national and global economic systems based on the principles of justice, equity, democracy, participation, transparency, accountability and inclusion.

\section{Leading actions}

\section{A. Mobilizing domestic financial resources for development}

10. In our common pursuit of growth, poverty eradication and sustainable development, a critical challenge is to ensure the necessary internal conditions for mobilizing domestic savings, both public and private, sustaining adequate levels of productive investment and increasing human capacity. A crucial task is to enhance the efficacy, coherence and consis- 
tency of macroeconomic policies. An enabling domestic environment is vital for mobilizing domestic resources, increasing productivity, reducing capital flight, encouraging the private sector, and attracting and making effective use of international investment and assistance. Efforts to create such an environment should be supported by the international community.

11. Good governance is essential for sustainable development. Sound economic policies, solid democratic institutions responsive to the needs of the people and improved infrastructure are the basis for sustained economic growth, poverty eradication and employment creation. Freedom, peace and security, domestic stability, respect for human rights, including the right to development, and the rule of law, gender equality, market-oriented policies, and an overall commitment to just and democratic societies are also essential and mutually reinforcing.

12. We will pursue appropriate policy and regulatory frameworks at our respective national levels and in a manner consistent with national laws to encourage public and private initiatives, including at the local level, and foster a dynamic and well functioning business sector, while improving income growth and distribution, raising productivity, empowering women and protecting labour rights and the environment. We recognize that the appropriate role of government in market-oriented economies will vary from country to country.

13. Fighting corruption at all levels is a priority. Corruption is a serious barrier to effective resource mobilization and allocation, and diverts resources away from activities that are vital for poverty eradication and economic and sustainable development.

14. We recognize the need to pursue sound macroeconomic policies aimed at sustaining high rates of economic growth, full employment, poverty eradication, price stability and sustainable fiscal and external balances to ensure that the benefits of growth reach all people, especially the poor. Governments should attach priority to avoiding inflationary distortions and abrupt economic fluctuations that negatively affect income distribution and resource allocation. Along with prudent fiscal and monetary policies, an appropriate exchange rate regime is required.

15. An effective, efficient, transparent and accountable system for mobilizing public resources and managing their use by Governments is essential. We recognize the need to secure fiscal sustainability, along with equitable and efficient tax systems and administration, as well as improvements in public spending that do not crowd out productive private investment. We also recognize the contribution that medium-term fiscal frameworks can make in that respect.

16. Investments in basic economic and social infrastructure, social services and social protection, including education, health, nutrition, shelter and 
social security programmes, which take special care of children and older persons and are gender sensitive and fully inclusive of the rural sector and all disadvantaged communities, are vital for enabling people, especially people living in poverty, to better adapt to and benefit from changing economic conditions and opportunities. Active labour market policies, including worker training, can help to increase employment and improve working conditions. The coverage and scope of social protection needs to be further strengthened. Economic crises also underscore the importance of effective social safety nets.

17. We recognize the need to strengthen and develop the domestic financial sector, by encouraging the orderly development of capital markets through sound banking systems and other institutional arrangements aimed at addressing development financing needs, including the insurance sector and debt and equity markets, that encourage and channel savings and foster productive investments. That requires a sound system of financial intermediation, transparent regulatory frameworks and effective supervisory mechanisms, supported by a solid central bank. Guarantee schemes and business development services should be developed for easing the access of small and medium-sized enterprises to local financing.

18. Microfinance and credit for micro-, small and medium-sized enterprises, including in rural areas, particularly for women, as well as national savings schemes, are important for enhancing the social and economic impact of the financial sector. Development banks, commercial and other financial institutions, whether independently or in cooperation, can be effective instruments for facilitating access to finance, including equity financing, for such enterprises, as well as an adequate supply of medium- and longterm credit. In addition, the promotion of private-sector financial innovations and public-private partnerships can also deepen domestic financial markets and further develop the domestic financial sector. The prime objective of pension schemes is social protection, but when those schemes are funded they can also be a source of savings. Bearing in mind economic and social considerations, efforts should be made to incorporate the informal sector into the formal economy, wherever feasible. It is also important to reduce the transfer costs of migrant workers' remittances and create opportunities for development-oriented investments, including housing.

19. It is critical to reinforce national efforts in capacity-building in developing countries and countries with economies in transition in such areas as institutional infrastructure, human resource development, public finance, mortgage finance, financial regulation and supervision, basic education in particular, public administration, social and gender budget policies, early warning and crisis prevention, and debt management. In that regard, par- 
ticular attention is required to address the special needs of Africa, the least developed countries, small island developing States and landlocked developing countries. We reaffirm our commitment to the Programme of Action for the Least Developed Countries for the Decade 2001-2010, ${ }^{2}$ adopted by the Third United Nations Conference on the Least Developed Countries, held in Brussels from 14 to 20 May 2001, and the Global Programme of Action for the Sustainable Development of Small Island Developing States. ${ }^{3}$ International support for those efforts, including technical assistance and through United Nations operational activities for development, is indispensable. We encourage South-South cooperation, including through triangular cooperation, to facilitate exchange of views on successful strategies, practices and experience and replication of projects.

\section{B. Mobilizing international resources for development: foreign direct investment and other private flows}

20. Private international capital flows, particularly foreign direct investment, along with international financial stability, are vital complements to national and international development efforts. Foreign direct investment contributes toward financing sustained economic growth over the long term. It is especially important for its potential to transfer knowledge and technology, create jobs, boost overall productivity, enhance competitiveness and entrepreneurship, and ultimately eradicate poverty through economic growth and development. A central challenge, therefore, is to create the necessary domestic and international conditions to facilitate direct investment flows, conducive to achieving national development priorities, to developing countries, particularly Africa, least developed countries, small island developing States, and landlocked developing countries, and also to countries with economies in transition.

21. To attract and enhance inflows of productive capital, countries need to continue their efforts to achieve a transparent, stable and predictable investment climate, with proper contract enforcement and respect for property rights, embedded in sound macroeconomic policies and institutions that allow businesses, both domestic and international, to operate efficiently and profitably and with maximum development impact. Special efforts are required in such priority areas as economic policy and regula-

\footnotetext{
${ }^{2}$ A/CONF.191/11.

${ }^{3}$ Report of the Global Conference on the Sustainable Development of Small Island Developing States, Bridgetown, Barbados, 25 April-6 May 1994 (United Nations publication, Sales No. E.94.I.18 and corrigenda), chap. I, resolution 1, annex II.
} 
tory frameworks for promoting and protecting investments, including the areas of human resource development, avoidance of double taxation, corporate governance, accounting standards, and the promotion of a competitive environment. Other mechanisms, such as public/private partnerships and investment agreements, can be important. We emphasize the need for strengthened, adequately resourced technical assistance and productive capacity-building programmes, as requested by recipients.

22. To complement national efforts, there is the need for the relevant international and regional institutions as well as appropriate institutions in source countries to increase their support for private foreign investment in infrastructure development and other priority areas, including projects to bridge the digital divide, in developing countries and countries with economies in transition. To this end, it is important to provide export credits, co-financing, venture capital and other lending instruments, risk guarantees, leveraging aid resources, information on investment opportunities, business development services, forums to facilitate business contacts and cooperation between enterprises of developed and developing countries, as well as funding for feasibility studies. Inter-enterprise partnership is a powerful means for transfer and dissemination of technology. In this regard, strengthening of the multilateral and regional financial and development institutions is desirable. Additional source country measures should also be devised to encourage and facilitate investment flows to developing countries.

23. While Governments provide the framework for their operation, businesses, for their part, are expected to engage as reliable and consistent partners in the development process. We urge businesses to take into account not only the economic and financial but also the developmental, social, gender and environmental implications of their undertakings. In that spirit, we invite banks and other financial institutions, in developing countries as well as developed countries, to foster innovative developmental financing approaches. We welcome all efforts to encourage good corporate citizenship and note the initiative undertaken in the United Nations to promote global partnerships.

24. We will support new public/private sector financing mechanisms, both debt and equity, for developing countries and countries with economies in transition, to benefit in particular small entrepreneurs and small and medium-size enterprises and infrastructure. Those public/private initiatives could include the development of consultation mechanisms between international and regional financial organizations and national Governments with the private sector in both source and recipient countries as a means of creating business-enabling environments.

25. We underscore the need to sustain sufficient and stable private financial flows to developing countries and countries with economies in transition. It is important to promote measures in source and destination countries 
to improve transparency and the information about financial flows. Measures that mitigate the impact of excessive volatility of short-term capital flows are important and must be considered. Given each country's varying degree of national capacity, managing national external debt profiles, paying careful attention to currency and liquidity risk, strengthening prudential regulations and supervision of all financial institutions, including highly leveraged institutions, liberalizing capital flows in an orderly and well sequenced process consistent with development objectives, and implementation, on a progressive and voluntary basis, of codes and standards agreed internationally, are also important. We encourage public/private initiatives that enhance the ease of access, accuracy, timeliness and coverage of information on countries and financial markets, which strengthen capacities for risk assessment. Multilateral financial institutions could provide further assistance for all those purposes.

\section{International trade as an engine for development}

26. A universal, rule-based, open, non-discriminatory and equitable multilateral trading system, as well as meaningful trade liberalization, can substantially stimulate development worldwide, benefiting countries at all stages of development. In that regard, we reaffirm our commitment to trade liberalization and to ensure that trade plays its full part in promoting economic growth, employment and development for all. We thus welcome the decisions of the World Trade Organization to place the needs and interests of developing countries at the heart of its work programme, and commit ourselves to their implementation.

27. To benefit fully from trade, which in many cases is the single most important external source of development financing, the establishment or enhancement of appropriate institutions and policies in developing countries, as well as in countries with economies in transition, is needed. Meaningful trade liberalization is an important element in the sustainable development strategy of a country. Increased trade and foreign direct investment could boost economic growth and could be a significant source of employment.

28. We acknowledge the issues of particular concern to developing countries and countries with economies in transition in international trade to enhance their capacity to finance their development, including trade barriers, trade-distorting subsidies and other trade-distorting measures, particularly in sectors of special export interest to developing countries, including agriculture; the abuse of anti-dumping measures; technical barriers and sanitary and phytosanitary measures; trade liberalization in labour intensive manufactures; trade liberalization in agricultural products; trade in services; tariff peaks, high tariffs and tariff escalation, as well as 
non-tariff barriers; the movement of natural persons; the lack of recognition of intellectual property rights for the protection of traditional knowledge and folklore; the transfer of knowledge and technology; the implementation and interpretation of the Agreement on Trade-Related Aspects of Intellectual Property Rights ${ }^{4}$ in a manner supportive of public health; and the need for special and differential treatment provisions for developing countries in trade agreements to be made more precise, effective and operational.

29. To ensure that world trade supports development to the benefit of all countries, we encourage the members of the World Trade Organization to implement the outcome of its Fourth Ministerial Conference, held in Doha, Qatar from 9 to 14 November 2001.

30. We also undertake to facilitate the accession of all developing countries, particularly the least developed countries, as well as countries with economies in transition, that apply for membership in the World Trade Organization.

31. We will implement the commitments made in Doha to address the marginalization of the least developed countries in international trade as well as the work programme adopted to examine issues related to the trade of small economies.

32. We also commit ourselves to enhancing the role of regional and subregional agreements and free trade areas, consistent with the multilateral trading system, in the construction of a better world trading system. We urge international financial institutions, including the regional development banks, to continue to support projects that promote subregional and regional integration among developing countries and countries with economies in transition.

33. We recognize the importance of enhanced and predictable access to all markets for the exports of developing countries, including small island developing States, landlocked developing countries, transit developing countries and countries in Africa, as well as countries with economies in transition.

34. We call on developed countries that have not already done so to work towards the objective of duty-free and quota-free access for all least developed countries' exports, as envisaged in the Programme of Action for the Least Developed Countries adopted in Brussels. Consideration of proposals for developing countries to contribute to improved market access for least developed countries would also be helpful.

${ }^{4}$ The Results of the Uruguay Round of Multilateral Trade Negotiations: The Legal Texts (Geneva, GATT secretariat, 1994), annex 1C. 
35. We further recognize the importance for developing countries as well as countries with economies in transition of considering reducing trade barriers among themselves.

36. In cooperation with the interested Governments and their financial institutions and to further support national efforts to benefit from trade opportunities and effectively integrate into the multilateral trading system, we invite multilateral and bilateral financial and development institutions to expand and coordinate their efforts, with increased resources, for gradually removing supply-side constraints; improve trade infrastructure; diversify export capacity and support an increase in the technological content of exports; strengthen institutional development and enhance overall productivity and competitiveness. To that end, we further invite bilateral donors and the international and regional financial institutions, together with the relevant United Nations agencies, funds and programmes, to reinforce the support for trade-related training, capacity and institution building and trade-supporting services. Special consideration should be given to least developed countries, landlocked developing countries, small island developing States, African development, transit developing countries and countries with economies in transition, including through the Integrated Framework for Trade-Related Technical Assistance to Least Developed Countries and its follow-up, the Joint Integrated Technical Assistance Programme, the World Trade Organization Doha Development Agenda Global Trust Fund, as well as the activities of the International Trade Centre.

37. Multilateral assistance is also needed to mitigate the consequences of depressed export revenues of countries that still depend heavily on commodity exports. Thus, we recognize the recent review of the International Monetary Fund Compensatory Financing Facility and will continue to assess its effectiveness. It is also important to empower developing country commodity producers to insure themselves against risk, including against natural disasters. We further invite bilateral donors and multilateral aid agencies to strengthen their support to export diversification programmes in those countries.

38. In support of the process launched in Doha, immediate attention should go to strengthening and ensuring the meaningful and full participation of developing countries, especially the least developed countries, in multilateral trade negotiations. In particular, developing countries need assistance in order to participate effectively in the World Trade Organization work programme and negotiating process through the enhanced cooperation of all relevant stakeholders, including the United Nations Conference on Trade and Development, the World Trade Organization and the World Bank. To those ends, we underscore the importance of 
effective, secure and predictable financing of trade-related technical assistance and capacity-building.

\section{Increasing international financial and technical cooperation for development}

39. Official development assistance (ODA) plays an essential role as a complement to other sources of financing for development, especially in those countries with the least capacity to attract private direct investment. ODA can help a country to reach adequate levels of domestic resource mobilization over an appropriate time horizon, while human capital, productive and export capacities are enhanced. ODA can be critical for improving the environment for private sector activity and can thus pave the way for robust growth. ODA is also a crucial instrument for supporting education, health, public infrastructure development, agriculture and rural development, and to enhance food security. For many countries in Africa, least developed countries, small island developing States and landlocked developing countries, ODA is still the largest source of external financing and is critical to the achievement of the development goals and targets of the Millennium Declaration and other internationally agreed development targets.

40. Effective partnerships among donors and recipients are based on the recognition of national leadership and ownership of development plans and, within that framework, sound policies and good governance at all levels are necessary to ensure ODA effectiveness. A major priority is to build those development partnerships, particularly in support of the neediest, and to maximize the poverty reduction impact of ODA. The goals, targets and commitments of the Millennium Declaration and other internationally agreed development targets can help countries to set short- and medium-term national priorities as the foundation for building partnerships for external support. In that context, we underline the importance of the United Nations funds, programmes and specialized agencies, and we will strongly support them.

41. We recognize that a substantial increase in ODA and other resources will be required if developing countries are to achieve the internationally agreed development goals and objectives, including those contained in the Millennium Declaration. To build support for ODA, we will cooperate to further improve policies and development strategies, both nationally and internationally, to enhance aid effectiveness.

42. In that context, we urge developed countries that have not done so to make concrete efforts towards the target of 0.7 per cent of gross national product (GNP) as ODA to developing countries and 0.15 to 0.20 per cent of GNP of developed countries to least developed countries, as reconfirmed at the Third United Nations Conference on Least Developed 
Countries, and we encourage developing countries to build on progress achieved in ensuring that ODA is used effectively to help achieve development goals and targets. We acknowledge the efforts of all donors, commend those donors whose ODA contributions exceed, reach or are increasing towards the targets, and underline the importance of undertaking to examine the means and time frames for achieving the targets and goals.

43. Recipient and donor countries, as well as international institutions, should strive to make ODA more effective. In particular, there is a need for the multilateral and bilateral financial and development institutions to intensify efforts to:

- Harmonize their operational procedures at the highest standard so as to reduce transaction costs and make ODA disbursement and delivery more flexible, taking into account national development needs and objectives under the ownership of the recipient country;

- Support and enhance recent efforts and initiatives, such as untying aid, including the implementation of the Organisation for Economic Cooperation and Development/Development Assistance Committee recommendation on untying aid to the least developed countries, as agreed by the Organisation for Economic Cooperation and Development in May 2001. Further efforts should be made to address burdensome restrictions;

- Enhance the absorptive capacity and financial management of the recipient countries to utilize aid in order to promote the use of the most suitable aid delivery instruments that are responsive to the needs of developing countries and to the need for resource predictability, including budget support mechanisms, where appropriate, and in a fully consultative manner;

- Use development frameworks that are owned and driven by developing countries and that embody poverty reduction strategies, including poverty reduction strategy papers, as vehicles for aid delivery, upon request;

- Enhance recipient countries' input into and ownership of the design, including procurement, of technical assistance programmes; and increase the effective use of local technical assistance resources;

- Promote the use of ODA to leverage additional financing for development, such as foreign investment, trade and domestic resources;

- Strengthen triangular cooperation, including countries with economies in transition, and South-South cooperation, as delivery tools for assistance;

- Improve ODA targeting to the poor, coordination of aid and measurement of results.

We invite donors to take steps to apply the above measures in support of all developing countries, including immediately in support of the comprehensive strategy that is embodied in the New Partnership for Africa's Development and 
similar efforts in other regions, as well as in support of least developed countries, small island developing States and landlocked developing countries. We acknowledge and appreciate the discussions taking place in other forums on proposals to increase the concessionality of development financing, including greater use of grants.

44. We recognize the value of exploring innovative sources of finance provided that those sources do not unduly burden developing countries. In that regard, we agree to study, in the appropriate forums, the results of the analysis requested from the Secretary-General on possible innovative sources of finance, noting the proposal to use special drawing rights allocations for development purposes. We consider that any assessment of special drawing rights allocations must respect the International Monetary Fund's Articles of Agreement and the established rules of procedure of the Fund, which requires taking into account the global need for liquidity at the international level.

45. Multilateral and regional development banks continue to play a vital role in serving the development needs of developing countries and countries with economies in transition. They should contribute to providing an adequate supply of finance to countries that are challenged by poverty, follow sound economic policies and may lack adequate access to capital markets. They should also mitigate the impact of excessive volatility of financial markets. Strengthened regional development banks and subregional financial institutions add flexible financial support to national and regional development efforts, enhancing ownership and overall efficiency. They also serve as a vital source of knowledge and expertise on economic growth and development for their developing member countries.

46. We will ensure that the long-term resources at the disposal of the international financial system, including regional and subregional institutions and funds, allow them to adequately support sustained economic and social development, technical assistance for capacity-building, and social and environmental protection schemes. We will also continue to enhance their overall lending effectiveness through increased country ownership, operations that raise productivity and yield measurable results in reducing poverty, and closer coordination with donors and the private sector.

\section{E. External debt}

47. Sustainable debt financing is an important element for mobilizing resources for public and private investment. National comprehensive strategies to monitor and manage external liabilities, embedded in the domestic preconditions for debt sustainability, including sound macro- 
economic policies and public resource management, are a key element in reducing national vulnerabilities. Debtors and creditors must share the responsibility for preventing and resolving unsustainable debt situations. Technical assistance for external debt management and debt tracking can play an important role and should be strengthened.

48. External debt relief can play a key role in liberating resources that can then be directed towards activities consistent with attaining sustainable growth and development, and therefore, debt relief measures should, where appropriate, be pursued vigorously and expeditiously, including within the Paris and London Clubs and other relevant forums. Noting the importance of re-establishing financial viability for those developing countries facing unsustainable debt burdens, we welcome initiatives that have been undertaken to reduce outstanding indebtedness and invite further national and international measures in that regard, including, as appropriate, debt cancellation and other arrangements.

49. The enhanced Heavily Indebted Poor Countries Initiative provides an opportunity to strengthen the economic prospects and poverty reduction efforts of its beneficiary countries. Speedy, effective and full implementation of the enhanced Initiative, which should be fully financed through additional resources, is critical. Heavily indebted poor countries should take the policy measures necessary to become eligible for the Initiative. Future reviews of debt sustainability should also bear in mind the impact of debt relief on progress towards the achievement of the development goals contained in the Millennium Declaration. We stress the importance of continued flexibility with regard to the eligibility criteria. Continued efforts are needed to reduce the debt burden of heavily indebted poor countries to sustainable levels. The computational procedures and assumptions underlying debt sustainability analysis need to be kept under review. Debt sustainability analysis at the completion point needs to take into account any worsening global growth prospects and declining terms of trade. Debt relief arrangements should seek to avoid imposing any unfair burdens on other developing countries.

50. We stress the need for the International Monetary Fund and the World Bank to consider any fundamental changes in countries' debt sustainability caused by natural catastrophes, severe terms of trade shocks or conflict, when making policy recommendations, including for debt relief, as appropriate.

51. While recognizing that a flexible mix of instruments is needed to respond appropriately to countries' different economic circumstances and capacities, we emphasize the importance of putting in place a set of clear principles for the management and resolution of financial crises that provide for fair burden-sharing between public and private sectors and between debtors, creditors and investors. We encourage donor countries to take steps to ensure that resources provided for debt relief do not detract from 
ODA resources intended to be available for developing countries. We also encourage exploring innovative mechanisms to comprehensively address debt problems of developing countries, including middle-income countries and countries with economies in transition.

\section{F. Addressing systemic issues: enhancing the coherence and consistency of the interna- tional monetary, financial and trading systems in support of development}

52. In order to complement national development efforts, we recognize the urgent need to enhance coherence, governance, and consistency of the international monetary, financial and trading systems. To contribute to that end, we underline the importance of continuing to improve global economic governance and to strengthen the United Nations leadership role in promoting development. With the same purpose, efforts should be strengthened at the national level to enhance coordination among all relevant ministries and institutions. Similarly, we should encourage policy and programme coordination of international institutions and coherence at the operational and international levels to meet the Millennium Declaration development goals of sustained economic growth, poverty eradication and sustainable development.

53. Important international efforts are under way to reform the international financial architecture. Those efforts need to be sustained with greater transparency and the effective participation of developing countries and countries with economies in transition. One major objective of the reform is to enhance financing for development and poverty eradication. We also underscore our commitment to sound domestic financial sectors, which make a vital contribution to national development efforts, as an important component of an international financial architecture that is supportive of development.

54. Strong coordination of macroeconomic policies among the leading industrial countries is critical to greater global stability and reduced exchange rate volatility, which are essential to economic growth as well as for enhanced and predictable financial flows to developing countries and countries with economies in transition.

55. The multilateral financial institutions, in particular the International Monetary Fund, need to continue to give high priority to the identification and prevention of potential crises and to strengthening the underpinnings of international financial stability. In that regard, we stress the need for the Fund to further strengthen its surveillance activities of all economies, with particular attention to short-term capital flows and their impact. We encourage the International Monetary Fund to facilitate the timely detection of external vulnerability through well designed surveil- 
lance and early warning systems and to coordinate closely with relevant regional institutions or organizations, including the regional commissions.

56. We stress the need for multilateral financial institutions, in providing policy advice and financial support, to work on the basis of sound, nationally owned paths of reform that take into account the needs of the poor and efforts to reduce poverty, and to pay due regard to the special needs and implementing capacities of developing countries and countries with economies in transition, aiming at economic growth and sustainable development. The advice should take into account social costs of adjustment programmes, which should be designed to minimize negative impact on the vulnerable segments of society.

57. It is essential to ensure the effective and equitable participation of developing countries in the formulation of financial standards and codes. It is also essential to ensure implementation, on a voluntary and progressive basis, as a contribution to reducing vulnerability to financial crisis and contagion.

58. Sovereign risk assessments made by the private sector should maximize the use of strict, objective and transparent parameters, which can be facilitated by high-quality data and analysis.

59. Noting the impact of financial crisis or risk of contagion in developing countries and countries with economies in transition, regardless of their size, we underline the need to ensure that the international financial institutions, including the International Monetary Fund, have a suitable array of financial facilities and resources to respond in a timely and appropriate way in accordance with their policies. The International Monetary Fund has a range of instruments available and its current financial position is strong. The contingent credit line is an important signal of the strength of countries' policies and a safeguard against contagion in financial markets. The need for special drawing rights allocations should be kept under review. In that regard, we also underline the need to enhance the stabilizing role of regional and subregional reserve funds, swap arrangements and similar mechanisms that complement the efforts of international financial institutions.

60. To promote fair burden-sharing and minimize moral hazard, we would welcome consideration by all relevant stakeholders of an international debt workout mechanism, in the appropriate forums, that will engage debtors and creditors to come together to restructure unsustainable debts in a timely and efficient manner. Adoption of such a mechanism should not preclude emergency financing in times of crisis.

61. Good governance at all levels is also essential for sustained economic growth, poverty eradication and sustainable development worldwide. To better reflect the growth of interdependence and enhance legitimacy, economic governance needs to develop in two areas: broadening the 
base for decision-making on issues of development concern and filling organizational gaps. To complement and consolidate advances in those two areas, we must strengthen the United Nations system and other multilateral institutions. We encourage all international organizations to seek to continually improve their operations and interactions.

62. We stress the need to broaden and strengthen the participation of developing countries and countries with economies in transition in international economic decision-making and norm-setting. To those ends, we also welcome further actions to help developing countries and countries with economies in transition to build their capacity to participate effectively in multilateral forums.

63. A first priority is to find pragmatic and innovative ways to further enhance the effective participation of developing countries and countries with economies in transition in international dialogues and decision-making processes. Within the mandates and means of the respective institutions and forums, we encourage the following actions:

- International Monetary Fund and World Bank: to continue to enhance participation of all developing countries and countries with economies in transition in their decision-making, and thereby to strengthen the international dialogue and the work of those institutions as they address the development needs and concerns of these countries;

- World Trade Organization: to ensure that any consultation is representative of its full membership and that participation is based on clear, simple and objective criteria;

- Bank for International Settlements, Basel Committees and Financial Stability Forum: to continue enhancing their outreach and consultation efforts with developing countries and countries with economies in transition at the regional level, and to review their membership, as appropriate, to allow for adequate participation;

- Ad hoc groupings that make policy recommendations with global implications: to continue to improve their outreach to non-member countries, and to enhance collaboration with the multilateral institutions with clearly defined and broad-based intergovernmental mandates.

64. To strengthen the effectiveness of the global economic system's support for development, we encourage the following actions:

- Improve the relationship between the United Nations and the World Trade Organization for development, and strengthen their capacity to provide technical assistance to all countries in need of such assistance;

- Support the International Labour Organization and encourage its ongoing work on the social dimension of globalization;

- Strengthen the coordination of the United Nations system and all other multilateral financial, trade and development institutions to support eco- 
nomic growth, poverty eradication and sustainable development worldwide;

- Mainstream the gender perspective into development policies at all levels and in all sectors;

- Strengthen international tax cooperation, through enhanced dialogue among national tax authorities and greater coordination of the work of the concerned multilateral bodies and relevant regional organizations, giving special attention to the needs of developing countries and countries with economies in transition;

- Promote the role of the regional commissions and the regional development banks in supporting policy dialogue among countries at the regional level on macroeconomic, financial, trade and development issues.

65. We commit ourselves to negotiating and finalizing as soon as possible a United Nations convention against corruption in all its aspects, including the question of repatriation of funds illicitly acquired to countries of origin, and also to promoting stronger cooperation to eliminate moneylaundering. We encourage States that have not yet done so to consider signature and ratification of the United Nations Convention against Transnational Organized Crime. ${ }^{5}$

66. We urge as a matter of priority all States that have not yet done so to consider becoming parties to the International Convention for the Suppression of the Financing of Terrorism,${ }^{6}$ and call for increased cooperation with the same objective.

67. We attach priority to reinvigorating the United Nations system as fundamental to the promotion of international cooperation for development and to a global economic system that works for all. We reaffirm our commitment to enabling the General Assembly to play effectively its central role as the chief deliberative, policy-making and representative organ of the United Nations, and to further strengthening the Economic and Social Council to enable it to fulfil the role ascribed to it in the Charter of the United Nations.

\section{Staying engaged}

68. To build a global alliance for development will require an unremitting effort. We thus commit ourselves to keeping fully engaged, nationally, regionally and internationally, to ensuring proper follow-up to the implementation of agreements and commitments reached at the present

${ }^{5}$ General Assembly resolution 55/25.

${ }^{6}$ General Assembly resolution 54/109, annex. 
Conference, and to continuing to build bridges between development, finance, and trade organizations and initiatives, within the framework of the holistic agenda of the Conference. Greater cooperation among existing institutions is needed, based on a clear understanding and respect for their respective mandates and governance structures.

69. Building on the successful experience of the Conference and the process leading up to it, we shall strengthen and make fuller use of the General Assembly and the Economic and Social Council, as well as the relevant intergovernmental/governing bodies of other institutional stakeholders, for the purposes of conference follow-up and coordination, by substantively connecting, in ascending series, the following elements:

(a) Interactions between representatives of the Economic and Social Council and the directors of the executive boards of the World Bank and the International Monetary Fund can serve as preliminary exchanges on matters related to follow-up to the Conference and preparations for the annual spring meeting between those institutions. Similar interactions can also be initiated with representatives of the appropriate intergovernmental body of the World Trade Organization;

(b) We encourage the United Nations, the World Bank and the International Monetary Fund, with the World Trade Organization, to address issues of coherence, coordination and cooperation, as a followup to the Conference, at the spring meeting between the Economic and Social Council and the Bretton Woods institutions. The meeting should include an intergovernmental segment to address an agenda agreed to by the participating organizations, as well as a dialogue with civil society and the private sector;

(c) The current high-level dialogue on strengthening international cooperation for development through partnership, held every two years in the General Assembly, would consider the financing for development-related reports coming from the Economic and Social Council and other bodies, as well as other financing for development-related issues. It would be reconstituted to enable it to become the intergovernmental focal point for the general follow-up to the Conference and related issues. The highlevel dialogue would include a policy dialogue, with the participation of the relevant stakeholders, on the implementation of the results of the Conference, including the theme of coherence and consistency of the international monetary, financial and trading systems in support of development;

(d) Appropriate modalities to enable participation in the reconstituted high-level dialogue by all relevant stakeholders, as necessary, will be considered. 
70. To support the above elements at the national, regional and international levels, we resolve:

- To continue to improve our domestic policy coherence through the continued engagement of our ministries of development, finance, trade and foreign affairs, as well as our central banks;

- To harness the active support of the regional commissions and the regional development banks;

- To keep the financing for development process on the agenda of the intergovernmental bodies of all main stakeholders, including all United Nations funds, programmes and agencies, including the United Nations Conference on Trade and Development.

71. We recognize the link between financing of development and attaining internationally agreed development goals and objectives, including those contained in the Millennium Declaration, in measuring development progress and helping to guide development priorities. We welcome in that regard the intention of the United Nations to prepare a report annually. We encourage close cooperation between the United Nations, the World Bank, the International Monetary Fund and the World Trade Organization in the preparation of that report. We shall support the United Nations in the implementation of a global information campaign on the internationally agreed development goals and objectives, including those contained in the Millennium Declaration. In that respect, we would like to encourage the active involvement of all relevant stakeholders, including civil society organizations and the private sector.

72. To underpin those efforts, we request the Secretary-General of the United Nations to provide - with collaboration from the secretariats of the major institutional stakeholders concerned, fully utilizing the United Nations System Chief Executives Board for Coordination mechanism - sustained follow-up within the United Nations system to the agreements and commitments reached at the present Conference and to ensure effective secretariat support. That support will build on the innovative and participatory modalities and related coordination arrangements utilized in the preparations of the Conference. The Secretary-General of the United Nations is further requested to submit an annual report on those followup efforts.

73. We call for a follow-up international conference to review the implementation of the Monterrey Consensus. The modalities of that conference shall be decided upon not later than 2005. 


\section{Finarncing for \\ Development}

Cover design from marble facing at the United Nations

Secretariat Building in New York

Credit: UN Photo 
Plan of Action

\section{A. Introduction}

1. The common vision and guiding principles of the Declaration are translated in this Plan of Action into concrete action lines to advance the achievement of the internationally-agreed development goals, including those in the Millennium Declaration, the Monterrey Consensus and the Johannesburg Declaration and Plan of Implementation, by promoting the use of ICT-based products, networks, services and applications, and to help countries overcome the digital divide. The Information Society envisaged in the Declaration of Principles will be realized in cooperation and solidarity by governments and all other stakeholders.

2. The Information Society is an evolving concept that has reached different levels across the world, reflecting the different stages of development. Technological and other change is rapidly transforming the environment in which the Information Society is developed. The Plan of Action is thus an evolving platform to promote the Information Society at the national, regional and international levels. The unique two-phase structure of the World Summit on the Information Society (WSIS) provides an opportunity to take this evolution into account.

3. All stakeholders have an important role to play in the Information Society, especially through partnerships:

a) Governments have a leading role in developing and implementing comprehensive, forward looking and sustainable national e-strategies. The private sector and civil society, in dialogue with governments, have an important consultative role to play in devising national e-strategies.

b) The commitment of the private sector is important in developing and diffusing information and communication technologies (ICTs), for infrastructure, content and applications. The private sector is not only a market player but also plays a role in a wider sustainable development context.

c) The commitment and involvement of civil society is equally important in creating an equitable Information Society, and in implementing ICT-related initiatives for development.

d) International and regional institutions, including international financial institutions, have a key role in integrating the use of ICTs in the development process and making available necessary resources for building the Information Society and for the evaluation of the progress made. 


\section{B. Objectives, goals and targets}

4. The objectives of the Plan of Action are to build an inclusive Information Society; to put the potential of knowledge and ICTs at the service of development; to promote the use of information and knowledge for the achievement of internationally agreed development goals, including those contained in the Millennium Declaration; and to address new challenges of the Information Society, at the national, regional and international levels. Opportunity shall be taken in phase two of the WSIS to evaluate and assess progress made towards bridging the digital divide.

5. Specific targets for the Information Society will be established as appropriate, at the national level in the framework of national e-strategies and in accordance with national development policies, taking into account the different national circumstances. Such targets can serve as useful benchmarks for actions and for the evaluation of the progress made towards the attainment of the overall objectives of the Information Society.

6. Based on internationally agreed development goals, including those in the Millennium Declaration, which are premised on international cooperation, indicative targets may serve as global references for improving connectivity and access in the use of ICTs in promoting the objectives of the Plan of Action, to be achieved by 2015 . These targets may be taken into account in the establishment of the national targets, considering the different national circumstances:

a) to connect villages with ICTs and establish community access points;

b) to connect universities, colleges, secondary schools and primary schools with ICTs;

c) to connect scientific and research centres with ICTs;

d) to connect public libraries, cultural centres, museums, post offices and archives with ICTs;

e) to connect health centres and hospitals with ICTs;

f) to connect all local and central government departments and establish websites and email addresses;

g) to adapt all primary and secondary school curricula to meet the challenges of the Information Society, taking into account national circumstances;

h) to ensure that all of the world's population have access to television and radio services;

i) to encourage the development of content and to put in place technical conditions in order to facilitate the presence and use of all world languages on the Internet;

j) to ensure that more than half the world's inhabitants have access to ICTs within their reach.

7. In giving effect to these objectives, goals and targets, special attention will be paid to the needs of developing countries, and in particular to countries, peoples and groups cited in paragraphs 11-16 of the Declaration of Principles.

\section{Action Lines}

\section{C1. The role of governments and all stakeholders in the promotion of ICTs for development}

8. The effective participation of governments and all stakeholders is vital in developing the Information Society requiring cooperation and partnerships among all of them.

a) Development of national e-strategies, including the necessary human capacity building, should be encouraged by all countries by 2005 , taking into account different national circumstances.

b) Initiate at the national level a structured dialogue involving all relevant stakeholders, including through public/private partnerships, in devising e-strategies for the Information Society and for the exchange of best practices. 
c) In developing and implementing national e-strategies, stakeholders should take into consideration local, regional and national needs and concerns. To maximize the benefits of initiatives undertaken, these should include the concept of sustainability. The private sector should be engaged in concrete projects to develop the Information Society at local, regional and national levels.

d) Each country is encouraged to establish at least one functioning Public/Private Partnership (PPP) or Multi-Sector Partnership (MSP), by 2005 as a showcase for future action.

e) Identify mechanisms, at the national, regional and international levels, for the initiation and promotion of partnerships among stakeholders of the Information Society.

f) Explore the viability of establishing multi-stakeholder portals for indigenous peoples at the national level.

g) By 2005, relevant international organizations and financial institutions should develop their own strategies for the use of ICTs for sustainable development, including sustainable production and consumption patterns and as an effective instrument to help achieve the goals expressed in the United Nations Millennium Declaration.

h) International organizations should publish, in their areas of competence, including on their website, reliable information submitted by relevant stakeholders on successful experiences of mainstreaming ICTs.

i) Encourage a series of related measures, including, among other things: incubator schemes, venture capital investments (national and international), government investment funds (including micro-finance for Small, Medium-sized and Micro Enterprises (SMMEs), investment promotion strategies, software export support activities (trade counseling), support of research and development networks and software parks.

\section{C2. Information and communication infrastructure: an essential foundation for the Information Society}

9. Infrastructure is central in achieving the goal of digital inclusion, enabling universal, sustainable, ubiquitous and affordable access to ICTs by all, taking into account relevant solutions already in place in developing countries and countries with economies in transition, to provide sustainable connectivity and access to remote and marginalized areas at national and regional levels.

a) Governments should take action, in the framework of national development policies, in order to support an enabling and competitive environment for the necessary investment in ICT infrastructure and for the development of new services.

b) In the context of national e-strategies, devise appropriate universal access policies and strategies, and their means of implementation, in line with the indicative targets, and develop ICT connectivity indicators.

c) In the context of national e-strategies, provide and improve ICT connectivity for all schools, universities, health institutions, libraries, post offices, community centres, museums and other institutions accessible to the public, in line with the indicative targets.

d) Develop and strengthen national, regional and international broadband network infrastructure, including delivery by satellite and other systems, to help in providing the capacity to match the needs of countries and their citizens and for the delivery of new ICT-based services. Support technical, regulatory and operational studies by the International Telecommunication Union (ITU) and, as appropriate, other relevant international organizations in order to:

i) broaden access to orbital resources, global frequency harmonization and global systems standardization;

ii) encourage public/private partnership;

iii) promote the provision of global high-speed satellite services for underserved areas such as remote and sparsely populated areas;

iv) explore other systems that can provide high-speed connectivity.

e) In the context of national e-strategies, address the special requirements of older people, persons with disabilities, children, especially marginalized children and other disadvantaged and vulnerable groups, 
including by appropriate educational administrative and legislative measures to ensure their full inclusion in the Information Society.

f) Encourage the design and production of ICT equipment and services so that everyone, has easy and affordable access to them including older people, persons with disabilities, children, especially marginalized children, and other disadvantaged and vulnerable groups, and promote the development of technologies, applications, and content suited to their needs, guided by the Universal Design Principle and further enhanced by the use of assistive technologies.

g) In order to alleviate the challenges of illiteracy, develop affordable technologies and non-text based computer interfaces to facilitate people's access to ICT,

h) Undertake international research and development efforts aimed at making available adequate and affordable ICT equipment for end users.

i) Encourage the use of unused wireless capacity, including satellite, in developed countries and in particular in developing countries, to provide access in remote areas, especially in developing countries and countries with economies in transition, and to improve low-cost connectivity in developing countries. Special concern should be given to the Least Developed Countries in their efforts in establishing telecommunication infrastructure.

j) Optimize connectivity among major information networks by encouraging the creation and development of regional ICT backbones and Internet exchange points, to reduce interconnection costs and broaden network access.

k) Develop strategies for increasing affordable global connectivity, thereby facilitating improved access. Commercially negotiated Internet transit and interconnection costs should be oriented towards objective, transparent and non-discriminatory parameters, taking into account ongoing work on this subject.

1) Encourage and promote joint use of traditional media and new technologies.

\section{C3. Access to information and knowledge}

10. ICTs allow people, anywhere in the world, to access information and knowledge almost instantaneously. Individuals, organizations and communities should benefit from access to knowledge and information.

a) Develop policy guidelines for the development and promotion of public domain information as an important international instrument promoting public access to information.

b) Governments are encouraged to provide adequate access through various communication resources, notably the Internet, to public official information. Establishing legislation on access to information and the preservation of public data, notably in the area of the new technologies, is encouraged.

c) Promote research and development to facilitate accessibility of ICTs for all, including disadvantaged, marginalized and vulnerable groups.

d) Governments, and other stakeholders, should establish sustainable multi-purpose community public access points, providing affordable or free-of-charge access for their citizens to the various communication resources, notably the Internet. These access points should, to the extent possible, have sufficient capacity to provide assistance to users, in libraries, educational institutions, public administrations, post offices or other public places, with special emphasis on rural and underserved areas, while respecting intellectual property rights (IPRs) and encouraging the use of information and sharing of knowledge.

e) Encourage research and promote awareness among all stakeholders of the possibilities offered by different software models, and the means of their creation, including proprietary, open-source and free software, in order to increase competition, freedom of choice and affordability, and to enable all stakeholders to evaluate which solution best meets their requirements.

f) Governments should actively promote the use of ICTs as a fundamental working tool by their citizens and local authorities. In this respect, the international community and other stakeholders should support capacity building for local authorities in the widespread use of ICTs as a means of improving local governance. 
g) Encourage research on the Information Society, including on innovative forms of networking, adaptation of ICT infrastructure, tools and applications that facilitate accessibility of ICTs for all, and disadvantaged groups in particular.

h) Support the creation and development of a digital public library and archive services, adapted to the Information Society, including reviewing national library strategies and legislation, developing a global understanding of the need for "hybrid libraries", and fostering worldwide cooperation between libraries.

i) Encourage initiatives to facilitate access, including free and affordable access to open access journals and books, and open archives for scientific information.

j) Support research and development of the design of useful instruments for all stakeholders to foster increased awareness, assessment, and evaluation of different software models and licences, so as to ensure an optimal choice of appropriate software that will best contribute to achieving development goals within local conditions.

\section{C4. Capacity building}

11. Everyone should have the necessary skills to benefit fully from the Information Society. Therefore capacity building and ICT literacy are essential. ICTs can contribute to achieving universal education worldwide, through delivery of education and training of teachers, and offering improved conditions for lifelong learning, encompassing people that are outside the formal education process, and improving professional skills.

a) Develop domestic policies to ensure that ICTs are fully integrated in education and training at all levels, including in curriculum development, teacher training, institutional administration and management, and in support of the concept of lifelong learning.

b) Develop and promote programmes to eradicate illiteracy using ICTs at national, regional and international levels.

c) Promote e-literacy skills for all, for example by designing and offering courses for public administration, taking advantage of existing facilities such as libraries, multipurpose community centres, public access points and by establishing local ICT training centres with the cooperation of all stakeholders. Special attention should be paid to disadvantaged and vulnerable groups.

d) In the context of national educational policies, and taking into account the need to eradicate adult illiteracy, ensure that young people are equipped with knowledge and skills to use ICTs, including the capacity to analyse and treat information in creative and innovative ways, share their expertise and participate fully in the Information Society.

e) Governments, in cooperation with other stakeholders, should create programmes for capacity building with an emphasis on creating a critical mass of qualified and skilled ICT professionals and experts.

f) Develop pilot projects to demonstrate the impact of ICT-based alternative educational delivery systems, notably for achieving Education for All targets, including basic literacy targets.

g) Work on removing the gender barriers to ICT education and training and promoting equal training opportunities in ICT-related fields for women and girls. Early intervention programmes in science and technology should target young girls with the aim of increasing the number of women in ICT careers. Promote the exchange of best practices on the integration of gender perspectives in ICT education.

h) Empower local communities, especially those in rural and underserved areas, in ICT use and promote the production of useful and socially meaningful content for the benefit of all.

i) Launch education and training programmes, where possible using information networks of traditional nomadic and indigenous peoples, which provide opportunities to fully participate in the Information Society.

j) Design and implement regional and international cooperation activities to enhance the capacity, notably, of leaders and operational staff in developing countries and LDCs, to apply ICTs effectively in the whole range of educational activities. This should include delivery of education outside the educational structure, such as the workplace and at home. 
k) Design specific training programmes in the use of ICTs in order to meet the educational needs of information professionals, such as archivists, librarians, museum professionals, scientists, teachers, journalists, postal workers and other relevant professional groups. Training of information professionals should focus not only on new methods and techniques for the development and provision of information and communication services, but also on relevant management skills to ensure the best use of technologies. Training of teachers should focus on the technical aspects of ICTs, on development of content, and on the potential possibilities and challenges of ICTs.

1) Develop distance learning, training and other forms of education and training as part of capacity building programmes. Give special attention to developing countries and especially LDCs in different levels of human resources development.

m) Promote international and regional cooperation in the field of capacity building, including country programmes developed by the United Nations and its Specialized Agencies

n) Launch pilot projects to design new forms of ICT-based networking, linking education, training and research institutions between and among developed and developing countries and countries with economies in transition.

o) Volunteering, if conducted in harmony with national policies and local cultures, can be a valuable asset for raising human capacity to make productive use of ICT tools and build a more inclusive Information Society. Activate volunteer programmes to provide capacity building on ICT for development, particularly in developing countries.

p) Design programmes to train users to develop self-learning and self-development capacities.

\section{C5. Building confidence and security in the use of ICTs}

12. Confidence and security are among the main pillars of the Information Society.

a) Promote cooperation among the governments at the United Nations and with all stakeholders at other appropriate fora to enhance user confidence, build trust, and protect both data and network integrity; consider existing and potential threats to ICTs; and address other information security and network security issues.

b) Governments, in cooperation with the private sector, should prevent, detect and respond to cyber-crime and misuse of ICTs by: developing guidelines that take into account ongoing efforts in these areas; considering legislation that allows for effective investigation and prosecution of misuse; promoting effective mutual assistance efforts; strengthening institutional support at the international level for preventing, detecting and recovering from such incidents; and encouraging education and raising awareness.

c) Governments, and other stakeholders, should actively promote user education and awareness about online privacy and the means of protecting privacy.

d) Take appropriate action on spam at national and international levels.

e) Encourage the domestic assessment of national law with a view to overcoming any obstacles to the effective use of electronic documents and transactions including electronic means of authentication.

f) Further strengthen the trust and security framework with complementary and mutually reinforcing initiatives in the fields of security in the use of ICTs, with initiatives or guidelines with respect to rights to privacy, data and consumer protection.

g) Share good practices in the field of information security and network security and encourage their use by all parties concerned.

h) Invite interested countries to set up focal points for real-time incident handling and response, and develop a cooperative network between these focal points for sharing information and technologies on incident response.

i) Encourage further development of secure and reliable applications to facilitate online transactions. 
j) Encourage interested countries to contribute actively to the ongoing United Nations activities to build confidence and security in the use of ICTs.

\section{C6. Enabling environment}

13. To maximize the social, economic and environmental benefits of the Information Society, governments need to create a trustworthy, transparent and non-discriminatory legal, regulatory and policy environment. Actions include:

a) Governments should foster a supportive, transparent, pro-competitive and predictable policy, legal and regulatory framework, which provides the appropriate incentives to investment and community development in the Information Society.

b) We ask the Secretary General of the United Nations to set up a working group on Internet governance, in an open and inclusive process that ensures a mechanism for the full and active participation of governments, the private sector and civil society from both developing and developed countries, involving relevant intergovernmental and international organizations and forums, to investigate and make proposals for action, as appropriate, on the governance of Internet by 2005 . The group should, inter alia:

i) develop a working definition of Internet governance;

ii) identify the public policy issues that are relevant to Internet governance;

iii) develop a common understanding of the respective roles and responsibilities of governments, existing intergovernmental and international organisations and other forums as well as the private sector and civil society from both developing and developed countries;

iv) prepare a report on the results of this activity to be presented for consideration and appropriate action for the second phase of WSIS in Tunis in 2005.

c) Governments are invited to:

i) facilitate the establishment of national and regional Internet Exchange Centres;

ii) manage or supervise, as appropriate, their respective country code top-level domain name (ccTLD);

iii) promote awareness of the Internet.

d) In cooperation with the relevant stakeholders, promote regional root servers and the use of internationalized domain names in order to overcome barriers to access.

e) Governments should continue to update their domestic consumer protection laws to respond to the new requirements of the Information Society.

f) Promote effective participation by developing countries and countries with economies in transition in international ICT forums and create opportunities for exchange of experience.

g) Governments need to formulate national strategies, which include e-government strategies, to make public administration more transparent, efficient and democratic.

h) Develop a framework for the secure storage and archival of documents and other electronic records of information.

i) Governments and stakeholders should actively promote user education and awareness about online privacy and the means of protecting privacy.

j) Invite stakeholders to ensure that practices designed to facilitate electronic commerce also permit consumers to have a choice as to whether or not to use electronic communication.

k) Encourage the ongoing work in the area of effective dispute settlement systems, notably alternative dispute resolution (ADR), which can promote settlement of disputes.

1) Governments, in collaboration with stakeholders, are encouraged to formulate conducive ICT policies that foster entrepreneurship, innovation and investment, and with particular reference to the promotion of participation by women. 
m) Recognising the economic potential of ICTs for Small and Medium-Sized Enterprises (SMEs), they should be assisted in increasing their competitiveness by streamlining administrative procedures, facilitating their access to capital and enhancing their capacity to participate in ICT-related projects.

n) Governments should act as model users and early adopters of e-commerce in accordance with their level of socio-economic development.

o) Governments, in cooperation with other stakeholders, should raise awareness of the importance of international interoperability standards for global e-commerce.

p) Governments, in cooperation with other stakeholders, should promote the development and use of open, interoperable, non-discriminatory and demand-driven standards.

q) ITU, pursuant to its treaty capacity, coordinates and allocates frequencies with the goal of facilitating ubiquitous and affordable access.

r) Additional steps should be taken in ITU and other regional organisations to ensure rational, efficient and economical use of, and equitable access to, the radio-frequency spectrum by all countries, based on relevant international agreements.

\section{C7. ICT applications: benefits in all aspects of life}

14. ICT applications can support sustainable development, in the fields of public administration, business, education and training, health, employment, environment, agriculture and science within the framework of national e-strategies. This would include actions within the following sectors:

\section{E-government}

a) Implement e-government strategies focusing on applications aimed at innovating and promoting transparency in public administrations and democratic processes, improving efficiency and strengthening relations with citizens.

b) Develop national e-government initiatives and services, at all levels, adapted to the needs of citizens and business, to achieve a more efficient allocation of resources and public goods.

c) Support international cooperation initiatives in the field of e-government, in order to enhance transparency, accountability and efficiency at all levels of government.

\section{E-business}

a) Governments, international organizations and the private sector, are encouraged to promote the benefits of international trade and the use of e-business, and promote the use of e-business models in developing countries and countries with economies in transition.

b) Through the adoption of an enabling environment, and based on widely available Internet access, governments should seek to stimulate private sector investment, foster new applications, content development and public/private partnerships.

c) Government policies should favour assistance to, and growth of SMMEs, in the ICT industry, as well as their entry into e-business, to stimulate economic growth and job creation as an element of a strategy for poverty reduction through wealth creation.

\section{E-learning (see section $\mathrm{C} 4$ )}

\section{E-health}

a) Promote collaborative efforts of governments, planners, health professionals, and other agencies along with the participation of international organizations for creating a reliable, timely, high quality and affordable health care and health information systems and for promoting continuous medical training, education, and research through the use of ICTs, while respecting and protecting citizens' right to privacy.

b) Facilitate access to the world's medical knowledge and locally-relevant content resources for strengthening public health research and prevention programmes and promoting women's and men's health, 
such as content on sexual and reproductive health and sexually transmitted infections, and for diseases that attract full attention of the world including HIV/AIDS, malaria and tuberculosis.

c) Alert, monitor and control the spread of communicable diseases, through the improvement of common information systems.

d) Promote the development of international standards for the exchange of health data, taking due account of privacy concerns.

e) Encourage the adoption of ICTs to improve and extend health care and health information systems to remote and underserved areas and vulnerable populations, recognising women's roles as health providers in their families and communities.

f) Strengthen and expand ICT-based initiatives for providing medical and humanitarian assistance in disasters and emergencies.

\section{E-employment}

a) Encourage the development of best practices for e-workers and e-employers built, at the national level, on principles of fairness and gender equality, respecting all relevant international norms.

b) Promote new ways of organizing work and business with the aim of raising productivity, growth and well-being through investment in ICTs and human resources.

c) Promote teleworking to allow citizens, particularly in the developing countries, LDCs, and small economies, to live in their societies and work anywhere, and to increase employment opportunities for women, and for those with disabilities. In promoting teleworking, special attention should be given to strategies promoting job creation and the retention of the skilled working force.

d) Promote early intervention programmes in science and technology that should target young girls to increase the number of women in ICT carriers.

\section{E-environment}

a) Governments, in cooperation with other stakeholders are encouraged to use and promote ICTs as an instrument for environmental protection and the sustainable use of natural resources.

b) Government, civil society and the private sector are encouraged to initiate actions and implement projects and programmes for sustainable production and consumption and the environmentally safe disposal and recycling of discarded hardware and components used in ICTs.

c) Establish monitoring systems, using ICTs, to forecast and monitor the impact of natural and man-made disasters, particularly in developing countries, LDCs and small economies.

\section{E-agriculture}

a) Ensure the systematic dissemination of information using ICTs on agriculture, animal husbandry, fisheries, forestry and food, in order to provide ready access to comprehensive, up-to-date and detailed knowledge and information, particularly in rural areas.

b) Public-private partnerships should seek to maximize the use of ICTs as an instrument to improve production (quantity and quality).

\section{E-science}

a) Promote affordable and reliable high-speed Internet connection for all universities and research institutions to support their critical role in information and knowledge production, education and training, and to support the establishment of partnerships, cooperation and networking between these institutions.

b) Promote electronic publishing, differential pricing and open access initiatives to make scientific information affordable and accessible in all countries on an equitable basis.

c) Promote the use of peer-to-peer technology to share scientific knowledge and pre-prints and reprints written by scientific authors who have waived their right to payment. 
d) Promote the long-term systematic and efficient collection, dissemination and preservation of essential scientific digital data, for example, population and meteorological data in all countries.

e) Promote principles and metadata standards to facilitate cooperation and effective use of collected scientific information and data as appropriate to conduct scientific research.

\section{C8. Cultural diversity and identity, linguistic diversity and local content}

23. Cultural and linguistic diversity, while stimulating respect for cultural identity, traditions and religions, is essential to the development of an Information Society based on the dialogue among cultures and regional and international cooperation. It is an important factor for sustainable development.

a) Create policies that support the respect, preservation, promotion and enhancement of cultural and linguistic diversity and cultural heritage within the Information Society, as reflected in relevant agreed United Nations documents, including UNESCO's Universal Declaration on Cultural Diversity. This includes encouraging governments to design cultural policies to promote the production of cultural, educational and scientific content and the development of local cultural industries suited to the linguistic and cultural context of the users.

b) Develop national policies and laws to ensure that libraries, archives, museums and other cultural institutions can play their full role of content-including traditional knowledge-providers in the Information Society, more particularly by providing continued access to recorded information.

c) Support efforts to develop and use ICTs for the preservation of natural and, cultural heritage, keeping it accessible as a living part of today's culture. This includes developing systems for ensuring continued access to archived digital information and multimedia content in digital repositories, and support archives, cultural collections and libraries as the memory of humankind.

d) Develop and implement policies that preserve, affirm, respect and promote diversity of cultural expression and indigenous knowledge and traditions through the creation of varied information content and the use of different methods, including the digitization of the educational, scientific and cultural heritage.

e) Support local content development, translation and adaptation, digital archives, and diverse forms of digital and traditional media by local authorities. These activities can also strengthen local and indigenous communities.

f) Provide content that is relevant to the cultures and languages of individuals in the Information Society, through access to traditional and digital media services.

g) Through public/private partnerships, foster the creation of varied local and national content, including that available in the language of users, and give recognition and support to ICT-based work in all artistic fields.

h) Strengthen programmes focused on gender-sensitive curricula in formal and non-formal education for all and enhancing communication and media literacy for women with a view to building the capacity of girls and women to understand and to develop ICT content.

i) Nurture the local capacity for the creation and distribution of software in local languages, as well as content that is relevant to different segments of population, including non-literate, persons with disabilities, disadvantaged and vulnerable groups especially in developing countries and countries with economies in transition.

j) Give support to media based in local communities and support projects combining the use of traditional media and new technologies for their role in facilitating the use of local languages, for documenting and preserving local heritage, including landscape and biological diversity, and as a means to reach rural and isolated and nomadic communities.

k) Enhance the capacity of indigenous peoples to develop content in their own languages.

1) Cooperate with indigenous peoples and traditional communities to enable them to more effectively use and benefit from the use of their traditional knowledge in the Information Society. 
m) Exchange knowledge, experiences and best practices on policies and tools designed to promote cultural and linguistic diversity at regional and sub-regional levels. This can be achieved by establishing regional, and sub-regional working groups on specific issues of this Plan of Action to foster integration efforts.

n) Assess at the regional level the contribution of ICT to cultural exchange and interaction, and based on the outcome of this assessment, design relevant programmes.

o) Governments, through public/private partnerships, should promote technologies and R\&D programmes in such areas as translation, iconographies, voice-assisted services and the development of necessary hardware and a variety of software models, including proprietary, open source software and free software, such as standard character sets, language codes, electronic dictionaries, terminology and thesauri, multilingual search engines, machine translation tools, internationalized domain names, content referencing as well as general and application software.

\section{C9. Media}

24. The media - in their various forms and with a diversity of ownership — as an actor, have an essential role in the development of the Information Society and are recognized as an important contributor to freedom of expression and plurality of information.

a) Encourage the media — print and broadcast as well as new media — to continue to play an important role in the Information Society.

b) Encourage the development of domestic legislation that guarantees the independence and plurality of the media.

c) Take appropriate measures - consistent with freedom of expression - to combat illegal and harmful content in media content.

d) Encourage media professionals in developed countries to establish partnerships and networks with the media in developing ones, especially in the field of training.

e) Promote balanced and diverse portrayals of women and men by the media.

f) Reduce international imbalances affecting the media, particularly as regards infrastructure, technical resources and the development of human skills, taking full advantage of ICT tools in this regard.

g) Encourage traditional media to bridge the knowledge divide and to facilitate the flow of cultural content, particularly in rural areas.

\section{C10. Ethical dimensions of the Information Society}

25. The Information Society should be subject to universally held values and promote the common good and to prevent abusive uses of ICTs.

a) Take steps to promote respect for peace and to uphold the fundamental values of freedom, equality, solidarity, tolerance, shared responsibility, and respect for nature.

b) All stakeholders should increase their awareness of the ethical dimension of their use of ICTs.

c) All actors in the Information Society should promote the common good, protect privacy and personal data and take appropriate actions and preventive measures, as determined by law, against abusive uses of ICTs such as illegal and other acts motivated by racism, racial discrimination, xenophobia, and related intolerance, hatred, violence, all forms of child abuse, including paedophilia and child pornography, and trafficking in, and exploitation of, human beings.

d) Invite relevant stakeholders, especially the academia, to continue research on ethical dimensions of ICTs. 


\section{C11. International and regional cooperation}

26. International cooperation among all stakeholders is vital in implementation of this plan of action and needs to be strengthened with a view to promoting universal access and bridging the digital divide, inter alia, by provision of means of implementation.

a) Governments of developing countries should raise the relative priority of ICT projects in requests for international cooperation and assistance on infrastructure development projects from developed countries and international financial organizations.

b) Within the context of the UN's Global Compact and building upon the United Nations Millennium Declaration, build on and accelerate public-private partnerships, focusing on the use of ICT in development.

c) Invite international and regional organizations to mainstream ICTs in their work programmes and to assist all levels of developing countries, to be involved in the preparation and implementation of national action plans to support the fulfilment of the goals indicated in the declaration of principles and in this Plan of Action, taking into account the importance of regional initiatives.

\section{Digital Solidarity Agenda}

27. The Digital Solidarity Agenda aims at putting in place the conditions for mobilizing human, financial and technological resources for inclusion of all men and women in the emerging Information Society. Close national, regional and international cooperation among all stakeholders in the implementation of this Agenda is vital. To overcome the digital divide, we need to use more efficiently existing approaches and mechanisms and fully explore new ones, in order to provide financing for the development of infrastructure, equipment, capacity building and content, which are essential for participation in the Information Society.

\section{D1. Priorities and strategies}

a) National e-strategies should be made an integral part of national development plans, including Poverty Reduction Strategies.

b) ICTs should be fully mainstreamed into strategies for Official Development Assistance (ODA) through more effective donor information-sharing and co-ordination, and through analysis and sharing of best practices and lessons learned from experience with ICT-for-development programmes.

\section{D2. Mobilizing resources}

a) All countries and international organizations should act to create conditions conducive to increasing the availability and effective mobilization of resources for financing development as elaborated in the Monterrey Consensus.

b) Developed countries should make concrete efforts to fulfil their international commitments to financing development including the Monterrey Consensus, in which developed countries that have not done so are urged to make concrete efforts towards the target of 0.7 per cent of gross national product (GNP) as ODA to developing countries and 0.15 to 0.20 per cent of GNP of developed countries to least developed countries.

c) For those developing countries facing unsustainable debt burdens, we welcome initiatives that have been undertaken to reduce outstanding indebtedness and invite further national and international measures in that regard, including, as appropriate, debt cancellation and other arrangements. Particular attention should be given to enhancing the Heavily Indebted Poor Countries initiative. These initiatives would release more resources that may be used for financing ICT for development projects.

d) Recognizing the potential of ICT for development we furthermore advocate:

i) developing countries to increase their efforts to attract major private national and foreign investments for ICTs through the creation of a transparent, stable and predictable enabling investment environment;

ii) developed countries and international financial organisations to be responsive to the strategies and 
priorities of ICTs for development, mainstream ICTs in their work programmes, and assist developing countries and countries with economies in transition to prepare and implement their national e-strategies. Based on the priorities of national development plans and implementation of the above commitments, developed countries should increase their efforts to provide more financial resources to developing countries in harnessing ICTs for development;

iii) the private sector to contribute to the implementation of this Digital Solidarity Agenda.

e) In our efforts to bridge the digital divide, we should promote, within our development cooperation, technical and financial assistance directed towards national and regional capacity building, technology transfer on mutually agreed terms, cooperation in R\&D programmes and exchange of know-how.

f) While all existing financial mechanisms should be fully exploited, a thorough review of their adequacy in meeting the challenges of ICT for development should be completed by the end of December 2004. This review shall be conducted by a Task Force under the auspices of the Secretary-General of the United Nations and submitted for consideration to the second phase of this summit. Based on the conclusion of the review, improvements and innovations of financing mechanisms will be considered including the effectiveness, the feasibility and the creation of a voluntary Digital Solidarity Fund, as mentioned in the Declaration of Principles.

g) Countries should consider establishing national mechanisms to achieve universal access in both underserved rural and urban areas, in order to bridge the digital divide.

\section{E) Follow-up and evaluation}

28. A realistic international performance evaluation and benchmarking (both qualitative and quantitative), through comparable statistical indicators and research results, should be developed to follow up the implementation of the objectives, goals and targets in the Plan of Action, taking into account different national circumstances.

a) In cooperation with each country concerned, develop and launch a composite ICT Development (Digital Opportunity) Index. It could be published annually, or every two years, in an ICT Development Report. The index could show the statistics while the report would present analytical work on policies and their implementation, depending on national circumstances, including gender analysis.

b) Appropriate indicators and benchmarking, including community connectivity indicators, should clarify the magnitude of the digital divide, in both its domestic and international dimensions, and keep it under regular assessment, and tracking global progress in the use of ICTs to achieve internationally agreed development goals, including those of the Millennium Declaration.

c) International and regional organizations should assess and report regularly on universal accessibility of nations to ICTs, with the aim of creating equitable opportunities for the growth of ICT sectors of developing countries.

d) Gender-specific indicators on ICT use and needs should be developed, and measurable performance indicators should be identified to assess the impact of funded ICT projects on the lives of women and girls.

e) Develop and launch a website on best practices and success stories, based on a compilation of contributions from all stakeholders, in a concise, accessible and compelling format, following the internationally-recognized web accessibility standards. The website could be periodically updated and turned into a permanent experience-sharing exercise.

f) All countries and regions should develop tools so as to provide statistical information on the Information Society, with basic indicators and analysis of its key dimensions. Priority should be given to setting up coherent and internationally comparable indicator systems, taking into account different levels of development. 


\section{F) Towards WSIS phase 2 (Tunis)}

29. Recalling General Assembly Resolution 56/183 and taking into account the outcome of the Geneva phase of the WSIS, a preparatory meeting will be held in the first half of 2004 to review those issues of the Information Society which should form the focus of the Tunis phase of the WSIS and to agree on the structure of the preparatory process for the second phase. In line with the decision of this Summit concerning its Tunis phase, the second phase of the WSIS should consider, inter alia:

a) Elaboration of final appropriate documents based on the outcome of the Geneva phase of the WSIS with a view to consolidating the process of building a global Information Society, and reducing the Digital Divide and transforming it into digital opportunities.

b) Follow-up and implementation of the Geneva Plan of Action at national, regional and international levels, including the United Nations system, as part of an integrated and coordinated approach, calling upon the participation of all relevant stakeholders. This should take place, inter alia, through partnerships among stakeholders. 


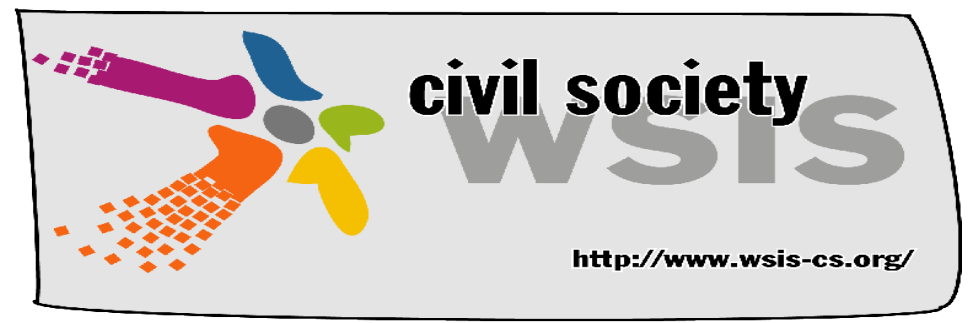

\title{
"Shaping Information Societies for Human Needs"
}

\author{
Civil Society Declaration \\ to the World Summit on the Information Society
}

WSIS Civil Society Plenary

Geneva, 8 December 2003 $^{1}$

${ }^{1}$ Version with corrections: $12-12-2003$ 


\title{
"Shaping Information Societies for Human Needs"
}

\author{
Civil Society Declaration to the World Summit on the Information Society
}

Unanimously Adopted by the WSIS Civil Society Plenary on 8 December 2003

We, women and men from different continents, cultural backgrounds, perspectives, experience and expertise, acting as members of different constituencies of an emerging global civil society, considering civil society participation as fundamental to the first ever held UN Summit on Information and Communication issues, the World Summit on the Information Society, have been working for two years inside the process, devoting our efforts to shaping people-centred, inclusive and equitable concept of information and communication societies. ${ }^{2}$

Working together both on-line and off-line as civil society entities, practising an inclusive and participatory use of information and communication technologies, has allowed us to share views and shape common positions, and to collectively develop a vision of information and communication societies.

At this step of the process, the first phase of the Summit, Geneva, December 2003, our voices and the general interest we collectively expressed are not adequately reflected in the Summit documents. We propose this document as part of the official outcomes of the Summit. Convinced that this vision can become reality through the actions and lives of women and men, communities and people, we hereby present our own vision to all, as an invitation to participate in this ongoing dialogue and to join forces in shaping our common future.

\footnotetext{
2 There is no single information, communication or knowledge society: there are, at the local, national and global levels, possible future societies; moreover, considering communication is a critical aspect of any information society, we use in this document the phrase "information and communication societies." For consistency with previous WSIS language, we retain the use of the phrase "Information Society" when directly referencing WSIS.
} 


\section{A VISIONARY SOCIETY}

At the heart of our vision of information and communications societies is the human being. The dignity and rights of all peoples and each person must be promoted, respected, protected and affirmed. Redressing the inexcusable gulf between levels of development and between opulence and extreme poverty must therefore be our prime concern.

We are committed to building information and communication societies that are people-centred, inclusive and equitable. Societies in which everyone can freely create, access, utilise, share and disseminate information and knowledge, so that individuals, communities and peoples are empowered to improve their quality of life and to achieve their full potential. Societies founded on the principles of social, political, and economic justice, and peoples' full participation and empowerment, and thus societies that truly address the key development challenges facing the world today. Societies that pursue the objectives of sustainable development, democracy, and gender equality, for the attainment of a more peaceful, just, egalitarian and thus sustainable world, premised on the principles enshrined in the Charter of the United Nations and in the Universal Declaration of Human Rights.

We aspire to build information and communication societies where development is framed by fundamental human rights and oriented to achieving a more equitable distribution of resources, leading to the elimination of poverty in a way that is non-exploitative and environmentally sustainable. To this end we believe technologies can be engaged as fundamental means, rather than becoming ends in themselves, thus recognising that bridging the Digital Divide is only one step on the road to achieving development for all. We recognise the tremendous potential of information and communications technologies (ICTs) in overcoming the devastation of famine, natural catastrophes, new pandemics such as HIV/AIDS, as well as the proliferation of arms.

We reaffirm that communication is a fundamental social process, a basic human need and a foundation of all social organisation. Everyone, everywhere, at any time should have the opportunity to participate in communication processes and no one should be excluded from their benefits. This implies that every person must have access to the means of communication and must be able to exercise their right to freedom of opinion and expression, which includes the right to hold opinions and to seek, receive and impart information and ideas through any media and regardless of frontiers. Similarly, the right to privacy, the right to access public information and the public domain of knowledge, and many other universal human rights of specific relevance to information and communication processes, must also be upheld. Together with access, all these communication rights and freedoms must be actively guaranteed for all in clearly written national laws and enforced with adequate technical requirements.

Building such societies implies involving individuals in their capacity as citizens, as well as their organisations and communities, as participants and decision-makers in shaping frameworks, policies and governing mechanisms. This means creating an enabling environment for the engagement and commitment of all generations, both women and men, and ensuring the involvement of diverse social and linguistic groups, cultures and peoples, rural and urban populations without exclusion. In addition, governments should maintain and promote public services where required by citizens and establish accountability to citizens as a pillar of public policy, in order to ensure that models of information and communication societies are open to continuing correction and improvement.

We recognise that no technology is neutral with respect to its social impacts and, therefore, the possibility of having so-called "technology-neutral" decision-making processes is a fallacy. It is critical to make careful social and technical choices concerning the introduction of new technologies from the inception of their design through to their deployment and operational phases. Negative 
social and technical impacts of information and communications systems that are discovered late in the design process are usually extremely difficult to correct and, therefore, can cause lasting harm. We envision an information and communication society in which technologies are designed in a participatory manner with and by their end-users so as to prevent or minimise their negative impacts.

We envision societies where human knowledge, creativity, cooperation and solidarity are considered core elements; where not only individual creativity, but also collective innovation, based on cooperative work are promoted. Societies where knowledge, information and communication resources are recognised and protected as the common heritage of humankind; societies that guarantee and foster cultural and linguistic diversity and intercultural dialogue, in environments that are free from discrimination, violence and hatred.

We are conscious that information, knowledge and the means of communication are available on a magnitude that humankind has never dreamt of in the past; but we are also aware that exclusion from access to the means of communication, from information and from the skills that are needed to participate in the public sphere, is still a major constraint, especially in developing countries. At the same time information and knowledge are increasingly being transformed into private resources which can be controlled, sold and bought, as if they were simple commodities and not the founding elements of social organisation and development. Thus, as one of the main challenges of information and communication societies, we recognise the urgency of seeking solutions to these contradictions.

We are convinced that with the sufficient political will to mobilise this wealth of human knowledge and the appropriate resources, humanity could certainly achieve the goals of the Millennium Declaration, and even surpass them. As civil society organisations, we accept our part of responsibility in making this goal and our vision a reality. 
"Shaping Information Societies for Human Needs"

Civil Society Declaration to the World Summit on the Information Society

TABle of Contents

1. A VISIONARY SOCIETY-

2. CORE PRINCIPLES AND CHALLENGES

2.1 Social Justice and People-Centred Sustainable Development

2.1.1 Poverty Eradication

2.1.2 Global Citizenship

2.1.3 Gender Justice

2.1.4 Importance of Youth

2.1.5 Access to Information and the Means of Communication

2.1.6 Access to Health Information

2.1.7 Basic Literacy

2.1.8 Development of Sustainable and Community-based ICT Solutions

2.1.9 Conflict Situations

2.2 Centrality of Human Rights

2.2.1 Freedom of Expression

2.2.2 Right to Privacy

2.2.3 Right to Participate in Public Affairs

2.2.4 Workers' Rights

2.2.5 Rights of Indigenous Peoples

2.2.6 Women's Rights

2.2.7 Rights of the Child

2.2.8 Rights of Persons with Disabilities

2.2.9 Regulation and the Rule of Law

2.3 Culture, Knowledge and Public Domain

2.3.1 Cultural and Linguistic Diversity

2.3.1.1 Capacity Building and Education

2.3.1.2 Language

2.3.1.3 International Law and Regulation

2.3.2 Media

2.3.2.1 The Role of the Media

2.3.2.2 Community Media

2.3.3 Public Domain of Global Knowledge

2.3.3.1 Indigenous Peoples' Knowledge

2.3.3.2 Copyright, Patents and Trademarks

2.3.3.3 Software

2.3.3.4 Research

2.4 Enabling Environment

2.4.1 Ethical Dimensions

2.4.2 Democratic and Accountable Governance

2.4.3 Infrastructure and Access

2.4.4 Financing and Infrastructure 
2.4.5 Human Development - Education and Training

2.4.6 Information Generation and Knowledge Development

2.4.7 Global Governance of ICT and Communications

\section{CONCLUSION}




\section{"Shaping Information Societies for Human Needs" Civil Society Declaration to the World Summit on the Information Society}

\section{CORE PRINCIPLES AND CHALLENGES}

In accordance with this vision, it is essential that the development of information and communication societies be grounded in core principles that reflect a full awareness of the challenges to be met and the responsibility of different stakeholders. This includes the full recognition of the need to address gender concerns and to make a fundamental commitment to gender equality, non-discrimination and women's empowerment, and recognise these as non-negotiable and essential prerequisites to an equitable and people-centred development within information and communication societies. Such a commitment means consciously redressing the effects of the intersection of unequal power relations in the social, economic and political spheres, which manifests in differential access, choice, opportunity, participation, status and control over resources between women and men as well as communities in terms of class, ethnicity, age, religion, race, geographical location and development status.

We have identified the following as key areas of concern. We recognise and uphold the following principles; and we have identified certain priority areas for action by the international community.

\subsection{Social Justice and People-Centred Sustainable Development}

Within a social justice framework, human development implies cultural, social, economic, political and environmental living conditions that fulfill and empower individuals and communities. Despite the enormous advancements in knowledge and technology achieved by humanity, a majority of people continue to live in appalling conditions.

Social justice in the information and communication societies can only be pursued by taking into account geo-political and historical injustices along economic, social, political and cultural lines. Current global dynamics are characterised by tensions resulting from the inter-linkages of global economic liberalisation, cultural globalisation, increased militarism, rising fundamentalisms, racism and the suspension and violation of basic human rights.

The unequal distribution of ICTs and the lack of information access for a large majority of the world's population, often referred to as the digital divide, is in fact a mapping of new asymmetries onto the existing grid of social divides. These include the divide between the North and South, rich and poor, men and women, urban and rural populations, those with access to information and those without. Such disparities are found not only between different cultures, but also within national borders. The international community must exercise its collective power to ensure action on the part of individual states in order to bridge domestic digital divides.

Redressing all forms of discrimination, exclusion and isolation that different marginalised and vulnerable groups and communities experience will require more than the deployment of technology alone. Their full participation in information and communication societies requires us to reject at a fundamental level, the solely profit-motivated and market-propelled promotion of ICTs for development. Conscious and purposeful actions need to be taken in order to ensure that new ICTs are not deployed to further perpetuate existing negative trends of economic globalisation and market monopolisation. Instead, ICT development and applications should be oriented to advance the social, 
economic and cultural progress of the world's peoples and contribute to transforming the development paradigm.

Technological decisions should be taken with the goal of meeting the life-critical needs of people, not with goal of enriching companies or enabling undemocratic control by governments. Therefore, fundamental decisions concerning the design and use of technologies must be made in cooperation with Civil Society, including individual end-users, engineers, and scientists. In particular, where community-based technologies are concerned the study and practice of community informatics must be applied in order to respond adequately to the particular characteristics and needs of communities in design processes.

\subsubsection{Poverty Eradication}

Poverty Eradication must be a key priority on the WSIS agenda. Without challenging existing inequalities, no sustainable development embracing the new ICTs can be achieved. People living in extreme poverty must be enabled to contribute their experiences and knowledge in a dialogue involving all parties. Challenging poverty requires more than setting 'development agendas'. It requires a fundamental commitment to examine the current frameworks, to improve local access to information that is of relevance for the specific context, to improve training in ICT-related skills, and to allocate significant financial and other resources. Also, because volunteers are working at the grassroots level, they play an important role in social inclusion.

Financial resources, linked with social and digital solidarity, need to be channelled through existing and new financial mechanisms that are managed transparently and inclusively by all sectors of society. Among the frameworks that need to be examined in terms of their potentially adverse effects on equitable development are the current arrangements for recognition and governance of monopolised knowledge and information, including the work of WIPO and the functioning of the TRIPS agreement.

\subsubsection{Global Citizenship}

Information and communication societies have the potential to catalyse and help release the enormous financial, technical, human and moral resources required for sustainable development. These resources will only be freed up as the peoples of the world develop a profound sense of responsibility for the fate of the planet and the well-being of the entire human family. In this regard, there is a need for the development in the individual and in communities, as well as governments, of a global consciousness, and a sense of world citizenship. Since the body of humankind is one and indivisible, each member of the human race is born into the world as a trust of the whole and is best served by ensuring the equal importance of each member through the proactive exercise and application of international human rights standards.

\subsubsection{Gender Justice}

Equitable, open and inclusive information and communication societies must be based on gender justice and be particularly guided by the interpretation of principles of gender equality, nondiscrimination and women's empowerment as contained in the Beijing Declaration and Platform for Action (Fourth World Conference on Women) and the Convention on the Elimination of All Forms of Discrimination Against Women (CEDAW). Actions must demonstrate not only a strong commitment but also a high level of consciousness to an intersectional approach to redressing discrimination resulting from unequal power relations at all levels of society. Proactive policies and programmes across all sectors must be developed for women as active and primary agents of change in owning, designing, using and adapting ICT. To empower girls and women throughout their life cycle, as shapers and leaders of society, gender responsive educational programs and appropriate learning environments need to be promoted. Gender analysis and the development of both 
quantitative and qualitative indicators in measuring gender equality through an extensive and integrated national system of monitoring and evaluation are "musts."

\subsubsection{Importance of Youth}

We recognise also that young people are the future workforce and leading creators and earliest adopters of ICTs. They must therefore be empowered as learners, developers, contributors, entrepreneurs and decision-makers. We must focus especially on young people who have not yet been able to benefit fully from the opportunities provided by information and communication societies. In particular, we must seek to assist and empower youth from disadvantaged backgrounds, especially young people in developing countries. Equality of opportunity for girls and young women must be integral to our efforts, and we must create a greater awareness of their specific needs and potential in the field of ICT. Issues facing young workers in ICT industries, such as low pay, poor working conditions, and a lack of job stability and collective representation, must also be addressed. As main users of ICTs, young people are most affected and vulnerable to the health risks exposed by their use. Therefore we commit to develop and use only those ICTs that ensure the well-being, protection, and harmonious development of all children.

\subsubsection{Access to Information and the Means of Communication}

Access to information and the means of communication as a public and global commons should be participatory, universal, inclusive and democratic. Inequalities in access must be addressed in terms of the North/South divide as well as in terms of enduring inequalities within developed and less developed nations. Barriers that need to be overcome are of an economic, educational, technical, political, social, ethnic, and age nature, and inequitable gender relations are embedded into all of these and need to be specifically addressed.

Universal access to information that is essential for human development must be ensured.

Infrastructure and the most appropriate forms of information and communication technologies must be accessible for all in their different social context, and the social appropriation of these technologies must be encouraged. This implies addressing diverse realities experienced by distinct social groups such as indigenous peoples, diasporas and migrants, and privileging local or targeted solutions. Traditional media and community-based information and communication initiatives have a vital role to play in these respects, and so does the effective use of the new ICTs. The regulatory and legal framework in all information and communication societies must be strengthened to support broad-based sharing of technologies, information, and knowledge, and to foster community control, respectful of human rights and freedoms.

Specific needs and requirements of all stakeholders, including those with disabilities, must be considered in ICT development. Accessibility and inclusiveness of ICTs is best done at an early stage of design, development and production, so that the information and communication society becomes the society for all, at minimum cost.

The need to access, send and receive information represents a particularly vital challenge to vulnerable people such as refugees, those displaced by war, and asylum seekers who often do not know their rights, which are frequently violated. Access to means of communication for these groups is necessary for the defence and promotion of their rights, in order to make legitimate claims in conformity with international law.

\subsubsection{Access to Health Information}

The delivery of life-critical mental and physical health information can be facilitated and improved through ICT-based solutions. Lack of access to information and communication has been identified as a critical factor in the public mental and physical health crises around the world. Experts have 
suggested that providing citizens of developing countries with community level points of access to mental and physical health information would be a critical starting point for addressing the mental and physical health care crises. However, such access points should support more than one-way flows of information (for example, from expert to community or patient). Communities must be allowed to participate in the selection and creation of communication flows that they find useful and necessary to address the prevention, treatment, and promotion of mental and physical health care for all people. Open access to medical information is absolutely essential so that all known data are available to medical doctors and practitioners.

\subsubsection{Basic Literacy}

Literacy and free universal access to education is a key principle. Knowledge societies require an informed and educated citizenry. Capacity-building needs to include skills to use ICTs, media and information literacy, and the skills needed for active citizenship including the ability to find, appraise, use and create information and technology. Approaches that are local, horizontal, genderresponsive and socially driven and mediated should be prioritised. A combination of traditional and new media as well as open access to knowledge and information should be encouraged. Libraries both real and virtual - have an important role to play to ensure access to knowledge and information available to everyone. At the international and multilateral level, the public domain of knowledge and culture needs to be protected. People-centred information technologies can foster eradication of illnesses and epidemics, can help give everyone food, shelter, freedom and peace.

Literacy, education and research are fundamental components of information, communication and knowledge societies. Knowledge creation and acquisition should be nurtured as a participatory and collective process and not considered a one-way flow or confined to one section of capacity building. Education (formal, informal, and lifelong) builds democracy both by creating a literate citizenry and a skilled workforce. But only an informed and educated citizenry with access to the means and outputs of pluralistic research can fully participate in and effectively contribute to knowledge societies.

Urgent attention should be paid to the potential positive and negative impacts of ICTs on the issues of illiteracy in regional, national and international languages of the great majority of the world's peoples. Literacy, education, and research efforts in the information and communication societies must include a focus on the needs of people who have physical impairments and all means of transcending those impairments (for example, voice recognition, e-learning, and open university training) must be promoted.

\subsubsection{Development of Sustainable and Community-based ICT Solutions}

In order that communities and individuals may fully enjoy the benefits of the information and communication society, ICTs must be designed and manufactured according to environmentally sustainable principles. Technological solutions must also be sustainable in the sense that communities are able to support their use and evolution.

Equipment recycling must meet environmental standards. The production of technologies must not consume an unsustainable amount of energy or natural resources.

It is essential to develop concrete proposals and policies to improve resource efficiency and develop renewable energy resources. This involves 'dematerialising' (for example, using less paper) and reducing ICT-related waste; increasing the useful life of hardware; improving recycling conditions; ensuring safe disposal of discarded ICT hardware and parts; and encouraging the development of alternatives to toxic ICT components. This also implies giving the highest priority to creating and 
using renewable energy resources to address the basic needs of populations living in developing countries. Renewable energy resources should be used for ICT-based dissemination of information and communications, including radio and television. Africa can particularly benefit from solar power due to its high level of exposure to direct solar radiation. By mobilising regional synergies, complemented by the necessary technical and financial cooperation, Africa could play a leading role in this strategic domain in the next decade.

Communities must have the ability to participate directly in the development and maintenance of ICT-based solutions to their own problems. In order that communities may create and sustain their own solutions using ICTs, they must be empowered to develop their own productive forces and control the means of production within information societies. This must include the right to participate fully in the development and sustenance of ICT-based projects through democratic processes, including decision making with respect to economic, cultural, environmental, and other issues. ICTs should be used as an instrument for the creation of genuine and sustainable sources of work, thus providing new labour opportunities.

In order that communities and individuals may create economically and technically sustainable solutions, they must have the right to use Free Software. This makes software more affordable, and, allows people to participate in its development and maintenances. ICT-based innovation should adhere to the use of international technical standards for hardware, software, and processes, which are open, freely implementable, publicly documented, interoperable, non-discriminatory and demand-driven.

It is important to support community-based communications using both traditional and new media and communication technologies. There is a need for the development and nurturing of the discipline of community informatics, which focuses on the particular characteristics and needs of communities, in relation to design, development, deployment, and operation of ICTs, as well as local content production.

\subsubsection{Conflict Situations}

We recognise that the use of media can be both positive and negative in conflict situations, including post-conflict peace building. We therefore insist that the rights of journalists and of all people to gather and communicate information, using any media, be especially respected during conflicts. These rights should be inviolate at all times but are crucial during war, violent conflict, and nonviolent protest.

We are particularly concerned about the deployment of "information warfare" technologies and techniques, including the purposeful jamming, blocking, or destruction of civilian communication systems during conflict situations; the use of 'embedded' journalists coupled with the targeting of non-embedded journalists; the use of media and communication systems to promote hatred and genocide; by military, police, or other security forces, be they governmental, privately owned, or non-state actors, during conflict situations both international and domestic.

Information intervention in conflict situations should be bound by international law, and the WSIS should encourage work on a future convention against information warfare to address these concerns.

\footnotetext{
${ }^{3}$ In this document, we use the term "Free Software" to refer to the specific concept defined by the Free Software Foundation.Free

Software is software that is licensed in such a way that people have the freedom to run, copy, distribute, study, change and improve it. Free Software implies access to source code as does "open source software"; however, open source software as the term is popularly used is not necessarily Free Software in our definition. Some organisations release open source software without permitting all of these actions. See http://www.fsf.org and http://www.fsfeurope.org for in-depth discussions of this concept.
} 
At the same time, the WSIS should not only limit information warfare and the control of media in conflict situations, but also actively promote media and communications for peace. To that end, we encourage governments to decrease public subsidy for military communications technology, and instead spend money directly on developing peaceful communications tools and applications.

\subsection{Centrality of Human Rights}

An information and communication society should be based on human rights and human dignity. With the Charter of the United Nations and the Universal Declaration of Human Rights as its foundation, it must embody the universality, indivisibility, interrelation and interdependence of all human rights - civil, political, economic, social and cultural - including the right to development and linguistic rights. This implies the full integration, concrete application and enforcement of all rights and the recognition of their centrality to democracy and sustainable development. Information and communication societies must be inclusive, so that all people, without distinction of any kind, can achieve their full potential. The principles of non-discrimination and diversity must be mainstreamed in all ICT regulation, policies, and programmes.

\subsubsection{Freedom of Expression}

Article 19 of the Universal Declaration of Human Rights is of fundamental and specific importance, since it forms an essential condition for human rights-based information and communication societies. Article 19 requires that everyone has the right to freedom of opinion and expression and the right to seek, receive and impart information and ideas, through any media and regardless of frontiers. This implies free circulation of ideas, pluralism of the sources of information and the media, press freedom, and availability of the tools to access information and share knowledge. Freedom of expression on the Internet must be protected by the rule of law rather than through selfregulation and codes of conduct. There must be no prior censorship, arbitrary control of, or constraints on, participants in the communication process or on the content, transmission and dissemination of information. Pluralism of the sources of information and the media must be safeguarded and promoted.

\subsubsection{Right to Privacy}

The right to privacy, enshrined in Article 12 of the Universal Declaration of Human Rights, is essential for self-determined human development in regard to civic, political, social, economic and cultural activities. The right to privacy faces new challenges in information and communication societies, and must be protected in public spaces, online, offline, at home and in the workplace. Every person must have the right to decide freely whether and in what manner he or she wants to receive information and communicate with others. The possibility of communicating anonymously must be ensured for everyone. The power of the private sector and of governments over personal data increases the risk of abuse, including monitoring and surveillance. Such activities must be kept to a legally legitimised minimum in a democratic society, and must remain accountable. The collection, retention, processing, use and disclosure of personal data, no matter by whom, should remain under the control of and determined by the individual concerned.

\subsubsection{Right to Participate in Public Affairs}

Good government administration and justice in a democratic society implies openness, transparency, accountability, participation and compliance with the rule of law. Respect for these principles is needed to enforce the right to take part in the conduct of public affairs. Public access to information produced or maintained by governments should be enforced, ensuring that the information is timely, complete and accessible in a format and language the public can understand. This further applies to 
access to documents of corporations relating to their activities affecting the public interest, especially in situations where the government has not made such information public.

\subsubsection{Workers' Rights}

ICTs are progressively changing our way of working. The creation of fair, secure, safe and healthy working conditions, in the manufacture of equipment and software, and in the utilisation of ICTs in the workplace in general, which respect international labour standards, for instance through tripartite social dialogue, is fundamental. ICTs should be used to promote awareness of, respect for and enforcement of human rights standards and international labour standards. Human rights, such as privacy, freedom of expression, linguistic rights, the right for on-line workers to form and join trade unions and the right of trade unions to function freely, including communicating with employees, must be respected in the workplace.

\subsubsection{Rights of Indigenous Peoples}

The evolution of information and communication societies must be founded on the respect and promotion of the recognition of the Rights of Indigenous Peoples and their distinctiveness as outlined in international conventions. Indigenous Peoples have fundamental rights to protect, preserve and strengthen their own language, culture and identity. ICT's should be used to support and promote diversity and the rights and means of Indigenous Peoples to benefit fully and with priority from their cultural, intellectual and so-called natural resources.

\subsubsection{Women's Rights}

In order to realise women's rights in the information and communication societies, as spelled out in the Convention on the Elimination of All Forms of Discrimination Against Women (CEDAW) and the Beijing Declaration and Platform for Action (Fifth World Conference on Women), it is crucial to acknowledge and address the differences, disparities and disadvantages that women experience. This means taking into account the ways in which women are different from men, and how these differences translate into differential levels of access, opportunity, participation and use of ICTs. It must be ensured that policy or legal interventions and programmes consciously address these differences. To ensure effective equality of women, and thereby enabling women's full ability to claim and exercise their human rights, it is necessary to adopt a substantive equality approach in the analysis, which informs the content of ICT policy and programmes. This approach implies that actions to promote women's rights must transform the unequal power relation between women and men. Women need not only equality of opportunity, but also equality of access to opportunities and the ability to fully participate in availing such opportunities.

\subsubsection{Rights of the Child}

Information and communication societies must respect and promote the principles of the Convention on the Rights of the Child. Every child is entitled to a happy childhood and to enjoy the rights and freedoms available to all persons under the Universal Declaration of Human Rights. All persons, civil society, private sector and governments should commit to uphold the Rights of the Child in information and communication societies.

\subsubsection{Rights of Persons with Disabilities}

In inclusive information and communication societies, the rights of persons with disabilities to have full and equal access to information and communications including ICTs, regardless of types and degree of disabilities, must be ensured by public policies, laws and regulations at all levels. In order to achieve this goal, a Universal Design principle and the use of assistive technologies must be seriously promoted and supported throughout the whole process of building and nurturing 
information and communication societies in which persons with disabilities and their organisations must be allowed to participate fully and on equal terms with non-disabled people.

\subsubsection{Regulation and the Rule of Law}

National regulation should be in full compliance with international human rights standards, adhering to the rule of law. Information and communication societies must not result in any discrimination or deprivation of human rights resulting from the acts or omission of governments or of non-state actors under their jurisdictions. Any restriction on the use of ICTs must pursue a legitimate aim under international law, be prescribed by law, be strictly proportionate to such an aim, and be necessary in a democratic society.

\subsection{Culture, Knowledge and the Public Domain}

Information and communication societies are enriched by their diversity of cultures and languages, retained and passed on through oral tradition or recorded and transmitted through a variety of media, and together contributing to the sum of human knowledge. Human knowledge is the heritage of all humankind and the reservoir from which all new knowledge is created. The preservation of cultural and linguistic diversity, the freedom of the media and the defence and extension of the public domain of global knowledge are as essential, for information and communication societies, as the diversity of our natural environment.

\subsubsection{Cultural and Linguistic Diversity}

Cultural and linguistic diversity is an essential dimension of people-centred information and communication societies. Every culture has dignity and value that must be respected and preserved. Cultural and linguistic diversity is based, among other things, on the freedom of information and expression and the right of everyone to freely participate in the cultural life of the community, at local, national and international levels. This participation includes activities both as users and producers of cultural content. ICTs including traditional communications media have a particularly important role to play in sustaining and developing the world's cultures and languages.

\subsubsection{Capacity Building and Education}

Cultural and linguistic diversity should not only be preserved; it needs to be fostered. This implies capacity to express oneself, in one's own language, at any time, by any means, including traditional media and new ICTs. In order to become a contributor and a creator in the information and communication societies, not only technical skills are needed, but critical and creative competence. Media education in the sense of the UNESCO Grunwald Declaration must be given specific attention in education and training programs. Cultural and linguistic diversity also implies equal access to the means of expression and of dissemination of cultural goods and services. Priority should be given to community-driven initiatives.

\subsubsection{Language}

Plurality of languages is at the core of vibrant information and communication societies. ICTs can be applied to bridge cultural and linguistic divides, given the right priorities. In the past, ICT development has too often reinforced inequalities, such as dominance of roman letter based languages (especially English) and marginalization of local, regional and minority languages. Priority should be given in ICT research and development to overcoming barriers and addressing inequalities between languages and cultures. 


\subsubsection{International Law and Regulation}

International law and regulation should strengthen cultural, linguistic and media diversity, in accordance with existing international declarations and covenants, in particular Article 19 and Article 27 of the Universal Declaration of Human Rights; Articles 19 and 27 of the International Covenant on Civil and Political Rights; Articles 13 and 15 of the International Covenant on Economic, Social and Cultural Rights; and Articles 5 and 6 of the Universal Declaration of Cultural Diversity adopted by UNESCO in 2001. International trade agreements should treat culture, including audio-visual content and services, not simply as a commodity, but should take account of the need for cultural, linguistic and media diversity. The establishment of an International Convention on Cultural Diversity should be accelerated, with a view to achieving an effective and binding international agreement. Existing international copyright regulation instruments including TRIPS and WIPO should be reviewed to ensure that they promote cultural, linguistic and media diversity and contribute to the development of human knowledge.

\subsubsection{Media}

\subsubsection{The Role of the Media}

Freedom of Expression and Freedom of the Media are central to any conception of information and communication societies. The media is an integral enabling mechanism for a global communications vision. Its role in producing, gathering and distributing diverse content in which all citizens are included and can actively participate, is vital. Especially for the developing countries, broadcast radio and television will continue to be the most effective ways to deliver high-quality information. All forms of media can make crucial contributions to social cohesion and development in the digital era.

Article 19 is the foundation for five regional declarations on media freedom and plurality that must continue to frame the role of the media in all its means of delivery. These texts have been unanimously endorsed by the member states of UNESCO.

Security and other considerations should not be allowed to compromise freedom of expression and media freedom. Media pluralism and diversity should be guaranteed through appropriate laws to avoid excessive media concentration.

Editorial independence of media professionals and creators must be protected and the formulation of professional and ethical standards in journalism and other media production must be the responsibility of media workers themselves. Online authors, journalists and editors should have the same contractual rights and social protections as other media workers.

Public service broadcasting has a specific and crucial role to play in ensuring the participation of all in the information and communication societies. State-controlled media should be transformed into editorially independent public service organisations.

\subsubsection{Community Media}

Community media, that is media which are independent, community-driven and civil society-based, have a particular role to play in enabling access to and participation for all in information and communication societies, especially the poorest and most marginalized communities. Community media can be vital enablers of information, voice and capacities for dialogue. Legal and regulatory

\footnotetext{
${ }^{4}$ The Windhoek Declaration on the Promotion of Free and Pluralistic African Press, 1991; the Declaration of Alma Ata on Promoting Independent and Pluralistic Asian Media, 1992; the Declaration of Sana'a on Promoting Independent and Pluralistic Media, 1994; the Sofia Declaration on Promoting European Pluralistic and Independent Media, 1997 (adopted in 95 and 97)
} 
frameworks that protect and enhance community media are especially critical for ensuring vulnerable groups access to information and communication.

Governments should ensure that legal frameworks for community media are non-discriminatory and provide for equitable allocation of frequencies through transparent and accountable mechanisms. Targets should be established for the opening up of broadcast licenses to allow for the operation of community broadcasting where this is not currently permitted. Spectrum planning and regulation should ensure sufficient spectrum and channel capacity, and appropriate technical standards, for community media to develop in both the analogue and the digital environment.

A Community Media Fund should be established through a donor civil society partnership to invest in and support community-driven media, information and communication initiatives using traditional media and new ICTs including projects that make provision for the poorest communities, for cultural and linguistic diversity and for the equal participation of women and girls. Community-based media and communication centres should be encouraged and assisted to combine traditional media technologies, including radio and television, with access to new ICTs.

\subsubsection{The Public Domain of Global Knowledge}

A rich public domain of knowledge available to all is essential to sustainable information societies, to bridge the digital divide and to provide the grounds for a positive development of intellectual creativity, technological innovation and effective use of that technology. In information societies, new digital forms of storing information mean that this can be copied and transmitted in innovative ways that challenge existing customs and laws. The increasing privatisation of knowledge production threatens to restrict the availability of research results. Attempts have been made to commercially exploit traditional indigenous knowledge without consulting the communities, who are the owners of that knowledge.

\subsubsection{Indigenous Peoples' Knowledge}

Indigenous peoples are the guardians of their traditional knowledge and have the right to protect and control that knowledge. Existing intellectual property regimes are insufficient for the protection of indigenous people's cultural and intellectual property rights.

Traditional knowledge should be protected from any attempt at patenting. Indigenous peoples should freely decide whether their heritage should become part of the public domain or not. They should decide whether or not it should be exploited commercially and in what way.

We should give particular attention to measures to maintain knowledge diversity and to protect the cultural, intellectual and so-called natural resources of indigenous peoples, especially botanical and agricultural knowledge, from commercial exploitation and appropriation.

We urge the United Nations to establish specific legal frameworks, in accordance with Article 26.4 of the Agenda 21 of the Earth Summit, to recognise indigenous peoples' rights to self-determination and ancestral territories, as a necessary prerequisite to ensure the protection, preservation and development of their traditional knowledge in information and communication societies.

\subsubsection{Copyright, Patents and Trademarks}

Limited intellectual monopolies, also known as intellectual property rights, are granted only for the benefit of society, most notably to encourage creativity and innovation. The benchmark against which they must be reviewed and adjusted regularly is how well they fulfill this purpose. Today, the vast majority of humankind has no access to the public domain of global knowledge, a situation that 
is contributing to the growth of inequality and exploitation of the poorest peoples and communities. Yet instead of extending and strengthening the global domain, recent developments are restricting information more and more to private hands. Patents are being extended to software (and even to ideas), with the consequent effect of limiting innovation and reinforcing monopolies. Drugs that could save millions of lives are denied to disease sufferers because pharmaceutical companies that hold the patents resist making them available to those countries that can not pay high prices. Copyright periods have been extended again and again, making them practically indefinite and defeating their original purpose.

\subsubsection{Software}

Software provides the medium and regulatory framework for digital information, and access to software determines who may participate. Equal access to software is fundamental for inclusive and empowering digital information and communication societies, and a diversity of platforms is essential to this.

We must recognise the political and regulatory impact of software on digital societies and build, through public policy and specific programs, awareness of the effects and benefits of different software models. In particular, Free Software, with its freedoms of use for any purpose, study, modification and redistribution should be promoted for its unique social, educational, scientific, political and economic benefits and opportunities. Its special advantages for developing countries, such as low cost, empowerment and the stimulation of sustainable local and regional economies, easier adaptation to local cultures and creation of local language versions, greater security, capacity building, etc, need to be recognised, publicised and taken advantage of. Governments should promote the use of Free Software in schools and higher education and in public administration.

The UN should carry out a fundamental review of the impact on poverty and human rights of current arrangements for recognition and governance of monopolised knowledge and information, including the work of WIPO and the functioning of the TRIPS agreement. Efforts should be made to ensure that limited intellectual monopolies stimulate innovation and reward initiative, rather than keeping knowledge in private hands until it is of little use to society.

\subsubsection{Research}

Increasing private sector participation in scientific research is leading to patents and scientific knowledge being held in private hands instead of being available in the public domain, and increasing competition among scientists and scientific teams sometimes results in poor scientific practices, secrecy and the patenting of discoveries that would previously have been available to all. Research should continue to be based on cooperation, openness and transparency.

Public bodies such as libraries, scientific research centres, universities, should be able to contribute to enrich the common good of culture and knowledge, by putting into the public domain the results of their publicly funded activities. The public domain of global knowledge should be defended and extended through public policy, awareness-building and investments in programmes. These should ensure that any work funded by public or philanthropic bodies enters the public domain and should increase accessibility of information in online and offline media by means of Free Documentation, public libraries and other initiatives to disseminate information, such as Open Access journals and Open Archives giving access to scientific and other public domain information. All scientific data, such as genomes of living beings, should be freely accessible to all in Open Access databases.

\subsection{Enabling Environment}




\subsubsection{Ethical Dimensions}

Information and communication societies are about how our societies create, share and utilise the information, cultural production and knowledge, which in turn shape the evolution of those societies. The value-base of the information society must be founded on the principles contained in the ensemble of internationally agreed-upon conventions, declarations, and charters.

More specifically, equal, fair and open access to knowledge and information resources, - whatever the technical means used to store and transmit them - must be established as fundamental principles of such societies. Technological, financial and regulatory considerations must conform to these principles.

Transparent and accountable governance, ethical business and accounting practices in communications sector firms and ethical media practice are of particular relevance in this context. Codes of ethics and standards should be adopted in these cases and mechanisms should be established to monitor their application as well as appropriate sanctions for their violation. Formulation of ethics and standards in journalism and other media production should be the responsibility of media workers themselves.

Respect for diversity must be a central criterion in establishing the principles and mechanisms for resolving conflicts that arise in information societies. Such societies, if they are built on values such as cooperation, equity, honesty, integrity, respect and solidarity, can have a significant impact on the quality of interaction between cultures and the promotion of meaningful dialogue among civilisations, and thus contribute to bringing about world peace.

\subsubsection{Democratic and Accountable Governance}

National and international regulations for information and communication societies should be in full compliance with international human rights standards. Openness, transparency, accountability and the rule of law should be the guiding principles for the democratic governance of societies at all levels, from the local to the national and international. Inclusive, participatory and peaceful information and communication societies rest on the responsiveness of governing bodies as well as on the commitment of all actors involved in governance, both of governmental and non governmental nature, to progressively implement greater political, social and economic equity.

A democratic perspective on information and communication societies, in which information is crucial for citizens, is necessary in order to make choices grounded on the awareness of alternatives and opportunities. Information and communication are the foundation for transparency, debate and decision-making. They can contribute to a culture and a practice of cooperation, basis for a renewal of democracy. Information and communication technologies offer potential benefits to the world's communities that will only be exploited if there is a political will to do so.

In this spirit, the aim of WSIS "to develop a common vision and understanding of the Information Society", and the methods to achieve such a vision, requires shared communication values and mechanisms including the right to communicate, respect for freedom of opinion and expression in all of its dimensions, and a commitment to transparency, accountability, and democracy.

\subsubsection{Infrastructure and Access}

The dramatic lack of a reliable infrastructure is the main physical obstacle for ICT-based services to be offered to populations living in Africa. Here, the fragmented and incomplete structure and the unreliability of the existing infrastructure and access networks constitute the underlying structure of the so-called Digital Divide. 
(Tele) communications infrastructure is essential for disseminating ICT-based services and is central in achieving the goal of universal, sustainable, ubiquitous and affordable access to and usage of these technologies and services by all. Furthermore, energy is a prerequisite for infrastructure and access.

Most voice, data and Internet traffic between African countries is currently routed outside of the continent because of the lack of an efficient African backbone network, increasing the cost of this traffic. Increased cost always limits access. Existing efforts to build an African network infrastructure must be supported and expanded (e.g. Internet exchange points).

The implementation and roll-out of (tele)communications infrastructure and access in DCs will require financial investments consistent with the huge needs in this area. In order to reduce the amount of financial resources needed, investments should be optimised by consolidating projects nationally or (sub) regionally, and by technological (re-) designing and updating. Furthermore, synergy between different sectors should be systematically exploited from the project phase, particular attention being paid to the energy and transport sectors that show very close links. Finally, the particularly strong synergy and technological similarity between ICT and Radio-TV networks should lead governments and planning authorities to deploy and use a common infrastructure for both their services to be transported and disseminated.

Community telecentres (public access centres) have become spaces for the effective access and strategic use of information and communication technologies with emphasis on the democratisation of communications. Governments should guarantee policies for the development of telecentres, among others, to provide equitable and affordable access to infrastructure and ICTs; to encourage digital inclusion policies for the population, independently of gender, ethnic aspects, language, culture and geographical situation. This would promote the discussion and active participation of communities in public policy processes related to the implementation and role of telecentres for local development.

Orbital satellite paths should be recognised as a public resource and should be allocated to benefit the public interest through transparent and accountable frameworks. Moreover, spectrum planning and regulation should ensure equitable access among a plurality of media including sufficient satellite capacity reserved for community media. A fixed percentage of orbital resources, satellite capacity and radio frequency spectrum should be reserved for educational, humanitarian, community and other non-commercial use.

The expansion of the global information infrastructure should be based on principles of equality and partnership and guided by rules of fair competition and regulation at both national and international levels.

The integration of access, infrastructure and training of the citizenry and the generation of local content, in a framework of social networks and clear public or private policies, is a key basis for the development of egalitarian and inclusive information societies.

\subsubsection{Financing and Infrastructure}

Existing and new financing measures should be envisaged and appraised. The "Digital Solidarity Fund" has been proposed by Africa. Such a fund could be a real hope for African peoples if it clearly states its goals, is transparently managed, and aims to foster primarily public services, especially for populations living in underserved and isolated areas. In addition, we stress the significant role that diaspora populations from all the world's regions can play in financing ICT programmes and projects. 
In order to optimise scarce financial resources, appropriate cost-effective technological options should be used, while avoiding duplication of infrastructure. Additionally, synergies between different sectors and networks can be exploited to this end, with particular attention to the energy and transport sectors, given their close links with the telecommunications sector.

A Community Media Fund should be established through a donor civil society partnership to invest in and support community-driven and community-based media, and information and communication initiatives using both traditional media and new ITC's. Effort should be made to eliminate the duplication of infrastructures and to consolidate projects in a national or regional frame to encourage investment funding. Where possible, ICT and radio/TV networks should use common infrastructure for dissemination.

\subsubsection{Human Development - Education and Training}

Literacy, education and research are fundamental and interrelated components of the information exchanges necessary to build knowledge societies. Knowledge creation and acquisition should be nurtured as a participatory and collective process; it should not be considered a one-way flow or confined to one section of capacity building. Education, in its different components - formal, informal, and lifelong - is fundamental to building democratic societies both by creating a literate citizenry and a skilled workforce.

To utilise the full potential of e-learning and long-distance education, they must be complemented by traditional educational resources and methods, in a local context of media pluralism and linguistic diversity.

Only informed and educated citizens with access to empowering education, a plurality of means of information, and the outputs of research efforts can fully participate in and effectively contribute to knowledge societies. Therefore it is also essential to recognise the right to education as stated both in the Declaration on the Right to Development and the Universal Declaration of Human Rights

Capacity building initiatives designed to empower individuals and communities in the information society must include, in addition to basic literacy and ICT skills, media and information literacy, the ability to find, appraise, use and create information and technology. In particular, educators, students and researchers must be able to use and develop Free Software, which allows the unfettered ability to study, change, copy, distribute, and run software. Finally, capacity building initiatives should be designed to stimulate the desire for general learning and respond to specific as well as special needs: those of young and elderly people, of women, of people with impairments, of indigenous peoples, of migrant communities, of refugees and returnees in post-conflict situations, in a life-long perspective. Volunteers can help transmit knowledge and enhance capacity, in particular of marginalized groups not reached by government training institutions.

Capacity building in the information and communication societies requires people who are competent in teaching media and communication literacy. Therefore training of trainers and training of educators in every level is equal important in order to reach out to people at the limits of the information society.

Libraries are an important tool to fight digital divide and to ensure continuous, out-of-market-ruled access to information, by freeing the results of research funded by public support, by sharing content and educational materials to promote literacy, build capacities and bring autonomy to learners of all kinds, world wide. This also entails convincing content producers to be active participants in the open access paradigm of knowledge. 
Global barriers to knowledge and education must be transparently evaluated by looking beyond technological obstacles at legal and institutional gridlocks (like Intellectual Property Laws and International standards) and promoting a new balance of intellectual properties as a common ground for creators to protect their works and for civil society to benefit from their contributions.

Civil society sees the need for alternative models for the production and exchange of knowledge and information. To secure and finance the global knowledge commons, civil society actors support new open and self-organised publishing models in science and software production and community-based communications, with in-built maintenance programs and upgrading capacities.

\subsubsection{Information Generation and Knowledge Development}

Research must be promoted in all fields related to the information and communication societies, and its development must be sensitive to the social uses of ICTs. In particular, research on community informatics must be supported ${ }^{5}$. This would include the development of a research agenda among practitioners, scholars, and communities; the cataloguing of community informatics projects and identification of both factors for failure and success; and support for research projects and systems trials. Fundamental research should be strengthened by expanding open access to primary scientific data and publications. Public bodies such as libraries, scientific research centres, universities should foster independent investigation, build a pluralistic body of knowledge and promote the results of activities which have been funded by public money. This body of knowledge should be made available in all public spaces, or spaces with public access (community centres, universities, schools, museums, libraries, media centres, and other dedicated entities), through appropriate and plural modes of access, avoiding the risk of high dependency on digital technology alone.

\subsubsection{Global Governance of ICT and Communications}

International "rules of the game" play an increasingly central role in the global information economy. In recent years, governments have liberalised traditional international regulatory regimes for telecommunications, radio frequency spectrum, and satellite services, and have created new multilateral arrangements for international trade in services, intellectual property, "information security," and electronic commerce. At the same time, business groups have established a variety of "self-regulatory" arrangements concerning Internet identifiers (names and numbers), infrastructure, and content.

It is not acceptable for these and related global governance frameworks to be designed by and for small groups of powerful governments and companies and then exported to the world asfaits accomplis. Instead, they must reflect the diverse views and interests of the international community as a whole. This overarching principle has both procedural and substantive dimensions.

Procedurally, decision-making processes must be based on such values as inclusive participation, transparency, and democratic accountability. In particular, institutional reforms are needed to facilitate the full and effective participation of marginalized stakeholders like developing and transitional countries, global civil society organisations, small and medium-sized enterprises, and individual users.

Substantively, global governance frameworks must promote a more equitable distribution of benefits across nations and social groups. To do so, they must strike a better balance between commercial considerations and other legitimate social objectives. For example, existing international

\footnotetext{
${ }^{5}$ Community informatics refers here to the interdisciplinary study and practice of the design, implementation, and management of information and communication technologies developed by communities to solve their own problems. This field takes into account social science research about the social impacts of ICTs -- also known as social informatics -- as well as information and communication systems analysis and design techniques.
} 
arrangements should be reformed to promote: efficient management of network interconnections and traffic revenue distribution, subject to the mutual agreement of corresponding operators; equitable allocations of radio frequency spectrum and satellite orbital slots that fully support developmental and non-commercial applications; fair trade in electronic goods and services, taking into account the developing countries' need for special and differential treatment; an open public domain of information resources and ideas; and the protection of human rights, consumer safety, and personal privacy. In parallel, new diverse international arrangements are needed to promote: financial support for sustainable e-development, especially but not only in less affluent nations; linguistic, cultural, and informational diversity; and the curtailment of concentrated market power in ICT and mass media industries.

In light of the relevant controversies in the WSIS process, special attention must be given to improving the global coordination of the Internet's underlying resources. It must be remembered that the Internet is not a singular communications "platform" akin to a public telephone network; it is instead a highly distributed set of protocols, processes, and voluntarily self-associating networks. Accordingly, the Internet cannot be governed effectively by any one organisation or set of interests. An exclusionary intergovernmental model would be especially ill suited to its unique characteristics; only a truly open, multistakeholder, and flexible approach can ensure the Internet's continued growth and transition into a multilingual medium. In parallel, when the conditions for system stability and sound management can be guaranteed, authority over inherently global resources like the root servers should be transferred to a global, multistakeholder entity.

The international community must have full and easy access to knowledge and information about ICT global governance decision making. This is a baseline prerequisite for implementation of the principles mentioned above, and indeed for the success of the WSIS process itself. We need publicinterest oriented monitoring and analysis of the relevant activities of both intergovernmental and "self-governance" bodies including, inter alia, the International Telecommunication Union, the World Trade Organization, the World Intellectual Property Organization, the United Nations Conference on International Trade Law, the Organization for Economic Cooperation and Development, the Hague Conference on International Private Law, the of Europe, the Asia Pacific Economic Cooperation, the North American Free Trade Agreement, the Internet Corporation for Assigned Names and Numbers, and Wassenaar Arrangement.

As a viable first step in this direction, we recommend the establishment of an independent and truly multistakeholder observatory committee to: (1) map and track the most pressing current developments in ICT global governance decision-making; (2) assess and solicit stakeholder input on the conformity of such decision-making with the stated objectives of the WSIS agenda; and (3) report to all stakeholders in the WSIS process on a periodic basis until 2005, at which time a decision could be made on whether to continue or terminate the activity. 


\section{CONCLUSION}

It is people who primarily form and shape societies, and information and communication societies are no exception. Civil society actors have been key innovators and shapers of the technology, culture and content of information and communication societies, and will continue to be in the future.

Human rights stand at the centre of our vision of the information and communication society $y^{6}$. From this standpoint, action plans, implementation, financing mechanisms and governance must all be shaped by and evaluated on the basis of their ability to meet life-critical human needs.

Host countries and institutions contributing to and participating in the post-Geneva WSIS process should fully respect the principles enunciated in the Declaration adopted at the Geneva Summit, including those relating to human rights that are fundamental to the information and communications society. These include, but are not limited to the freedoms of expression, association and information.

Toward this end, and in preparation for the second phase of WSIS, an independent commission should be established to review national and international ICT regulations and practices and their compliance with international human rights standards. This commission should also address the potential applications of ICTs to the realization of human rights, such as the right to development, the right to education and the right to a standard of living adequate for the mental and physical health and well-being of the individual and his or her family, including food, housing and medical care.

The full realisation of a just information society requires the full participation of civil society in its conception, implementation, and operation. To this end, we call on all governments involved in the preparatory processes of WSIS to work in good faith with non-governmental and civil society organisations and fully honour the recommendations of Resolution 56/183 of the United Nations General Assembly. In particular, participating governments must honour civil society's right to participate fully in the remaining intergovernmental preparatory processes leading to the second phase of WSIS.

We commit ourselves - independent of the modalities of participation granted to us by governments - to pursuing by all just and honourable means necessary the realization of the vision of the information society presented herein. To this end, civil society organisations will continue to cooperate with one another to develop a Plan of Action for the second phase of WSIS. We call upon the world's leaders to urgently assume the heavy responsibilities they face, in partnership with civil society, to make this vision a reality.

Endorsements of this declaration are being compiled at ct-endorse@wsis-cs.org and archived on http://www.wsis-cs.org.

\footnotetext{
${ }^{6}$ Nothing in this declaration may be interpreted as implying that civil society wishes to engage in any activity or to perform any act aimed at the destruction of any of the rights and freedoms set forth in the International Bill of Rights and other human rights treaties.
} 


\section{Déclaration de Tunis}

Nous, participants au Forum International des ONG/Société Civile sur les Technologies de l'Information et des Communications (TIC) et les Objectifs du Millénaire de Développement (OMD) organisé par l'Association Tunisienne des Mères et la Section des ONG/ONU ECOSOC en célébration de la Journée Nationale des ONG et dans le cadre de la préparation de la Phase II du Sommet Mondial de la Société de l'Information (SMSI) et du Segment de Haut Niveau de l'ECOSOC 2005, réunis au Technopole d'El Gazala, Ariana, Tunisie du 23 au 26 Avril 2005 autour du thème "Pour une Société de l'Information, du Savoir et du Développement pour tous, inclusive et axée sur les peuples ».

\section{* Appréciant :}

- Les délibérations fructueuses et globales de tous les participants du Forum et le fort soutien de Son Excellence Monsieur Zine El Abidine BEN ALI, Président de la République Tunisienne et de son Gouvernement ;

- Le travail remarquable préparatoire avec le grand appui de l'UN-NGOIRENE/NGO Section, de l'ONG organisatrice, l'Association Tunisienne des Mères (ATM), coordinatrice de l'UN-NGO-IRENE/Afrique, et son engagement à renforcer la Société Civile et sa contribution aux travaux de l'ECOSOC, pour la mise en oeuvre de la Déclaration du Millénaire et des OMD ainsi que la préparation du Sommet Mondial de la Société de l'Information :

- Le grand soutien de DESA et le partenariat du Bureau de Tunis du Programme des Nations Unies pour le Développement (PNUD) ainsi que celui de la Société Civile et du secteur privé ;

- Les résultats des rencontres antérieures tenues dans le cadre de la préparation de la Phase II du SMSI et du Segment de Haut Niveau de l'ECOSOC 2005 dans le cadre des réunions de suivi de la mise en œuvre de la Déclaration du Millénaire et des OMD.

* Reconnaissant que 1'année 2005 marque le $60^{\text {ème }}$ Anniversaire des Nations Unies et du suivi de la Déclaration du Millénaire et des ODM +5, et la tenue du Sommet Mondial de la Société de l'Information pour lesquels la Société Civile doit efficacement contribuer.

* Incitant tous les partenaires à déployer tous les efforts nécessaires pour la réalisation des objectifs dans ce document et autres sur les TIC : Déclaration du Millénaire et ODM , partenariat et accords y relatifs afin de conjuguer leurs efforts en vue d'une compagne universelle et cohésive ; à promouvoir une Gouvernance participative et un partenariat ;

A utiliser les TIC et les innovations technologiques en tant que moyen important pour la mise en place efficace des ODM sur tous les plans: Local, national, sousrégional, régional et mondial.

Prendre en considération les défis et les opportunités ainsi que le travail requis afin de réaliser une plus large égalité d'accès et d'utilisation des TIC en introduisant de 
nouvelles technologies dans la mise place des huit Objectifs de Développement du Millénaire ODM surtout au courant de l'année 2005 qui marque le $60^{\text {ème }}$ anniversaire des Nations Unies, l'évaluation des ODM +5 et la tenue de la II ${ }^{\text {ème }}$ Phase du Sommet Mondial sur la Société de l'Information de Tunis.

Nous, les participants au Forum International des $\mathrm{ONG} /$ Société Civile recommandons à diffuser les résultats du présent Forum et à oeuvrer pour leur applications et sollicitons les Gouvernements, les ONG, la Société Civile, le secteur privé et autres institutions à renforcer les TIC dans toutes les sphères de la vie afin de réaliser les ODM d'ici l'année 2015.

\section{Solliciter les Gouvernements de tous les pays à :}

1.1 Poursuivre leurs engagements en vue d'accroître l'accès et l'utilisation des TIC afin de réaliser la Déclaration du Millénaire et les ODM, de mettre en œuvre la Déclaration de Principe et le Plan d'Action du SMSI et de promouvoir l'intégration de ses objectifs dans leurs politiques respectives, leurs activités, leurs législations et programmes de développement en partenariat avec tous les acteurs.

1.2 Promouvoir les innovations relatives aux TIC dans des domaines de la Gouvernance, les Femmes, les Familles, les Enfants et les personnes aux besoins spécifiques, engageant les autorités municipales et locales, le secteur privé et la Société Civile à travers l'Education, la Formation continue et la formation professionnelle, les micro-finances et les crédits, les incitations fiscales, le développement des infrastructures, l'équipement ainsi que la gestion et le développement des ressources financières et humaines.

1.3 Mobiliser les ressources financières et techniques en garantissant les mécanismes adéquats et sûrs de financement, offrir un environnement favorable à l'investissement et à l'intégration des TIC d'une manière durable dans tous les domaines de l'Homme et accorder une attention particulière aux citoyens aux besoins spécifiques: Femmes, Enfants, Personnes handicapées, Populations rurales ou zones démunies, régions menacées par les catastrophes naturelles ou les conflits.

1.4 Faciliter l'incorporation des TIC dans tous les aspects de la Gouvernance participative en vue d'assurer une transparence, de multiples services efficaces, de bonne qualité et de haut niveau à tous les citoyens.

\section{Inciter tous les partenaires à :}

2.1 Promouvoir l'utilisation des TIC et les initiatives novatrices y afférentes, les projets et programmes menés en partenariat entre les divers acteurs (Gouvernements, ONG, Société Civile, secteur privé, Médias, autorités locales, parlementaires, communauté internationale et les Nations Unies), dans l'accomplissement de leurs engagements à l'égard de la Déclaration du Millénaire et des OMD visant le développement pour tous et une société de savoir sans exclusion.

2.2 Traiter l'impact culturel, ethnique et linguistique des TIC à travers la diversification et l'adaptation de leurs services afin de leur permettre de répondre 
aux besoins individuels et spécifiques de chaque groupe en répandant les moyens existants.

2.3 Inclure les préoccupations liées aux Droits de l'Homme dans tous les programmes, politiques et initiatives relatives aux TIC.

2.4 Lutter en vue d'éradiquer la discrimination des sexes dans l'accès aux services et financement des TIC par la création de centres techniques spécialisés et la mise en place de programmes de formation au profit de la Femme, de l'Enfant, de la Famille en favorisant un accès équitable et assurer une égalité des chances à l'emploi dans les différents secteurs relatifs aux TIC.

2.5 Accroître l'usage des TIC de haut niveau dans les programmes de l'enseignement à distance, la formation professionnelle en vue d'accélérer la réalisation des OMD.

2.6 Impliquer les personnes aux besoins spécifiques dans les activités reliées aux TIC en offrant des cours de formation, un accès plus facile aux moyens d'information et développer les technologies afin de leur faciliter une meilleure qualité de vie pour les personnes aux besoins spécifiques.

2.7 Définir clairement les objectifs et les buts des TIC et renforcer l'évaluation, l'assistance, les processus de contrôle et de suivi dans tous les pays en vue de permettre l'accès au progrès dans l'usage des TIC pour l'accomplissement de la Déclaration du Millénaire et des OMD.

Simultanément, nous les participants invitons toutes les composantes de la communauté nationale et internationale et les principaux partenaires à :

1. Renforcer leur volonté politique et leur soutien financier en vue de traduire leurs engagements en actions à travers la mise en place de e-stratégies, de politiques, de mécanismes financiers efficaces, adaptés, multilatéraux et transparents visant une Gouvernance d'Internet participative de tous les niveaux pour un développement durable et une paix pour tous.

2. Considérer les TIC efficientes et les innovations comme moyens nécessaires à la réalisation de la Déclaration du Millénaire et des OMD et à l'institution d'une Société de l'Information intégrée pour tous.

3. Réaffirmer le soutien international pour la Déclaration Universelle des Droits de l'Homme et de la Déclaration du Millénaire reconnaissant le rôle de l'égalité des sexes en tant qu'aspect fondamental des efforts de développement y compris tous les efforts nécessaires à la mise en place des OMD.

4. Appuyer une approche participative pour un suivi, des assistances régulières et des évaluations à tous les niveaux : Local, national, régional et international du processus et de pleines contributions aux résultats de la Réunion de Suivi des OMD+5.

5. Appuyer les ONG ayant les statuts consultatifs auprès de l'ECOSOC afin de suivre l'application de la Déclaration et du Plan d' Action de Tunis avec les partenaires ainsi que le rapport régulier de son avancement. Une rencontre internationale se 
réunirait chaque année, sur l'initiative des différents pays hôtes et pourrait assurer une mise en œuvre effective de la Déclaration et du Plan d'Action de Tunis.

6. Solliciter l'ATM pour soumettre la Déclaration et le Plan d'Action sous forme d'une Déclaration de Principe du Segment de l'ECOSOC de 2005 afin d'être considérés dans la Déclaration Ministérielle de l'ECOSOC.

7. Demander à l'ATM de diffuser la Déclaration et le Plan d'Action de Tunis afin de les soumettre et les présenter aux évènements parallèles au SMSI de Tunis en Novembre 2005.

Nous, les participants du Forum du Tunis réitérons notre volonté pour œuvrer à l'application de la Déclaration du Millénaire et de ses OMD en utilisant les TIC comme moyen effectif pour établir et construire une Société d'Information inclusive, centrée vers les peuples, et orientés au développement d'une société de savoir et d'information pour tous. 


\title{
WSIS 2nd Phase Tunis 2005
}

\section{ATM ECOSOC NGO / CIVIL SOCIETY PANEL}

\author{
ICT Diversity \\ E - Success Stories and Best Practices \\ for a Better World for All
}
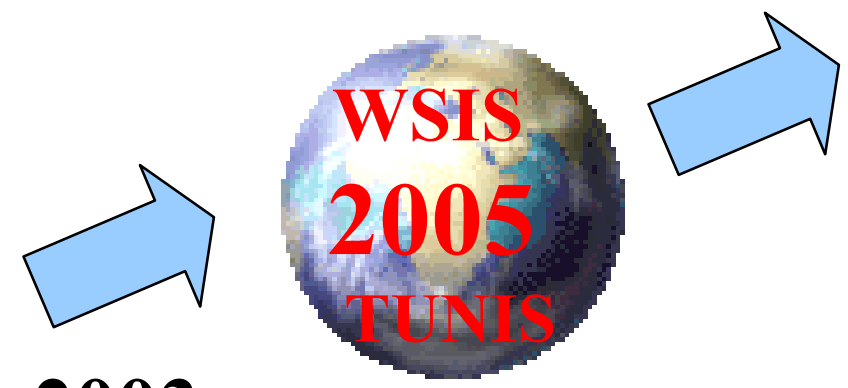

2015

\section{GENEVA 2003}

16 November, 2005 (12:00 pm - 15:00 pm)

Tunisia, Tunis - Le Kram, Room Le Kef

\section{AGENDA}

12:00 hrs Honorary Chair: The First Lady of Dominican Republic, Dra. Margarita Cedeno de Fernandez Chair: Mr. Sarbuland Khan, Director Office ECOSOC Support and Coordination, UNDESA Welcome address - Saida Aguerbi, President ATM \& UN-NGO-IRENE/Africa Coordinator Opening Remarks: UNICEF, UNESCO, CONGO

12:20 hrs

- Presentation on Cultural Diversity by Tracey NAUGHTON (WSIS Media Caucus)

- Presentation on e-Handicap by Boutheina LABIDI (BESMA)

- Multimedia: e-Caravan by Rafika KHOUINI (ATM)

- UN-NGO IRENE Contribution Worldwide by Najet KARABORNI (UNDESA)

- E- Education to support MDGs by Sidi CHERIF (World for World Organization)

- Presentation on Training Centre of Dakar, Binta DIOP (FAS)

- One Dollar for Development by Giovanni BISOGNI (FORMIT) \& Ambassador Francis LORENZO (Dominican Republic)

- Arab Women Training and Research Center by Soukeina BOURAOUI (CAWTAR)

- Euro-Arab Network for Integration and Development by Joumana TRAD (READI/ FPSC - Spain)

- Presentation on e- Blind by Dr. Imed CHAKER (UNAT)

- Training and Research by Sayda RAHMOUNI (CREDIF)

- Publinet for Disabled by Anis Khriji (CJV)

14: 10 hrs Discussions / Proposals and Recommendations

14:45 hrs Wrap up-Recommendations \& Closing - Hanifa MEZOUI (NGO Section/ECOSOC/DESA) 
Document WSIS-05/TUNIS/CONTR/13-E

23 December 2005

Original: English

Civil Society Declaration 


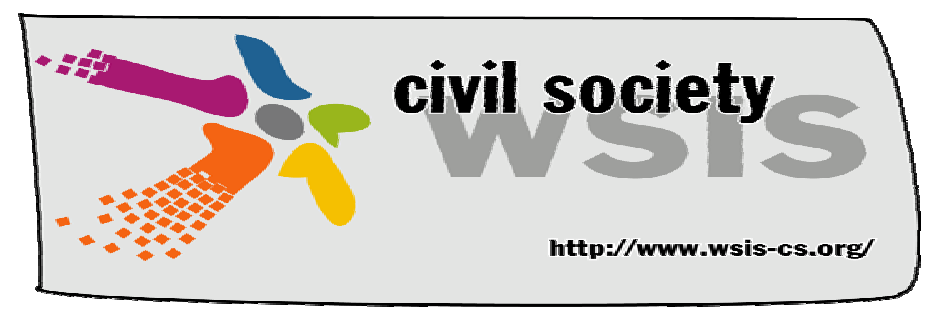

\title{
"Much more could have been achieved"
}

\section{Civil Society Statement}

\author{
on the \\ World Summit on the Information Society
}

18 December 2005 


\section{Content}

I. Introduction - Our Perspective After the WSIS Process

II. Issues Addressed During the Tunis Phase of WSIS 5

Social Justice, Financing and People-Centred Development 5

Human Rights__6 6

\begin{tabular}{|ll}
\hline Internet Governance & 7
\end{tabular}

\begin{tabular}{|ll}
\hline Global governance & 8
\end{tabular}

\begin{tabular}{|ll}
\hline Participation & 8
\end{tabular}

\begin{tabular}{lr|}
\hline III. Issues Addressed in the Geneva and Tunis Phases & 10 \\
\hline Gender Equality & 10 \\
\hline Culture, Knowledge, and the Public Domain & 10 \\
\hline Education, Research, and Practice & 12 \\
\hline Media & 13 \\
\hline Universal Design and Assistive Technologies & 13 \\
\hline Health Information & 14 \\
\hline Ehildren and Young People in the Information Society & 14 \\
\hline
\end{tabular}

IV. Where to Go From Here - Our Tunis Commitment 15

Element One: Evolution of Our Internal Organization 15

Element Two: Involvement in the Internet Governance Forum __ 15

Element Three: Involvement in Follow-Up and Implementation __15

Element Four: Lessons Learned for the UN System in General__ 16

Element five: Outreach to Other Constituencies__ 16 


\section{Introduction - Our Perspective After the WSIS Process}

The WSIS was an opportunity for a wide range of actors to work together to develop principles and prioritise actions that would lead to democratic, inclusive, participatory and development-oriented information societies at the local, national and international levels; societies in which the ability to access, share and communicate information and knowledge is treated as a public good and takes place in ways that strengthen the rich cultural diversity of our world.

Civil Society entered the Tunis Phase of WSIS with these major goals:

- Agreement on financing mechanisms and models that will close the growing gaps in access to information and communication tools, capacities and infrastructure that exist between countries, and in many cases within countries and that will enable opportunities for effective ICT uses.

- Agreement on a substantively broad and procedurally inclusive approach to Internet governance, the reform of existing governance mechanisms in accordance with the Geneva principles, and the creation of a new forum to promote multi-stakeholder dialogue, analysis, trend monitoring, and capacity building in the field of Internet governance.

- Ensuring that our human-centred vision of the 'Information Society', framed by a global commitment to human rights, social justice and inclusive and sustainable development, is present throughout the implementation phase.

- Achieving a change of tide in perceptions and practices of participatory decisionmaking. We saw the WSIS as a milestone from which the voluntary and transparent participation of Civil Society would become more comprehensive and integrated at local, national, regional and global levels of governance and decision making.

- Agreement on strong commitment to the centrality of human rights, especially the right to access and impart information and to individual privacy.

Civil Society affirms that, facing very limited resources, it has contributed positively to the WSIS process, a contribution that could have been even greater had the opportunity been made available for an even more comprehensive participation on our part. Our contribution will continue beyond the Summit. It is a contribution that is made both through constructive engagement and through challenge and critique.

While we value the process and the outcomes, we are convinced much more could have been achieved. We have taken a month after the closure of the Tunis Summit to discuss the outcomes and the process of WSIS. We built on our Geneva 2003 Civil Society Summit Declaration "Shaping Information Societies for Human Needs", and we evaluated the experiences and lessons learned in the four years of WSIS I and WSIS II. This statement was developed in a global online consultation process. It is presented as Civil Society's official contribution to the Summit outcomes.

The issues of greatest concern to Civil Society are addressed in sections II and III of this statement. For most of these items, minor achievements in the outcomes from WSIS were offset by major shortcomings, with much remaining to be done. Some of our greatest concerns involve what we consider to be insufficient attention or inadequate recommendations concerning people-centred issues such as the degree of attention paid to human rights and freedom of expression, the financial mechanisms for the promotion of development that was the original impetus for the WSIS process, and support for capacity building. In section IV, we lay out the first building blocks of Civil Society's "Tunis Commitment". Civil Society has every intention to remain involved in the follow-up and implementation processes after the Tunis summit. We trust governments realize that our participation is vital to achieve a more inclusive and just Information Society. 


\section{Issues Addressed During the Tunis Phase of WSIS}

\section{Social Justice, Financing and People-Centred Development}

The broad mandate for WSIS was to address the long-standing issues in economic and social development from the newly emerging perspectives of the opportunities and risks posed by the revolution in Information and Communications Technologies (ICTs). The summit was expected to identify and articulate new development possibilities and paradigms being made possible in the Information Society, and to evolve public policy options for enabling and realising these opportunities. Overall, it is impossible not to conclude that WSIS has failed to live up to these expectations. The Tunis phase in particular, which was presented as the "summit of solutions", did not provide concrete achievements to meaningfully address development priorities.

While the summit did discuss the importance of new financing mechanisms for ICT for Development (ICTD), it failed to recognize that ICTD presents a challenge beyond that of traditional development financing. Nor did the Tunis fully comprehend that new means and sources of financing and the exploration of new models and mechanisms are required.

Investments in ICTD - in infrastructure, capacity building, appropriate software and hardware and in developing applications and services - underpin all other processes of development innovation, learning and sharing, and should be seen in this light. Though development resources are admittedly scarce and have to be allocated with care and discretion, ICTD financing should not be viewed as directly in competition with the financing of other developmental sectors. Financing ICTD should be considered a priority at both national and international levels, with specific approaches to each country according to its level of development and with a long-term perspective adapted to a global vision of development and sharing within the global community.

Financing ICTD requires social and institutional innovation, with adequate mechanisms for transparency, evaluation, and follow-up. Financial resources need to be mobilised at all levels - local, national and international, including through the realization of ODA commitments agreed to in the Monterrey Consensus and including assistance to programs and activities whose short-term sustainability cannot be immediately demonstrated because of the low level of resources available as their starting point.

Internet access, for everybody and everywhere, especially among disadvantaged populations and in rural areas, must be considered as a global public good. In many cases market approaches are unlikely to address the connectivity needs of particularly disadvantaged regions and populations. In many such areas, initial priority may need to be given to the provision of more traditional ICTs - radio, TV, video and telephony - while the conditions are developed for ensuring the availability of complete Internet connectivity. Info-structure and development often require attention to the development of more traditional infrastructure as well such as roads and electricity.

While the summit in general has failed to agree on adequate funding for ICTD, Civil Society was able to introduce significant sections in the Tunis Commitment (paragraph 35 ) and in the Tunis Agenda (paragraph 21) on the importance of public policy in mobilizing resources for financing. This can serve as a balance to the market-based orientation of much of the text on financing.

The potential of ICT as tools for development, and not merely tools for communication, by now should have been realised by all states. National ICT strategies should be closely related to national strategies for development and poverty eradication. Aid strategies in developed countries should include clear guidelines for the incorporation of ICT into all aspects of development. In this way ICTs should be integrated into general development 
assistance and in this way contribute to the mobilisation of additional resources and an increase in the efficiency of development assistance.

We welcome the launch of the Digital Solidarity Fund (DSF) in March 2005 and take note of the support it got both from the United Nations and the Tunis Summit. Nevertheless, taking into account that the DSF was established on a voluntarily basis, we are concerned that there are no clear commitments from governments and the private sector to provide the needed material support to ensure the success of this fund. We invite all partners from the governmental and the private sector to commit themselves to the socalled "Geneva Principle" where each ICT contract concluded by a public administration with a private company includes a one percent contribution to the DSF. We particularly encourage local and regional administrations to adopt this principle and welcome the relevant statement made by the World Summit of Cities and Local Authorities in Bilbao, November 2005, on the eve of WSIS II.

\section{Human Rights}

The Information Society must be based on human rights as laid out in the Universal Declaration of Human Rights. This includes civil and political rights, as well as social, economic and cultural rights. Human rights and development are closely linked. There can be no development without human rights, no human rights without development.

This has been affirmed time and again, and was strongly stated in the Vienna World Conference on Human Rights in 1993. It was also affirmed in the WSIS 2003 Declaration of Principles. All legislation, policies, and actions involved in developing the global Information Society must respect, protect and promote human rights standards and the rule of law.

Despite the Geneva commitment to an Information Society respectful of human rights, there is still a long way to go. A number of human rights were barely addressed in the Geneva Declaration of Principles. This includes the cross-cutting principles of nondiscrimination, gender equality, and workers' rights. The right to privacy, which is the basis of autonomous personal development and thus at the root of the exertion of many other fundamental human rights, is only mentioned in the Geneva Declaration as part of "a global culture of cyber-security". In the Tunis Commitment, it has disappeared, to make room for extensive underlining of security needs, as if privacy were a threat to security, whereas the opposite is true: privacy is an essential requirement for security. The summit has also ignored our demand that the principle of the privacy and integrity of the vote be ensured if and when electronic voting technologies are used.

Other rights were more explicitly addressed, but are de facto violated on a daily basis. This goes for freedom of expression, freedom of information, freedom of association and assembly, the right to a fair trial, the right to education, and the right to a standard of living adequate for the health and well-being of the individual and his or her family.

Furthermore, as the second WSIS phase has amplified, a formal commitment is one thing, implementation is something else. Side events open to the general public were organised by civil society both at the Geneva and Tunis Summit, consistent with a long tradition in the context of UN summits. In Tunis, the initiative by parts of civil society to organize a "Citizens' Summit on the Information Society" was prevented from happening. At the Geneva Summit, the "We Seize" event was closed down and then reopened. This is a clear reminder that though governments have signed on to human rights commitments, fundamental human rights such as freedom of expression and freedom of assembly can not be taken for granted in any part of the world.

The summit has failed to define mechanisms and actions that would actively promote and protect human rights in the Information Society. Post-WSIS there is an urgent need to strengthen the means of human rights enforcement, to ensure the embedding of human rights proofing in national legislation and practises, to strengthen education and 
awareness raising in the area of rights-based development, to transform human rights standards into ICT policy recommendations, and to mainstream ICT issues into the global and regional human rights monitoring system - in summary: To move from declarations and commitments into action. Toward this end, an independent commission should be established to review national and international ICT regulations and practices and their compliance with international human rights standards. This commission should also address the potential applications of ICTs for the realization of human rights in the Information Society.

\section{Internet Governance}

Civil Society is pleased with the decision to create an Internet Governance Forum (IGF), which it has advocated for since 2003. We also are pleased that the IGF will have sufficient scope to deal with the issues we believe must be addressed, most notably the conformity of existing arrangements with the Geneva Principles, and other cross-cutting or multidimensional issues that cannot be optimally dealt with within current arrangements. However, we reiterate our concerns that the Forum must not be anchored in any existing specialized international organization, meaning that its legal form, finances, and professional staff should be independent. In addition, we reiterate our view that the forum should be more than a place for dialogue. As was recommended by the WGIG Report, it should also provide expert analysis, trend monitoring, and capacity building, including in close collaboration with external partners in the research community.

We are concerned about the absence of details on how this forum will be created and on how it will be funded. We insist that the modalities of the IGF be determined in full cooperation with Civil Society. We emphasize that success in the forum, as in most areas of Internet governance, will be impossible without the full participation of Civil Society. By full participation we mean much more than playing a mere advisory role. Civil Society must be able to participate fully and equally both in plenary and any working or drafting group discussions, and must have the same opportunities as other stakeholders to influence agendas and outcomes.

The Tunis Agenda addressed the issue of political oversight of critical Internet resources in its paragraphs 69 to 71 . This, in itself, is an achievement. It is also important that governments recognized the need for the development of a set of Internet-related public policy principles that would frame political oversight of Internet resources. These principles must respect, protect and promote human rights as laid down in international human rights treaties, ensure equitable access to information and online opportunities for all, and promote development.

It is important that governments have established that developing these principles should be a shared responsibility. However, it is very unfortunate that the Tunis Agenda suggests that governments are only willing to share this role and responsibility among themselves, in cooperation with international organisations. Civil Society remains strongly of the view that the formulation of appropriate and legitimate public policies pertaining to Internet governance requires the full and meaningful involvement of nongovernmental stakeholders.

With regard to paragraph 40 of the Tunis Agenda, we are disappointed that there is no mention that efforts to combat cyber-crime need to be exercised in the context of checks and balances provided by fundamental human rights, particularly freedom of expression and privacy.

With regard to paragraph 63, we believe that a country code Top Level Domain (ccTLD) is a public good both for people of the concerned country or economy and for global citizens who have various linkages to particular countries. While we recognize the important role of governments in protecting the ccTLDs that refer to their countries or economies, this role must be executed in a manner that respects human rights as 
expressed in existing international treaties through a democratic, transparent and inclusive process with full involvement of all stakeholders.

To ensure that development of the Internet and its governance takes place in the public interest, it is important for all stakeholders to better understand how core Internet governance functions - as for example, DNS management, IP address allocation, and others - are carried out. It is equally important that these same actors understand the linkages between broader Internet governance and Internet related matters such as cyber-crime, Intellectual Property Rights, e-commerce, e-government, human rights and capacity building and economic development. The responsibility of creating such awareness should be shared by everyone, including those at present involved in the governance and development of the Internet and emerging information and communication platforms. Equally it is essential that as this awareness develops in newer users of the Internet, older users must be open to the new perspectives that will emerge.

\section{Global governance}

A world that is increasingly more connected faces a considerable and growing number of common issues which need to be addressed by global governance institutions and processes. While Civil Society recognises that there are flaws and inefficiencies in the United Nations system that require urgent reform, we believe strongly that it remains most legitimate inter-governmental forum, where rich and poor countries have the same rights to speak, participate, and make decisions together.

We are concerned that during the WSIS it emerged that some governments, especially from developed countries, lack faith in, and appear to be unwilling to invest authority and resources in the present multilateral system, along with concerted efforts to further improve it. We also regret that debates on creating private-public partnerships and new para-institutions within the United Nations have over-shadowed the overall discussion on bridging the digital divide, which in turn has to be linked to a deep reform of the UN and the global economic system.

In our understanding, summits take place precisely to develop the principles that will underpin global public policy and governance structures; to address critical issues, and to decide on appropriate responses to these issues. Shrinking global public policy spaces raise serious questions concerning the kind of global governance toward which we are heading, and what this might mean for people who are socially, economically and politically marginalised: precisely those people who most rely on public policy to protect their interests.

\section{Participation}

In the course of four years, as a result of constant pressure from Civil Society, improvements in Civil Society participation in these processes have been achieved, including speaking rights in official plenaries and sub-committees, and ultimately rights to observe in drafting groups. The UN Working Group on Internet Governance created an innovative format where governmental and Civil Society actors worked on an equal footing and Civil Society actually carried a large part of the drafting load.

Due to the pressure of time and the need of governments to interact with Civil Society actors in the Internet Governance field, the resumed session of PrepCom3 was in fact the most open of all. We would like to underline that this openness, against all odds, contributed to reaching consensus.

WSIS has demonstrated beyond any doubt the benefits of interaction between all stakeholders. The innovative rules and practices of participation established in this process will be fully documented to provide a reference point and a benchmark for participants in UN organizations and processes in the future. 
Civil Society thanks those governments and international bodies that greatly supported our participation in the WSIS process. We hope and expect that these achievements are taken further and strengthened, especially in more politically contested spaces of global policymaking such as those concerning intellectual property rights, trade, environment, and peace and disarmament.

We note that some governments from developing countries were not actively supportive of greater observer participation believing that that it can lead to undue dominance of debate and opinions by international and developed countries' Civil Society organisations and the private sector. We believe that to change this perception, efforts should be engaged in to strengthen the presence, independence and participation of Civil Society constituencies in and from their own countries.

As for the period beyond the summit, the Tunis documents clearly establish that the soon-to-be created Internet Governance Forum, and the future mechanisms for implementation and follow-up (including the revision of the mandate of the ECOSOC Commission on Science and Technology for Development) must take into account the multi-stakeholder approach.

We want to express concern at the vagueness of text referring to the role of Civil Society. In almost every paragraph talking about multi-stakeholder participation, the phrase "in their respective roles and responsibilities" is used to limit the degree of multi-stakeholder participation. This limitation is due to the refusal of governments to recognize the full range of the roles and responsibilities of Civil Society. Instead of the reduced capabilities assigned in paragraph $35 \mathrm{C}$ of the Tunis Agenda that attempt to restrict Civil Society to a community role, governments should have at minima referred to the list of Civil Society roles and responsibilities listed in the WGIG report. These are:

- Awareness raising and capacity building (knowledge, training, skills sharing);

- Promote various public interest objectives;

- Facilitate network building;

- Mobilize citizens in democratic processes;

- Bring perspectives of marginalized groups including for example excluded communities and grassroots activists;

- Engage in policy processes;

- Bring expertise, skills, experience and knowledge in a range of ICT policy areas contributing to policy processes and policies that are more bottom-up, people-centred and inclusive;

- Research and development of technologies and standards;

- Development and dissemination of best practices;

- Helping to ensure that political and market forces are accountable to the needs of all members of society;

- Encourage social responsibility and good governance practice;

- Advocate for development of social projects and activities that are critical but may not be 'fashionable' or profitable;

- Contribute to shaping visions of human-centred information societies based on human rights, sustainable development, social justice and empowerment.

Civil Society has reason for concern that the limited concessions obtained in the last few days before the summit, from countries that previously refused the emergence of a truly multi-stakeholder format, will be at risk in the coming months. Civil Society actors therefore intend to remain actively mobilized. They need to proactively ensure that not only the needed future structures be established in a truly multi-stakeholder format, but also that the discussions preparing their mandates are conducted in an open, transparent and inclusive manner, allowing participation of all stakeholders on an equal footing. Civil Society hopes to be given the means to ensure all its representatives from different regions, languages and cultures, from developed and developing countries, can fully participate. 


\section{Issues Addressed in the Geneva and Tunis Phases}

\section{Gender Equality}

Equal and active participation of women is essential, especially in decision-making. This includes all forums that will be established in relation to WSIS and the issues it has taken up. With that, there is a need for capacity building that is focussed on women's engagement with the shaping of an Information Society at all levels, including policy making on infrastructure development, financing, and technology choice.

There is a need for real effort and commitment to transforming the masculinist culture embedded within existing structures and discourses of the Information Society which serves to reinforce gender disparity and inequality. Without full, material and engaged commitment to the principle of gender equality, women's empowerment and nondiscrimination, the vision of a just and equitable Information Society cannot be achieved.

Considering the affirmation of unequivocal support for gender equality and women's empowerment expressed in the Geneva Declaration of Principles and paying careful attention to Paragraph 23 of the Tunis Commitment, all government signatories must ensure that national policies, programmes and strategies developed and implemented to build a people-centred, inclusive and development-oriented Information Society demonstrate significant commitment to the principles of gender equality and women's empowerment.

We emphasise that financial structures and mechanisms need to be geared towards addressing the gender divide, including the provision of adequate budgetary allocations. Comprehensive gender-disaggregated data and indicators have to be developed at national levels to enable and monitor this process. We urge all governments to take positive action to ensure that institutions and practices, including those of the private sector, do not result in discrimination against women. Governments that are parties to the UN Convention on the Elimination of All Forms of Discrimination against Women (CEDAW) are in fact bound to this course of action.

\section{Culture, Knowledge, and the Public Domain}

Each generation of humankind is depending upon its predecessors to leave them with a liveable, sustainable and stable environment. The environment we were discussing throughout the WSIS is the public domain of global knowledge. Like our planet with its natural resources, that domain is the heritage of all humankind and the reservoir from which new knowledge is created. Limited monopolies, such as copyrights and patents were originally conceived as tools to serve that public domain of global knowledge to the benefit of humankind. Whenever society grants monopolies, a delicate balance must be struck: Careless monopolization will make our heritage unavailable to most people, to the detriment of all.

It has become quite clear that this balance has been upset by the interests of the rightsholding industry as well as the digitalization of knowledge. Humankind now has the power to instantaneously share knowledge in real-time, without loss, and at almost no cost. Civil Society has worked hard to defend that ability for all of humankind.

Free Software is an integral part of this ability: Software is the cultural technique and most important regulator of the digital age. Access to it determines who may participate in a digital world. While in the Geneva phase, WSIS has recognised the importance of Free Software, it has not acted upon that declaration and this recognition faded in the Tunis phase. In the Tunis Commitment, Free Software is presented as a software model next to proprietary software, but paragraph 29 reiterates "the importance of proprietary software in the markets of the countries." This ignores that a proprietary software market is always striving towards dependency and monopolization, both of which are detrimental to economy and development as a whole. Proprietary software is under 
exclusive control of and to the benefit of its proprietor. Furthermore: Proprietary software is often written in modern sweat-shops for the benefit of developed economies, which are subsidized at the expense of developing and least-developed countries in this way.

While WSIS has somewhat recognised the importance of free and open source software, it has not asserted the significance of this choice for development. It is silent on other issues like open content (which goes beyond open access in the area of academic publications), new open telecom paradigms and community-owned infrastructure as important development enablers.

The WSIS process has failed to introduce cultural and linguistic diversity as a crosscutting issue in the Information Society. The Information Society and its core elements knowledge, information, communication and the information and communication technologies (ICT) together with related rules and standards - are cultural concepts and expressions. Accordingly, culturally defined approaches, protocols, proceedings and obligations have to be respected and culturally appropriate applications developed and promoted. In order to foster and promote cultural diversity it must be ensured that no one has to be a mere recipient of Western knowledge and treatment. Therefore development of the cultural elements of the Information Society must involve strong participation by all cultural communities. The WSIS has failed to recognize the need for developing knowledge resources to shift the current lack of diversity, to move from the dominant paradigm of over-developed nations and cultures to the need for being open to learning and seeing differently.

Indigenous Peoples, further to self-determination and pursuant to their traditional and customary laws, protocols, rules and regulations, oral and written, provide for the access, use, application and dissemination of traditional and cultural knowledge, oral histories, folklore and related customs and practices. WSIS has failed to protect these from exploitation, misuse and appropriation by third parties. As a result, the traditional knowledge, oral histories, folklore and related customs, practices and representations have been and continue to be exploited by both informal and formal (being copyright, trademark and patent) means, with no benefits to the rightful Indigenous holders of that knowledge.

\section{Education, Research, and Practice}

If we want future generations to understand the real basis of our digital age, freedom has to be preserved for the knowledge of humankind: Free Software, open courseware and free educational as well as scientific resources empower people to take their life into their own hands. If not, they will become only users and consumers of information technologies, instead of active participants and well informed citizens in the Information Society. Each generation has a choice to make: Schooling of the mind and creativity, or product schooling? Most unfortunately, the WSIS has shown a significant tendency towards the latter.

We are happy that universities, museums, archives, libraries have been recognized by WSIS as playing an important role as public institutions and with the community of researchers and academics. Unfortunately, telecenters are missing in the WSIS documents. Community informatics, social informatics, telecenters and human resources such as computer professionals, and the training of these, have to be promoted, so that ICT serves training and not training serves ICT. Thus special attention must be paid to supporting sustainable capacity building with a specific focus on research and skills development. In order to tackle development contexts training should have a sociological focus too and not be entirely technologically framed.

Problems of access, regulation, diversity and efficiency require attention to power relations both in the field of ICT policy-making and in the everyday uses of ICT. Academic research should play a pivotal role in evaluating whether ICT meets and serves the individuals' and the public's multiple needs and interests - as workers, women, 
migrants, racial, ethnic and sexual minorities, among others - across very uneven information societies throughout the world. Furthermore, because power relations and social orientations are often embedded in the very designs of ICT, researchers should be sensitive to the diverse and multiple needs of the public in the technological design of ICT. Similarly, educators at all levels should be empowered to develop curricula that provide or contribute to training for people not only as workers and consumers using ICT, but also in the basic science and engineering of ICT, in the participatory design of ICT by communities with computing professionals, the critical assessment of ICT, the institutional and social contexts of their development and implementation, as well as their creative uses for active citizenship. Young people - given their large numbers, particularly in developing countries, and enthusiasm and expertise in the use of ICTs remain an untapped resource as initiators of peer-to-peer learning projects at the community and school levels. These issues have largely been ignored by WSIS.

The actors that need to be involved in the process of making this vision a reality are the professionals and researchers, the students and their families, the support services and human resources of the resources centres, politicians at all levels, social organizations and NGOs, but also the private sector. However, in the teaching profession, it is necessary to recognize and accept the need for learning and evolution with regards to ICT.

We emphasize the special role that the computing, information science, and engineering professions have in helping to shape the Information Society to meet human needs. Their education must encourage socially-responsible practices in the design, implementation, and operation of ICT. The larger Information Society has an equally important and corresponding role to play by participating in the design of ICT. We, therefore, encourage increased cooperation between the computing, information science, and engineering professions and end-users of ICTs, particularly communities.

We furthermore have repeatedly underlined the unique role of ICT in socio-economic development and in promoting the fulfilment of internationally agreed development goals, including those contained in the Millennium Declaration. This is not least true in the reference to access to information and universal primary education. To secure the fulfilment of these goals, it is of key importance that the issue of ICT as tools for the improvement of education is also incorporated in the broader development strategies at both national and international levels.

\section{Media}

We are pleased that the principle of freedom of expression has been reaffirmed in the WSIS II texts and that they echo much of the language of Article 19 of the Universal Declaration of Human Rights. While we note that the Tunis Commitment recognises the place of the media in a new Information Society, this should never have been in question.

In the future, representatives of the media should be assured a place in all public forums considering development of the Internet and all other relevant aspects of the Information Society. As key actors in the Information Society, the media must have a place at the table, and this must be fully recognized both by governments and by Civil Society itself.

While recognizing media and freedom of expression, the WSIS documents are weak on offering support for developing diversity in the media sector and for avoiding a growing concentration and uniformity of content. They specifically neglect a range of projects and initiatives which are of particular value for Civil Society and which need a favourable environment: Community media, telecenters, grassroots and Civil Society-based media. These media empower people for independent and creative participation in knowledgebuilding and information-sharing. They represent the prime means for large parts of the world population to participate in the Information Society and should be an integral part 
of the public policy implementation of the goals of the Geneva Declaration, which refers to the promotion of the diversity of media and media ownership.

The WSIS documents also mostly focus on market-based solutions and commercial use. Yet the Internet, satellite, cable and broadcast systems all utilize public resources, such as airwaves and orbital paths. These should be managed in the public interest as publicly owned assets through transparent and accountable regulatory frameworks to enable the equitable allocation of resources and infrastructure among a plurality of media including community media. We reaffirm our commitment that commercial use of these resources begins with a public interest obligation.

\section{Universal Design and Assistive Technologies}

We are pleased to note that WSIS has identified the fact that ICT Design is the core issue of the Digital Divide for persons with disabilities. The Tunis Agenda for the Information Society clearly states in its paragraph 90e "paying special attention to the formulation of universal design concepts and the use of assistive technologies that promote access for all persons, including those with disabilities". Due to great efforts of all stake holders, in particular of those with disabilities, we recognize significant advancement in the common understanding on the Digital Divide of persons with disabilities and strategies to achieve the targets set out in the Geneva Plan of Action to be achieved by ICT development with the Universal Design Concept in combination with Assistive Technologies that meet specific requirements of persons with disabilities.

In terms of equal opportunities for the participation of persons with disabilities in WSIS the process of that was addressed in Geneva Declaration of the Global Forum on Disability in the Information Society in Geneva, we are grateful for all efforts extended by the summit organizers, who established a focal point for participants with disabilities bat the last stage. However, there is still a lot to do to ensure equal participation of persons with disabilities in the WSIS Action Plan implementation process.

We call upon all governments, private sectors, civil society and international organizations to make the implementation, evaluation and monitoring of all WSIS documents, both from the first and second phase, inclusive to persons with disabilities. We urge that persons with disabilities be included in all aspects of designing, developing, distributing and deploying of appropriate strategies for ICT, including information and communication services, so as to ensure accessibility for persons with disabilities, taking into account the universal design principle and the use of assistive technologies. We request that any international, regional and national development program, funding or assistance aimed to achieve the inclusive information society be made disabilityinclusive, both through mainstreaming and disability-specific approaches. We urge all governments to support the process of negotiation, adoption, ratification and implementation of the International Convention on the Rights of Persons with Disabilities, in particular through enactment of national legislation, as it contains strong elements concerning information and communication accessibility for persons with disabilities.

\section{Health Information}

Access to health information and knowledge is essential to collective and individual human development and has been identified as a critical factor in the public physical and mental health care crises around the world. The WSIS process has neglected to recognize that health is a cross-cutting issue and that health systems must include a holistic approach which is integral to the promotion of physical and mental health and the prevention and treatment of physical and mental illness for all people and to achieve the Millennium Development Goals (MDGs).

It is important to recognize that health expertise and scientific knowledge is essential to aid disease stricken, as well as traumatized populations affected by war, terrorism, disaster and other events, and further that the implementation of ICT systems for 
physical and mental health information and services must be a two-way path recognizing cultural and community norms and values.

It is essential that health care specialists, practitioners, and consumers participate in the development of public policy addressing privacy and related issues regarding physical and mental health information affecting information and delivery systems.

\section{Children and Young People in the Information Society}

In WSIS Phase I, the Geneva Declaration of Principles explicitly acknowledged young people, in paragraph 11 , as the "future workforce and leading creators and earliest adopters of ICTs" and that to fully realize this end, youth must be "empowered as learners, developers, contributors, entrepreneurs and decision-makers." The Tunis Commitment in paragraph 25 reaffirmed the strategic role of youth as stakeholders and partners in creating an inclusive Information Society. This recognition is further supported by paragraph 90 of the Tunis Agenda. However we are concerned as to how key decision-makers from Governments, the business community and Civil Society will realize this commitment when the existing structures are not open for genuine, full and effective participation by youth. None of the Tunis documents, specifically in the postWSIS implementation and follow-up parts, clearly defines how youth shall be "actively engaged in innovative ICT-based development programmes and ... in e-strategy processes," as paragraph 25 states. In this regard, we call upon governments, both national and local, and the proponents of the Digital Solidarity Fund, to engage young people as digital opportunities are created and national e-strategies developed. Youth must be tapped as community leaders and volunteers for ICT for Development projects and be consulted in global and national ICT policy-making processes and formulation.

While we support the great opportunities that ICTs offer children and young people, paragraphs 90q of the Tunis Agenda and article 24 of the Tunis Commitment outline the potential dangers that children and young people face in relation to ICTs. For this reason, article 92 of the Tunis Agenda encourages all governments to support an easy to remember, free of charge, national number for all children in need of care and protection. However, we had hoped that WSIS would have encouraged every stakeholder to support a more comprehensive proposal that ensured that every child, especially those that are marginalized and disadvantaged, has free access to ICTs, including but not limited to, toll free landlines, mobile telephones and Internet connection. In this regard, strategies should be developed that allow children and young people to reap the benefits that ICTs offer by making ICT an integral part of the formal and informal education sectors. There should also be strategies that protect children and young people from the potential risks posed by new technologies, including access to inappropriate content, unwanted contact and commercial pressures, particularly with regards to pornography, pedophilia and sexual trafficking, while fully respecting human rights standards on freedom of expression. We are committed to work in the WSIS follow-up process towards a world where telecommunication allows children and young people to be heard one-by-one and, through their voices, to fulfil their rights and true potential to shape the world.

\section{Ethical Dimensions}

The Tunis texts would have clearly been stronger if the aspects of the Information Society being people-centred, human rights-based and sustainable development-oriented were seen as the ethical point of departure in human relationships and community building and equally in bodies of international agreements. These ethical dimensions are foundational to a just, equitable and sustainable information and knowledge society.

Geneva identified the ethical values of respect for peace and the fundamental values of freedom, equality, solidarity, tolerance, shared responsibility, and respect for nature as enunciated in the Millennium Declaration. Tunis should have improved on these by including the principles of trust, stewardship and shared responsibility together with 
digital solidarity. The technologies we develop, and the solidarities we forge, must build relationships and strengthen social cohesion

Human rights conventions, for example, are critically important in evaluating ICTs so that they are tools to enable just and peaceable conditions for humanity. But Tunis failed to point in this direction. It did not, for example, restate what Geneva considered as acts inimical to the Information Society such as racism, intolerance, hatred, violence and others.

The strong emphasis on technology in the Tunis texts must not eclipse the human being as the subject of communication and development. Our humanity rests in our capacity to communicate with each other and to create community. It is in the respectful dialogue and sharing of values among peoples, in the plurality of their cultures and civilizations, that meaningful and accountable communication thrives. The Tunis texts did not give clear indications on how this can happen.

In an age of economic globalization and commodification of knowledge, the ethics and values of justice, equity, participation and sustainability are imperative. Beyond Tunis, all stakeholders must be encouraged to weave ethics and values language into the working on semantic web knowledge structures. Communication rights and justice are about making human communities as technology's home and human relationships as technology's heart.

\section{Where to Go From Here - Our Tunis Commitment}

Civil Society is committed to continuing its involvement in the future mechanisms for policy debate, implementation and follow-up on Information Society issues. To do this, Civil Society will build on the processes and structures that were developed during the WSIS process.

\section{Element One: Evolution of Our Internal Organization}

Civil Society will work on the continued evolution of its current structures. This will include the use of existing thematic caucuses and working groups, the possible creation of new caucuses, and the use of the Civil Society Plenary, the Civil Society Bureau, and the Civil Society Content and Themes Group. We will organise, at a date to be determined, to launch the process of creating a Civil Society charter.

\section{Element Two: Involvement in the Internet Governance Forum}

The Civil Society Internet Governance Caucus will actively participate in and support the work of the Internet Governance Forum (IGF), and is exploring ways to enhance its working methods and its engagement with relevant stakeholders, especially the research community, to these ends. In addition, the caucus is considering the creation of a new Working Group that will make recommendations on the IGF, and other Civil Society caucuses, and individual Civil Society Working Groups will develop ideas for and participate in the IGF as well.

\section{Element Three: Involvement in Follow-Up and Implementation}

In order to ensure that future implementation and follow-up mechanisms respect the spirit and letter of the Tunis documents and that governments uphold the commitments they have made during this second phase of the WSIS, Civil Society mechanisms will be used and created to ensure:

- the proactive monitoring of and participation in the implementation of the Geneva Plan of Action and the Tunis Agenda at the national level; 
- a structured interaction with all UN agencies and international organisations and regional as well as national mechanisms for follow-up, to ensure that they integrate the WSIS objectives in their own work plans, and that they put in place effective mechanisms for multi-stakeholder interaction, as mentioned in paragraphs 100 and 101 of the Tunis Agenda;

- that the Information Society as a complex social political phenomenon is not reduced to a technology-centred perspective. The ECOSOC Commission on Science and Technology for Development will have to change significantly its mandate and composition to adequately address the need for being an effective follow-up mechanism for WSIS while re-affirming its original mission of developing science and technology, in addition to ICT, for the development objectives of poor countries;

- not only that the reformed Commission on Science and Technology for Development becomes a truly multi-stakeholder commission for the Information Society, but also, that the process to revise it's mandate, composition and agenda is done in a fully open and inclusive manner.

\section{Element Four: Lessons Learned for the UN System in General}

We see the WSIS process as an experience to be learned from for the overall UN system and related processes. We will therefore work with the United Nations and all stakeholders on:

- developing clearer and less bureaucratic rules of recognition for accrediting Civil Society organisations in the UN system, for instance in obtaining ECOSOC status and summit accreditation, and to ensure that national governmental recognition of Civil Society entities is not the basis for official recognition in the UN system; and

- ensuring that all future summit processes be multi-stakeholder in their approach, allowing for appropriate flexibility. This would be achieved either by recognition of precedents set in summit processes, or by formulating a rules of procedure manual to guide future summit processes and day-to-day Civil Society interaction with the international community.

\section{Element five: Outreach to Other Constituencies}

The civil society actors that actively participated in the WSIS process are conscious that the Information Society, as its name suggests, is a society-wide phenomenon, and that advocacy on Information Society issues need to include every responsible interest and group. We therefore commit ourselves in the post-WSIS period to work to broaden our reach to include different Civil Society constituencies that for various reasons have not been active in the WSIS process; may have shown scepticism over the role of ICT in their core areas of activity; or for other reasons have remained disengaged from the Information Society discourse. 